\title{
DIFERENÇAS DE ESCOLARIDADE E RENDIMENTO DO TRABALHO NAS REGIÕES NORDESTE E SUDESTE DO BRASIL
}

\section{DILSON JOSE DE SENA PEREIRA}

Dissertação apresentada à Escola Superior de Agricultura "Luiz de Queiroz", Universidade de São Paulo, para obtenção do título de Mestre em Ciências, Área de Concentração: Economia Aplicada.

\section{PIRA CICABA}

Estado de São Paulo - Brasil

Março - 2001 


\title{
DIFERENÇAS DE ESCOLARIDADE E RENDIMENTO DO TRABALHO NAS REGIÕES NORDESTE E SUDESTE DO BRASIL
}

\section{DILSON JOSE DE SENA PEREIRA}

Bacharel em Ciências Econômicas

\section{Orientador: Prof. Dr. PAULO FERNANDO CIDADE DE ARAÚJO}

\author{
Dissertação apresentada à Escola Superior de \\ Agricultura "Luiz de Queiroz", Universidade de \\ São Paulo, para obtenção do título de Mestre em \\ Ciências, Área de Concentração: Economia \\ Aplicada.
}

\section{PIRACICABA}

Estado de São Paulo - Brasil

Março - 2001 
Dados Internacionais de Catalogação na Publicação (CIP)

DIVISÃO DE BIBLIOTECA E DOCUMENTAÇÃO - Campus “Luiz de Queiroz"/USP

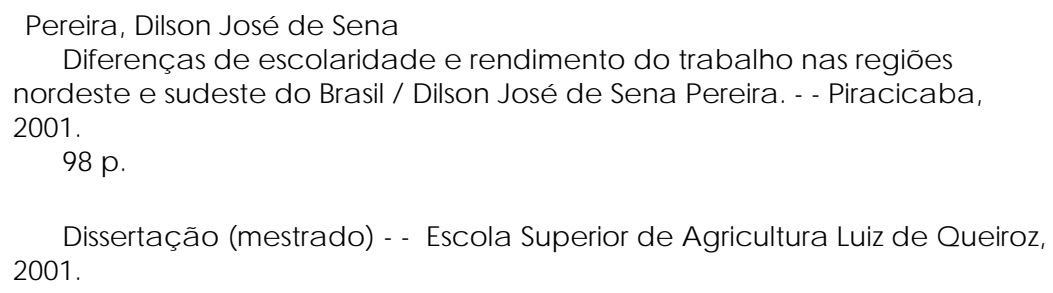

1. Brasil 2. Capital humano 3. Educação 4. Escolarização 5. Desigualda de 6. Distribuição de renda 7. Mercado de trabalho 8. Retomo I. Título

CDD 331.12

\section{"Permitida a cópia total ou parcial deste documento, desde que citada a fonte - $O$ autor"}


D edico

\author{
Às minhas \\ filhas Camila e \\ D ébora e aos \\ sobrinhos D eyse \\ e $D$ avison.
}




\section{AGRADECIMENTOS}

Ao Prof. Paulo Cidade de Araújo, pela amizade, orientação, incentivo e motivação constante pela vida acadêmica.

Ao Prof. Rodolfo Hoffmann pelas sugestões indispensáveis que em muito contribuíram para realização deste trabalho.

Aos Professores Alexandre Barros, Angela Corrêa e Ricardo Shirotta pelas críticas e sugestões ao aperfeiçoamento do estudo.

Meus agradecimentos a todos os Professores que fazem o Departamento de Economia, Administração e Sociologia Rural da ESALQ/USP, pela oportunidade, ensinamento e condições de trabalho oferecidas.

Aos funcionários do Departamento que estiveram sempre prontos a ajudar: Cristiane, Elenice, Fernando, Helena, Ligiana, Luciane, Maielli, Pedro e Valdeci.

A todos os colegas e grandes amigos da turma de pós-graduação em Economia Aplicada, pela amizade, companheirismo e estímulo, especialmente a Alexandre (Conchas), Carlos Eduardo (Cadu), Cinthia, Clayton, Cristiane, Glauco, Goncílio, Magri, Patrick, Paula e Valeriana. Aos demais colegas de pós-graduação, pela agradável convivência.

Expresso minha sincera gratidão, respeito e admiração aos familiares e amigos que não deixaram de incentivar um só momento. Especialmente a minha mãe Maria Rosa, pai e irmãos, Cleide, Enaura, Hélia, Elza Mendes, Maria Anita, João Neto, Fernando Agra, Edimilson Veras e Zeno.

Aos Colegas do Departamento de Economia da Universidade Federal de Alagoas e ao programa PICDT/UFAL/CAPES.

Finalmente, a todos que de uma forma ou de outra participaram da concretização deste trabalho. 


\section{SUMÁRIO}

Página

LISTA DE FIGURAS …............................................................................ vi

LISTA DE TABELAS ................................................................................. viii

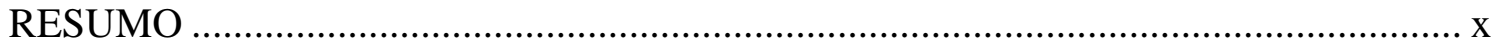

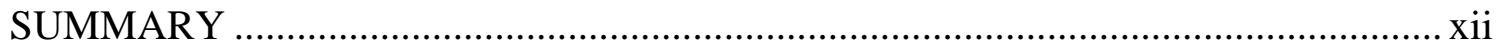

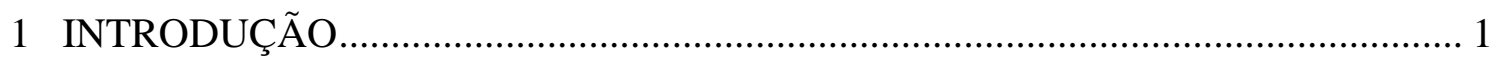

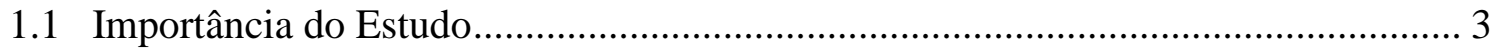

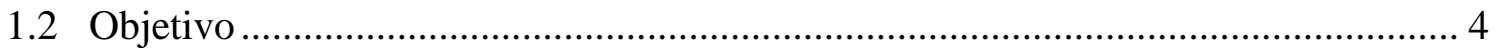

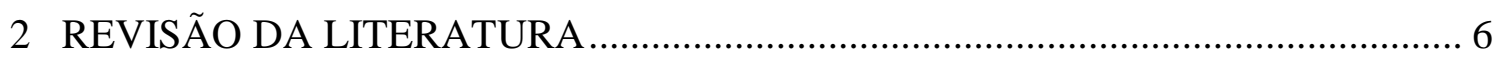

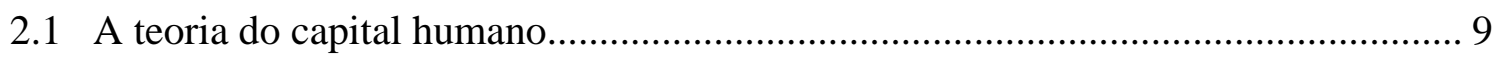

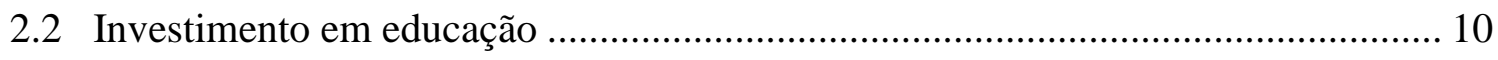

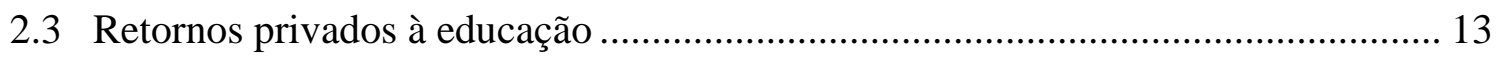

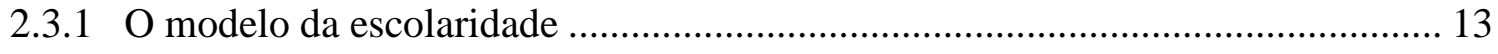

2.3.2 A função salário com investimento após a escola ........................................ 18

2.4 Breve revisão de estudos empíricos ............................................................ 23

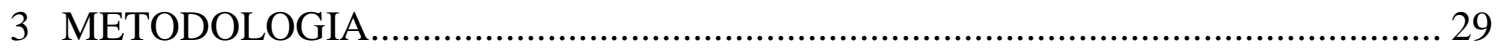

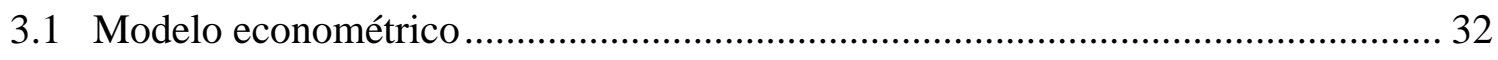

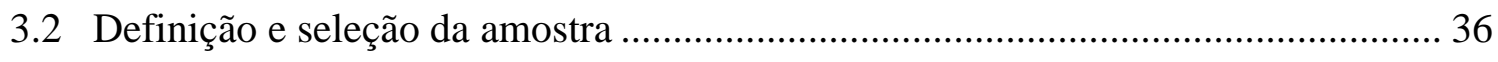

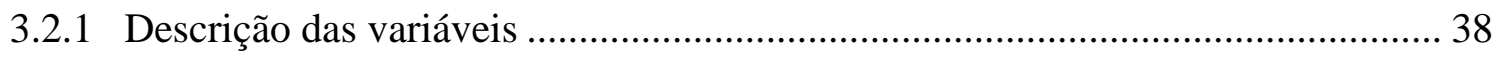

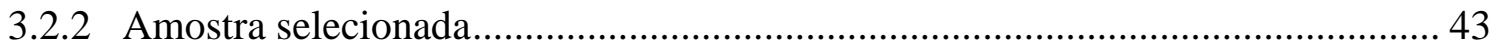


4 PERFIL SOCIOECONÔMICO DA AMOSTRA SELECIONADA ........................ 45

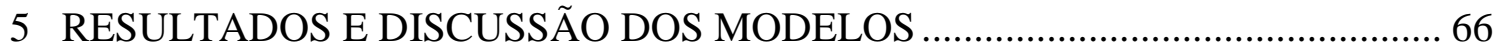

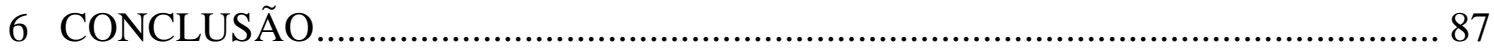

REFERÊNCIAS BIBLIOGRÁFICAS ............................................................... 90

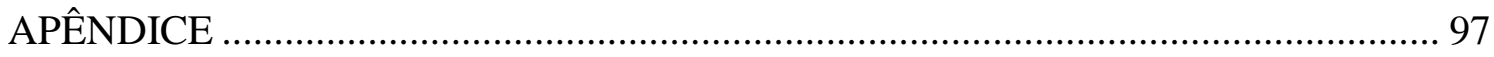




\section{LISTA DE FIGURAS}

Página

1 Relação entre rendimento e escolaridade. 16

2 Composição da amostra selecionada segundo classes etárias dos indivíduos de 15 anos ou mais de idade e com rendimento positivo no trabalho principal................. 48

3 Distribuição de anos de estudo por faixa etária, amostra selecionada.

4 Média de rendimento mensal (em SM), anos de estudo e nível de escolaridade dos pais por classes de idade.

5 Média de rendimento mensal (em SM), anos de estudo, pessoas no domicílio, idade de ingresso no mercado de trabalho e nível de escolaridade dos pais, por classes de anos de estudo.

6 Distribuição de grupo de anos de estudo segundo o nível de escolaridade da mãe e do pai.

7 Distribuição amostral e apropriação de rendimento do trabalho, em SM, segundo classe de rendimento mensal. 56

8 Média de anos de escolaridade, nível de instrução dos pais, pessoas no domicílio e idade de ingresso no mercado de trabalho, por classe de rendimento mensal. ...... 58

9 Média de rendimento mensal (em SM), escolaridade e experiência no trabalho segundo a posição na ocupação, amostra selecionada.

10 Valor médio de variáveis chave, por sexo.

11 Valor médio de rendimento mensal (SM), anos de estudo, nível de escolaridade dos pais, anos de experiência no mercado de trabalho, número de pessoas no domicílio e idade de ingresso no mercado de trabalho, por estrato geográfico, amostra selecionada. 
12 Estrato geográfico e estimativas de acréscimo no rendimento esperado em relação ao residente no nordeste rural segundo as regressão ajustada........................................ 79

13 Percentual de incremento no rendimento do trabalho principal segundo o nível de

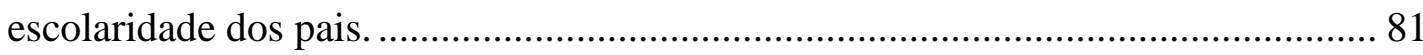




\section{LISTA DE TABELAS}

Página

1 Estrato geográfico e participação percentual na população total, na amostra selecionada e variação na participação.

2 Distribuição da amostra selecionada segundo sexo, condição na família, região, situação do domicílio, cor da pele e condição na ocupação....................................... 46

3 Média e coeficiente de variação de variáveis chave na amostra selecionada............ 47

4 Média e coeficiente de variação (CV) de variáveis chave por faixa etária................ 50

5 Média e coeficiente de variação (CV) de variáveis chave na amostra selecionada,

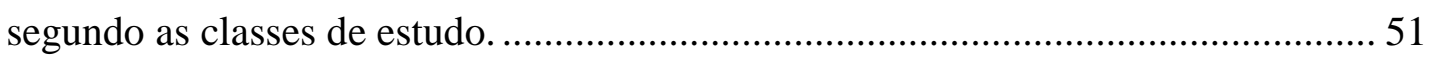

6 Média e coeficiente de variação (CV) de variáveis chave, segundo as classe de rendimento mensal na amostra selecionada. ........................................................... 57

7 Média e coeficiente de variação de variáveis chave segundo a condição na ocupação,

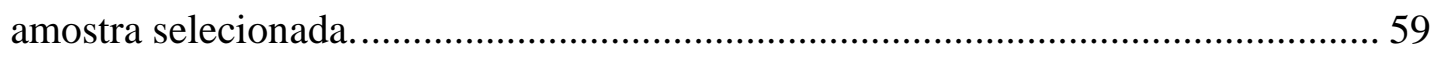

8 Média e coeficiente (CV) de variação de variáveis chave segundo o gênero, amostra selecionada.

9 Média e coeficiente de variação (CV) de variáveis chave, por estrato geográfico na amostra selecionada.

10 Participação setorial e taxa de rendimento mensal por região na amostra selecionada.

11 Coeficientes, valores de $t$, número de observações, coeficientes de determinação e estatística $F$ por regressão.

12 Percentual de acréscimo no rendimento esperado, idade de máximo rendimento e variação relativa, por regressão. 
13 Percentual de incremento no rendimento esperado associado ao nível de escolaridade

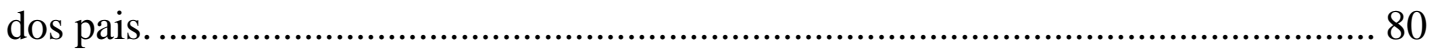

14 Coeficientes, valores $t$, número de observações, coeficiente de determinação e estatística $F$ estimado no modelo de variável instrumental................................... 82

15 Percentual de acréscimo no rendimento esperado e idade para máximo rendimento,

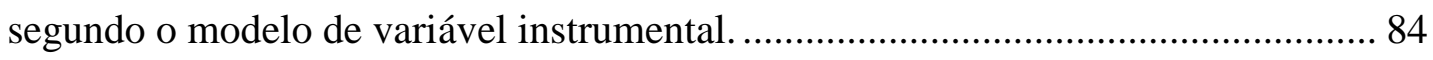

16 Percentual de aumento no rendimento esperado associado ao aumento da escolaridade do próprio indivíduo, amostra selecionada......................................... 85 


\title{
DIFERENÇAS DE ESCOLARIDADE E RENDIMENTO DO TRABALHO NAS REGIÕES NORDESTE E SUDESTE DO BRASIL
}

\author{
Autor: DILSON JOSÉ DE SENA PEREIRA \\ Orientador: Prof. Dr. PAULO FERNANDO CIDADE DE ARAÚJO
}

\section{RESUMO}

O objetivo deste estudo é identificar e estimar a influência da escolaridade e outros fatores socioeconômicos no rendimento do trabalho no nordeste e sudeste do Brasil. Retornos a escolaridade, sexo, cor da pele e nível educacional dos pais foram estimados com ajustamento de quatros diferentes modelos econométricos: três regressões lineares múltiplas e um modelo de variável instrumental. Neste estudo foi utilizada amostra de 3.169 observações, selecionada da Pesquisa sobre Padrões de Vida 1996-1997 - PPV do IBGE. A seleção da amostra se deu através da imposição de algumas restrições aos microdados da PPV, sendo as principais: i) observações com rendimento do trabalho positivo; ii) de pessoas com 15 anos ou mais de idade que conheciam o nível educacional dos pais.

O referencial teórico deste estudo é baseado na teoria do capital humano, com ênfase especial as contribuições de T. W. Schultz e Jacob Mincer. Os resultados encontrados são consistentes com os princípios propostos por Mincer. Em todas formulações o conjunto de variáveis mostrou-se relevante e o coeficiente de determinação satisfatório.

A pesquisa aponta para a existência de uma relação positiva entre educação e rendimento do trabalho. As taxas de retornos estimadas para escolaridade variam de $12 \%$ a $19 \%$ e parecem plausíveis para o caso brasileiro. Como relação de causa e efeito, 
pode-se esperar que um ano adicional de educação formal eleve tanto a produtividade quanto o rendimento do trabalho.

Também importante, é a constatação que o nível educacional dos pais exerce influência positiva sobre o rendimento do trabalho. Esta variável foi utilizada como proxy das características não observáveis que influenciam a escolarização dos indivíduos, denominadas de family background.

A média de anos de estudos completos na amostra selecionada situa-se muito acima das estatísticas oficiais do país, em torno de 10 anos, evidenciando a crescente importância com que instituições públicas e privadas do mercado de trabalho vêem a educação. Provavelmente, este fato tenderá a ser muito mais relevante no futuro, conduzindo os policymakers e as pessoas comuns a considerarem os investimentos em educação uma questão prioritária, se não a mais importante.

Outras variáveis especificadas nos modelos mostraram-se relevantes, como sexo, cor da pele e região. Algumas dessas variáveis explicam parcela significativa das diferenças regionais no Brasil. Diferenciais regionais de escolaridade e renda refletiram os contrastes entre pobreza rural e o crescimento desorganizado nas áreas urbanas. Nossos resultados mostram que o rendimento do trabalho é muito mais elevado nas metrópoles estudadas, especialmente no sudeste. Tanto no nordeste quanto no sudeste, o rendimento do trabalho no meio rural apresenta valores inferiores aos do meio urbano.

Os anos de idade das pessoas mostram-se relacionados positivamente com o rendimento do trabalho, até certo ponto no intervalo entre 52 e 58 anos, quando o rendimento do trabalho é máximo. Além desse limite, espera-se uma depreciação do estoque de capital humano acumulado pelo indivíduo.

Como sugerido pela variável representativa das pessoas de origem asiática, este grupo étnico apresenta rendimento do trabalho acima dos demais grupos da amostra selecionada. Finalmente, apesar das mulheres exibir escolaridade ligeiramente maior que os homens - um ano a mais - seu rendimento médio no trabalho corresponde a $75 \%$ do pelos homens. 


\title{
DIFFERENCES OF SCHOOLING \\ AND LABOR INCOME IN THE NORTHEAST \\ AND SOUTHEAST OF BRAZIL
}

\author{
Author: DILSON JOSÉ DE SENA PEREIRA \\ Adviser: Prof. Dr. PAULO FERNANDO CIDADE DE ARAÚJO
}

\section{SUMMARY}

The objective of this study is to identity and estimate the influence of schooling, and other social and economic factor on labor income in northeast and southeast regions of Brazil. Returns to schooling, gender, race, region and parents' level of schooling were then estimated through the adjustment of four different econometric models: three multiple regression equations, and one instrumental variable equation. The data used in the study were obtained from a selected sample with 3,169 observations. These observations came from a larger sample of the Research on Standards of Living, also called PPV, conducted by IBGE in the 1996-1997 period. The selected sample imposed to the PPV sample the following main restrictions: i) observations with a positive labor income in the labor market; and, ii) persons with aging 15 years or more and aware of their parents' level of schooling.

The theoretical background of the study is based on the theory of human capital, and special emphasis is given to the contributions of T.W. Schultz and Jacob Mincer. The results of the economic models are consistent with the theoretical principles proposed by Mincer.

The research findings support the principle of strong and positive relation between formal education and labor income, despite the frequent argument that social, economic, and cultural factors influencing the level of education makes difficult to 
know the real direction of such relationship. The rates of return estimated for schooling, ranging from 12 to $19 \%$, seem to be plausible for the Brazilian case. Previous research support this evidence. As a relation of cause and effect, it might be expected that one additional year of formal education will raise both labor productivity and labor income.

Also important, is the indication that parents' level of schooling is likely to exert a positive influence on labor income. This variable was used as a proxy of the family background, an attempt to capture the influence of a complex set of non observable variables on formal education.

The average schooling in the selected sample is much higher than the official statistics for the country, close to 10 years. A possible implication of such result is the growing importance that private and public institutions are given to education in the labor market. Probably, this fact will tend be more evident in the future, so that policymakers and common people have to consider investment in education a high priority issue, if not the highest one.

Other variables specified in the models also appear to be relevant. This is the case of gender, race, and region. Some of these variables explain a significant share of the regional differences found in the Brazilian society. Labor income regional differences reflect the so called contrasting scenarios between rural poor and turbulent growth in urban areas. Our findings indicate that labor income is much higher in the metropolitan areas studied, especially in the southeastern region. Labor income of rural people both in northeast and southeast falls behind the urban values.

The age variable tends to be positively associated to labor income up to a given point in time, between 52 and 58 years. This is the interval within which the peak of labor income is observed. Beyond that, it might be expected a depreciation effect on the stock of human capital.

As suggested by the variable representing the descendants from Asian people, this ethnic group shows the highest labor income in comparison to other groups in the selected sample. And finally, in spite of exhibiting a slightly higher level of formal education - one year more - the women of the sample earned only $75 \%$ of the average labor income of the sample. 


\section{INTRODUÇÃO}

O Brasil apresenta desigualdades entre regiões e setores econômicos. Aqui é possível conviver, por exemplo, no setor rural, com agricultura moderna, calcada no uso intensivo de capital, tecnologias avançadas e alta produtividade em determinadas áreas, e por outro lado, com agricultura tradicional, incipiente, quase de subsistência em outras. No segmento urbano, cidades com um parque industrial diferenciado e moderno e, em muitos casos, cidades sem uma única indústria. Em diversos centros urbanos, sobretudo naqueles localizados na porção norte-nordeste do país, há um expressivo contigente de pessoas abaixo da linha de pobreza, que se "afavelam" nas grandes cidades, delineando uma linha divisória bastante clara de paisagens. De norte a sul e de leste a oeste, o Brasil apresenta contrastes socioeconômicos, em muitos casos, comparáveis aos de países subdesenvolvidos da América Latina e da África ${ }^{1}$.

A taxa de analfabetismo das pessoas de 15 anos ou mais na região nordeste é de $26,6 \%$, enquanto no sudeste é de $7,8 \%{ }^{2}$. Do total dos rendimentos de todos os trabalhos, $10 \%$ das pessoas ocupadas de 10 anos ou mais de idade, no Brasil, apropriam-se de 45,7\% daquele total. Além disso, o rendimento nominal médio de todos os trabalhos, das pessoas do grupo "mais rico" (1\% da população ocupada) é 43 vezes superior a renda nominal média de metade da população no país ${ }^{3}$. O rendimento nominal médio no trabalho principal, no último trimestre do ano 2000, das pessoas ocupadas de

\footnotetext{
${ }^{1}$ Ver Barros \& Mendonça (1996) e Mendonça (1996)

2 Pesquisa Nacional por amostra de Domicílio - PNAD 1999. In: http:// www. ibge.gov.br/ ibge/ estatística/ condiçõesdevida (26/02/2001).

3 Pesquisa Nacional por amostra de Domicílio - PNAD 1999. In: http:// www. ibge.gov.br/ ibge/ estatística/condiçõesdevida(26/02/2001).

http://www.ibge.gov.br/ibge/estatistica/populacao/trabalhoerendimento/pnad99/sintese/tabela.shtm
} 
15 anos ou mais, nas capitais do sudeste é $60 \%$ maior que o verificado nas principais capitais do nordeste ${ }^{4}$.

Entre os diversos indicadores socioeconômicos, apresentando enormes diferenças entre os segmentos ou grupos sociais, destaca-se o referente à distribuição pessoal da renda.

Segundo o Instituto Brasileiro de Geografia e Estatística - IBGE, o índice de Gini da distribuição dos rendimentos de trabalho no período de 1989 a 1999 alcançou valor máximo (0,630) em 1989 e mínimo no ano de 1999 (0,567). O confronto regional mostrou que o grau de concentração dos rendimentos manteve-se mais elevado no nordeste e centro-oeste ${ }^{5}$.

Diversos estudos apontam que a renda do trabalho de um indivíduo (salário, pró-labore e rendimento dos trabalhadores por conta própria), dadas as condições de oferta e demanda, é determinado por um vasto conjunto de características pessoais que compreendem desde habilidades naturais e aporte financeiro da família, passando pelas características da sociedade, até os investimentos em capital humano realizados. O grau de desigualdade da distribuição de renda é determinado por taxas de retorno a esses atributos e por sua distribuição na economia Com efeito, Barros \& Mendonça (1996) fazendo uma analogia a um processo de competição, explicam a geração da desigualdade de renda em função da acumulação de capital humano do indivíduo que, por sua vez, é função dos recursos inatos do indivíduo, recursos públicos e recursos privados. Estes recursos geram desigualdades de condições no processo de formação da renda.

\footnotetext{
${ }^{4}$ Pesquisa Mensal de Emprego - PME. In: http://www.sidra.ibge.gov.br (26/02/2001).

${ }^{5}$ Pesquisa Nacional por amostra de domicílio 1999. In://http://www.ibge.gov.br/ibge/estatistica/populacao /trabalhoerendimento/pnad99/sintese/Tabela.shtm.
} 


\subsection{Importância do Estudo}

A relação entre educação e desigualdade salarial começou a ser estudada no Brasil em fins dos anos 60 e início de $70^{6}$ e, desde então, vários estudos tem demonstrado empiricamente o papel fundamental que a educação desempenha na explicação de diversos aspectos da economia brasileira, tais como desigualdade salarial e disparidades regionais de indicadores sociais. Segundo Barros \& Mendonça (1996), no Brasil, o elevado grau de desigualdade educacional faz com que a sensibilidade dos salários ao nível educacional do trabalhador seja uma das mais altas do mundo.

A relação entre educação e salários no Brasil foi analisada por Reis \& Barros (1990), cujas principais conclusões foram: i) no período 1976-1986, 50\% da desigualdade de salários, nos mercados de trabalho metropolitanos, é explicada pela educação, sendo esse índice mais elevado nos mercados localizados no nordeste; ii) o padrão de diferenciação regional mostra significativas diferenças nos diferenciais de salários e na distribuição de educação, sendo mais significativas que as diferenças temporais; iii) devido a maior oferta de trabalhadores com nível educacional mais elevado, as regiões sul e sudeste apresentam menor desigualdade salarial que o nordeste.

Segundo Leal \& Werlang (1991) os investimentos em educação no Brasil são dos mais rentáveis e responsáveis diretos por aproximadamente 50\% da desigualdade da distribuição da renda. Logo, se a estratificação de salários não fosse positivamente correlacionada com o nível de escolaridade, a desigualdade na distribuição da renda seria a metade dos níveis verificados atualmente. Daí, a clara necessidade de melhor distribuição da educação formal, para diminuir a desigualdade da distribuição da renda.

O investimento em educação no Brasil foi também objeto de estudo de Ramos (1996), cujo resultado empírico evidencia que o retorno, além de permanecer

\footnotetext{
${ }^{6}$ Castro (1971), compara resultados de três estudos pioneiros no Brasil: Langoni, C. A study in economic growth: the Brazilian case - Tese de Ph. D. para Universidade de Chicago, 1970; CASTRO, C. M. de. Investment in education in Brazil: A study of two industrial communities. - Tese de $\mathrm{Ph}$. D. para Universidade de Vanderbilt; e LEVY, S. An economic analysis of investment in education in the state of São Paulo - Instituto de Pesquisas Econômicas - USP, 1969.
} 
estável no período de 1976 à 1990, serve tanto para elevar a produtividade do indivíduo, à medida que este incrementa o capital humano, quanto como sinalizador da dotação de atributos de difícil observação que, apesar de influenciarem diretamente esta produtividade, não são diretamente afetados pela educação formal.

Garcia et al. (1999) estimaram, para alguns países da América Latina e estados brasileiros, uma relação entre renda média e escolaridade. O crescimento da renda, a taxas crescentes, está associado com o nível de escolaridade. ${ }^{7}$ Combinando este resultado com o índice de Gini definido em termos de escolaridade, os autores concluíram que a distribuição da renda está estreitamente associada à distribuição da escolaridade. Ou seja, numa economia com elevado índice de Gini, a maioria da população é pobre e dispõe de pouca escolaridade.

Recentemente, em análise dos fatores condicionantes dos rendimentos por meio do ajuste de equações de regressão múltipla, Hoffmann (2000) mostra que a escolaridade aparece como o fator mais importante à contribuição marginal para a soma de quadrados da regressão.

Seguindo esta mesma linha de pesquisa, o presente trabalho se propõe a estudar a relação entre escolaridade e rendimento do trabalho de pessoas residentes no nordeste e sudeste do Brasil, incorporando como fatores determinantes dos diferenciais de rendimentos, além de elementos tradicionais (como escolaridade, condição na ocupação, condição na família, sexo e cor) o nível educacional dos pais.

\subsection{Objetivo}

Nesta pesquisa pretende-se estudar a influência da educação e de fatores socioeconômicos no rendimento do trabalho. No caso educação, o objetivo é identificar separadamente as relações entre escolaridade dos pais e rendimento dos filhos e entre escolaridade e rendimento de pessoas que integram amostra de residentes em dez

\footnotetext{
${ }^{7}$ Os autores justificam o crescimento devido ao fator trabalho qualificado ser relativamente escasso nos países e regiões que compõem a amostra.
} 
estratos geográficos nas regiões nordeste e sudeste do país. Tal amostra foi especificada e analisada pelo IBGE na Pesquisa sobre Padrões de Vida 1996/97 (PPV). Aos demais fatores serão associados os diferenciais de rendimento dos indivíduos.

As taxas de retorno à educação serão obtidas com a estimação de equações de salários controladas por variáveis binárias. Em seguida, será analisada a influência dos níveis de escolaridade dos pais no rendimento do trabalho dos filhos, com a estimação de equações salários, em que a escolaridade dos pais é considerada proxy de características individuais não observáveis ou de difícil mensuração (denominadas family background ${ }^{8}$.

\footnotetext{
${ }^{8}$ Entende-se por family background toda assistência familiar que pode influenciar a escolaridade dos filhos, como renda e escolaridade dos pais.
} 


\section{REVISÃO DA LITERATURA}

No início da segunda metade do século $\mathrm{XX}$, vários economistas realizaram esforços no sentido de explicar o crescimento econômico das nações. A tríade clássica que constituía os fatores de produção - terra, capital e trabalho - e a argumentação de que o estoque de capital físico é a base para o crescimento econômico, ainda prevaleciam. Aceitava-se também que, para uma determinada economia se desenvolver em padrões modernos, seria necessária uma boa dotação de recursos naturais.

A visão de que o estoque de recursos naturais era uma das principais fontes para o desenvolvimento das economias cedeu lugar à idéia de um novo fator do crescimento econômico, a industrialização, com a percepção do bom exemplo do desenvolvimento de alguns países, como Japão e Suíça, que dispunham de parcas reservas de recursos naturais.

Como a anterior, essa suposição logo se mostra inoperante diante das evidências que a sucederam. A principal delas foi a rápida recuperação dos países que sofreram severamente com a segunda guerra mundial e, em seguida, a falta de uma agricultura moderna e/ou a incapacidade de se produzir itens industriais com custos inferiores ao custo de suas importações ${ }^{9}$.

A partir daí, muitos economistas abandonaram argumentos singulares e passaram a creditar ao estoque de capital, empregado na produção de bens e serviços, a explicação do crescimento econômico. Essencialmente, esse capital compreendia estruturas físicas, equipamentos, inventários de mercadorias e o quantum de mão-de-

\footnotetext{
${ }^{9}$ Theodore W. Schultz, O capital humano. Rio de Janeiro: Zahar editores, 1973.
} 
obra disponível. Contudo, quase sempre, ao estruturar esse raciocínio, os economistas esquivavam-se de quaisquer outros fenômenos que constituíssem potenciais fontes de crescimento econômico, exceto quando consideravam o progresso técnico como variável exógena.

Segundo Schultz (1973b), a concepção de tecnologia era muito restrita. Compreendia somente os 'bens de capital', excluindo a terra e o homem e concentrandose em instrumentos e equipamentos. Como implicação direta dessa concepção, a formulação clássica da teoria econômica a concebia permanentemente constante, considerando parte do crescimento do produto como resíduo. Subseqüentemente, notáveis economistas ${ }^{10}$ se empenharam em desenvolver modelos econômicos que incorporaram a mutação técnica como variável endógena. Schultz (1973) destaca o trabalho de Edward F. Denison que especifica e quantifica, arbitrariamente, um vasto número de importantes recursos do crescimento econômico, até então negligenciados, ao lado de outros relacionados ao capital humano, o que torna claro que o investimento em escolaridade, em treinamento realizado no trabalho, em saúde, informação de emprego e migração, possibilitam ganhos de produtividade do trabalho por resultarem em mudanças de qualidade que podem ser quantificadas (Schultz, 1973b).

Diante dessas evidências, Schultz propõe o abandono da abordagem clássica, segundo a qual o estado das artes permaneceria constante, em prol de duas inovações na teoria econômica. A primeira, é considerar as técnicas de produção como uma forma de capital, e por conseguinte, a transformação da tecnologia e dos demais mecanismos do processo produtivo em capital, os quais seriam passíveis de mensuração em termos econômicos. A segunda, consiste numa extensão do conceito de indústria para englobar a pesquisa científica, parte da educação e atividades que geram o aumento de capacidade, tanto de natureza humana, quanto de natureza não-humana. Com isso, Schultz amplia a heterogeneidade do capital e a própria natureza de custo e retorno relativos a diferentes formas de investimento.

\footnotetext{
${ }^{10}$ São citados por Schultz (1973b) Swan, Robert M. Solow e Edward F. Denison.
} 
A descoberta de novas informações pode ser considerada como um investimento em pesquisa ${ }^{11}$. A adoção de uma técnica nova (e mais eficiente), digamos no cultivo de certa cultura, é um investimento cujas características são semelhantes àquelas do investimento em capital físico; essa nova técnica terminará aumentando os rendimentos da terra, e dos demais fatores de produção. De modo semelhante, parcela significativa dos gastos pessoais com educação, treinamento, migração e saúde deve ser tratada como investimento em capital humano.

O investimento em pesquisa que resulta em informação nova, segundo Schultz (1973b), dissemina dois componentes, a saber: o que se transforma em novas capacidades técnicas que, quando absorvidas se transformam em capital humano; e outro que se transforma em novos materiais, que poderão ser formas de capital não-humano.

Schultz (1973b) defende a tese de que estas duas classes de investimento, no homem (capital humano) e em pesquisa, têm extrema importância no sistema econômico. A relutância dos economistas em examiná-los levaria a resultados pífios na explicação do crescimento econômico, onde quase sempre, uma parcela importante do crescimento apareceria como parâmetro residual. Ainda segundo Schultz (1973b), o conhecimento e a capacidade são produtos de investimento que combinados com outros investimentos humanos são causas fundamentais da superioridade produtiva de alguns países desenvolvidos.

Assim sendo, começaram a ser aceitas pelos economistas essas duas classes ou tipos de investimento, como forças potenciais de aumento da capacidade produtiva dos bens de capital, da força do trabalho e da tecnologia ${ }^{12}$.

Este trabalho restringe-se somente a uma forma de investimento em capital humano: dispêndio com educação. $\mathrm{O}$ estudo procura relacionar tal investimento com os rendimentos do trabalho principal dos indivíduos.

\footnotetext{
${ }^{11} \mathrm{~T}$. W. Schultz define a pesquisa como uma atividade especializada que exige capacitações especiais para descobrir e desenvolver formas especiais de uma nova informação (1973b).

12 Sobre tecnologia, T. W. Schultz (1973b) escreve: "Um conceito abrangente de tecnologia presumivelmente incluiria os atributos técnicos de todos os fatores e de todos os produtos. Incluiria, por conseguinte, as propriedades técnicas originais do solo no sentido ricardiano e, desta forma, levaria em conta as diferenças técnicas entre as parcelas da terra. Um conceito abrangente de tecnologia presumivelmente incluiria também as capacidades inatas do homem".
} 


\subsection{A teoria do capital humano}

O que se compreende por capital humano não é fato recente na literatura econômica, apesar de muitos estudiosos, entre os quais Gary S. Becker (1993), citarem como pioneiros, dentre outros, T. W. Schultz e Jacob Mincer. Adam Smith, Irving Fischer e Alfred Marshall, por exemplo, escreveram sobre a importância da qualidade e das habilidades do trabalhador no processo produtivo.

Providos de valores éticos e morais, os economistas sempre se recusaram a tratar os homens como bens de capital que pudessem ter valor econômico e passíveis de ampliação através de investimentos ${ }^{13}$, o que de certo modo reveste de veracidade a citação de Becker, corroborada pelas palavras de outro autor contemporâneo, quando diz:

"A expressão capital humano apareceu pela primeira vez na literatura econômica em 1961 em um artigo intitulado: Investindo em capital humano; publicado na American Economic Review, escrito por Schultz" (Crawford, 1994).

Segundo Schultz (1973b), parcela importante dos gastos com consumo pessoal são na verdade investimento em capital humano. Assim, os gastos com educação, saúde e migração interna para usufruir de vantagens oferecidas por melhores empregos são exemplos desse tipo de investimento, que ao ampliarem e melhorarem a qualidade do trabalho elevam sua produtividade, conferindo rendimento mais elevado a seus portadores.

Schuh (1990) amplia o conceito de capital humano, de forma a inserir nesse conjunto, além das categorias mencionadas acima, valores sociais e culturais de uma comunidade, como língua, leis e instituições, nutrição, habilidades e raça. Também chama atenção para uma particularidade de algumas formas de capital humano que

\footnotetext{
${ }^{13}$ Nas palavras de Schultz(1973b): "à exceção da escravatura, abominamos esta realidade".
} 
influenciam a produtividade dos indivíduos de uma sociedade: sua capacidade de ser produzido e reproduzido simultaneamente.

O que distingue o capital humano de outras classes de capital é que ele é parte do homem. "É humano porquanto se acha configurado no homem, e é capital porque é uma fonte de satisfação futura, ou de futuros rendimentos, ou de ambas as coisas" (Schultz, 1973b). Blaug (1973) ressalta que capital humano não implica dizer que as pessoas sejam tratadas como capital. Em outras palavras, capital humano é o valor atual das habilidades adquiridas pelas pessoas e não o valor das próprias pessoas. Seguindo esta linha de raciocínio, Becker (1993) enfatiza que a razão de ser humano é a impossibilidade de separar do indivíduo seu conhecimento, habilidade e destreza, saúde e outros aspectos que determinam o capital humano.

\subsection{Investimento em educação}

Segundo Ramos (1997) o investimento em educação é bastante diversificado e tem várias dimensões. Pode ser realizado via melhoria na quantidade ou qualidade da educação. Ademais, diferencia-se de acordo com o nível em que ocorre, podendo estar relacionado a uma melhoria ou aumento no ensino fundamental, secundário, superior ou técnico.

O suporte teórico do capital humano parte do princípio que a decisão individual quanto ao investimento em educação é semelhante ao processo decisório em relação ao investimento em capital físico numa firma. Em mercado competitivo, o indivíduo investe em escolaridade, treinamento, condições de saúde etc., como forma de elevar sua produtividade e, consequentemente, seu rendimento, até o ponto em que a taxa de retorno esperada se iguale à sua taxa de desconto intertemporal (Cacciamali \& Freitas, 1992). As pessoas investem em educação porque sabem que um ano a mais de estudo propicia informações adicionais que as tornam mais produtivas.

Quanto à decisão de realizar esse investimento, como mencionado anteriormente, os indivíduos agem racionalmente como qualquer empresário, tomando 
por base algum critério de decisão. Sob o critério da taxa interna de retorno, que corresponde à taxa que iguala o valor presente de um fluxo de custos ao valor presente das receitas, o indivíduo compara a taxa de retorno pessoal de um ano a mais de estudo com sua taxa alternativa. Considera como fluxo de saída (custos) a renda anual sacrificada por se abster a entrar de imediato no mercado de trabalho, acrescida dos custos diretos da educação. Por fluxo de entrada (receita), considera a renda anual a ser auferida após o período adicional de estudo. O indivíduo decide parar de estudar se a taxa de retorno pessoal for inferior à taxa alternativa.

$\mathrm{Na}$ realidade, o fato não se processa tão facilmente assim, devido à existência de outros fatores que interferem na decisão individual, tornando a taxa de retorno imensamente inferior à taxa alternativa. De acordo com Leal \& Werlang (1989)

“... muitos fatores podem tornar essa taxa alternativa proibitivamente elevada. Dentre estes, encontra-se a necessidade imediata de sustento, durante o ano adicional de estudo. Se a família puder sustentá-lo, a taxa alternativa é baixa. Caso contrário, pode ser proibitivamente elevada, fazendo com que o indivíduo abandone os estudos mais cedo do que se fosse possível a ele o acesso aos mercados de crédito pessoal."

Da citação anterior, merece destaque o fato de que, além de abordar essa realidade, os autores evidenciam a necessidade de uma política de crédito com a finalidade de facilitar o acesso à escola aos membros das famílias mais pobres, permitindo, dessa forma, melhor distribuição da educação.

Os investimentos em educação resultam em dois tipos de efeitos: sociais e privados. Os efeitos sociais são as externalidades decorrentes da educação de um indivíduo, que compreendem um vasto número de indicadores socioeconômicos de uma sociedade.

Por sua vez, os efeitos privados de uma elevação do nível de educação são os impactos exclusivamente sobre os indivíduos, resultantes de um aumento da sua 
capacidade produtiva e de um melhor estoque de qualificações que, mesmo sendo gerais, os posicionam em situação privilegiada em relação àqueles que não as obtiveram.

Estes impactos correspondem ao aumento salarial decorrente da maior produtividade e de uma melhor capacidade de adaptação ao meio em que vive, face as constantes e aceleradas mutações técnicas, econômicas e sociais. Exemplo disso é o reconhecimento, por parte do meio empresarial, que as pessoas com maior nível de escolaridade podem ser treinadas com menor custo. Há ainda uma série de efeitos de natureza privada, como o aumento da qualidade de vida advindo de uma utilização mais eficiente dos recursos familiares e da melhor compreensão das informações sobre saúde, nutrição, etc., que dentre outros impactos, podem, num segundo momento, reduzir o tamanho da família e diminuir a pobreza.

Em síntese, a visão de capital humano a respeito do investimento em educação é que aquisição de conhecimento e capacidade úteis à vida produtiva é resultado do investimento deliberado das pessoas em si mesmas, cuja finalidade é a formação e ampliação de seu capital humano, para obterem rendimentos cada vez mais elevados.

Segundo Ramos (1996) a visão do capital humano suscitou intenso debate teórico, favorecendo o surgimento de correntes que relativizam o papel da escolaridade na explicação dos diferenciais de rendimento, como as teorias da sinalização e credencialista.

A teoria da sinalização argumenta que a produtividade dos indivíduos não é afetada diretamente pela educação formal e sim por atributos, que por serem de difícil observação, transformam a educação formal num elemento sinalizador da maior produtividade do indivíduo. A corrente credencialista refuta a relação de causalidade entre educação e salários, ao afirmar que a educação formal não aumenta a produtividade do trabalho. Segundo sua visão, o sistema educacional funciona apenas como algo que possibilita manter a situação social virgente.

Pode-se destacar a distinção entre a visão de cada corrente com relação a teoria do capital humano, com a citação de Ramos (1996). Segundo ela “....a teoria da 
sinalização nega a relação causal entre educação e produtividade e, por fim, a teoria credencialista refuta ambos os vínculos".

\subsection{Retornos privados à educação}

Em 2.3.1 apresenta-se o modelo da escolaridade proposto por Mincer (1974), estabelecendo uma relação funcional entre distribuição de escolaridade e de rendimentos do trabalho. Em 2.3.2, é descrita a função salário com investimento após a escola, ou seja, quando o indivíduo já ingressou no mercado de trabalho.

\subsubsection{O modelo da escolaridade}

A maioria dos trabalhos sobre os elementos determinantes dos rendimentos é baseada no modelo de capital humano de Mincer (1974). A hipótese fundamental do modelo é de serem os anos de escolaridade de um indivíduo o principal elemento indutor das diferenças salariais dos trabalhadores, mas não o único, de modo a determinar a seguinte relação funcional:

$$
\ln Y_{i}=f\left(S_{i}, E_{i} e Z_{i}\right)+u_{i} ; \quad i=1,2, \ldots, n
$$

onde:

$\ln Y i=$ logaritmo natural do rendimento do trabalho do $i$-ésimo indivíduo;

$S i=$ número de anos de escolaridade do indivíduo $i$;

$E_{i}=$ anos de experiência no mercado de trabalho (investimento em capital humano pós escola);

$Z_{i}=$ vetor das variáveis de controle, $\mathrm{e}$; 
$u_{i}=$ resíduo representando todos os outros determinantes do rendimento auferido pelo $i$-ésimo indivíduo.

Convém observar que o modelo analisa os efeitos dos investimentos individuais em capital humano sobre os rendimentos, sem considerar, no entanto, os elementos condicionantes e limitantes das decisões sobre incorporação de capital humano pelo indivíduo.

O modelo parte do pressuposto de os rendimentos individuais estarem, em qualquer período de tempo, diretamente correlacionados com o montante de capital humano acumulado ao longo dos anos vividos pelo indivíduo. Assim, ao se decidir por um ano a mais de educação formal, o indivíduo retarda seu ingresso no mercado de trabalho. A decisão de permanecer na escola eqüivale a uma renúncia de renda correspondente ao nível de sua qualificação atual, isto é, o indivíduo deixa de ganhar uma certa renda que sua qualificação permitiria obter no mercado de trabalho, a qual passa a representar um custo adicional para o indivíduo. Esse custo corresponde ao que usualmente se conhece por custo de oportunidade, renda sacrificada ou custo indireto da educação.

Neste modelo, admite-se que os custos totais da educação se resumem aos custos indiretos, ou seja, a renda sacrificada durante o período de escolarização. Supõese também que os indivíduos ingressem no mercado de trabalho imediatamente após o período de educação formal ${ }^{14}$ e que o estoque de capital humano de um indivíduo não se eleva após sua entrada no mercado de trabalho.

Deriva-se assim uma ilustração gráfica, conforme dispõe a Figura 1, onde $Y i$ representa o nível salarial de um indivíduo com $i$-ésimos anos de escolarização. Considere o investimento de um ano em educação por parte de um particular indivíduo. O investimento em um ano de educação, durante o período de tempo 0-1, significa que o indivíduo terá de renunciar ao salário médio percebido por seus pares de igual nível de

\footnotetext{
${ }^{14}$ Assim como as demais, essa é um pressuposição muito forte, à medida que negligencia as condições de oferta e demanda do mercado de trabalho.
} 
educação, representado pela área sombreada e correspondente à renda sacrificada durante o período. Ao término desse período, o indivíduo se beneficiará de uma remuneração mais elevada, sendo a diferença $\left(Y_{1}-Y_{0}\right)=d$, a parcela correspondente ao ganho direto advindo do investimento em um ano de educação.

Igualando os custos ao valor presente do ganho proporcionado pelo investimento, tem-se que:

$$
\begin{aligned}
Y_{0} & =\left(Y_{1}-Y_{0}\right) / r_{1} \\
\therefore Y_{1} & =Y_{0} *\left(1+r_{1}\right)
\end{aligned}
$$

onde $Y_{0}$ é o nível de rendimento de um indivíduo que não fez investimento em educação, ou seja, o rendimento no ano zero; $Y_{l}$ é o nível rendimento correspondente a 1 ano de educação e $r_{l}$, por definição, é taxa interna de retorno do investimento em um ano de educação formal.

De modo análogo, a taxa de retorno a 2 anos de educação, é dada por

$$
Y_{2}=Y_{1 *}\left(1+r_{2}\right)
$$

Substituindo eq. (2) na eq. (3), obtém-se

$$
Y_{2}=Y_{0} *\left(1+r_{1}\right) *\left(1+r_{2}\right)
$$

Generalizando a expressão anterior para $S$ anos de escolaridade, tem-se

$$
Y_{s}=Y_{0} *\left(1+r_{1}\right) *\left(1+r_{2}\right) \ldots\left(1+r_{s}\right)
$$




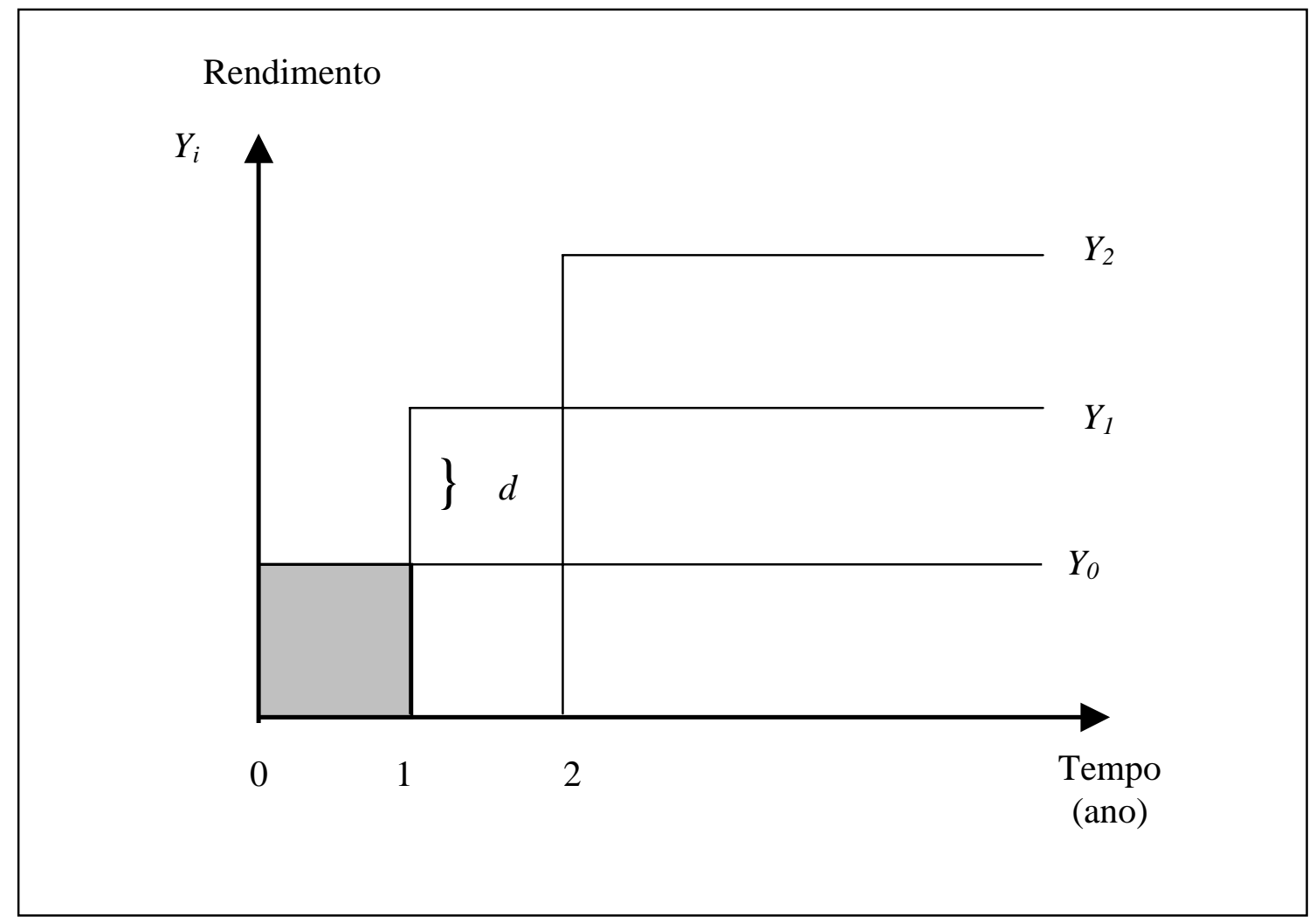

Fonte: Senna (1976).

Figura 1 - Relação entre rendimento e escolaridade.

Considerando que a taxa de retorno à escolaridade é igual para todos os níveis de educação, isto é, $r_{1}=r_{2}=\ldots . .=r_{s}$, onde $r_{s}$ é a taxa média de retorno ao investimento em $S$ anos de escolaridade sobre o nível de escolaridade imediatamente inferior ( $S-1)$, sob capitalização contínua, a expressão resultante é

$$
Y_{s}=Y_{0} *\left(1+r_{s}\right)^{S}
$$

Logaritimizando tal expressão, chega-se a

$$
\ln Y_{s} \cong \ln Y_{0}+\ln \left(1+r_{s}\right) * S
$$


Incorporando-se um termo representativo de perturbações aleatórias e adicionado-se o índice $i$ para representar o indivíduo, a equação anterior (8) passa a ter a forma

$$
\ln Y_{s} \cong \ln Y_{0}+r_{s} * S+u_{i} ; \quad i=1,2, \ldots, n
$$

Esta expressão (9) é a forma mais simples da equação minceriana de rendimento, onde $Y s$ é rendimento de um indivíduo com $S$ anos de investimento em educação; $r_{s}$ é a taxa de retorno do s-ésimo ano de educação; $S$ o número de anos de escolaridade completados pelo indivíduo. De acordo com essa expressão, aumento percentual de salário é diretamente proporcional à diferença absoluta no tempo gasto em escolaridade, sendo a taxa de retorno o coeficiente de proporcionalidade. De outra maneira, a eq. (9) mostra que o logaritmo do rendimento é função linear do tempo de escolaridade (Mincer, 1974). Convém lembrar mais uma vez, que na estimativa da taxa de retorno, somente os custos indiretos privados são considerados.

O modelo de capital humano acima foi alvo de diversas críticas ainda nos anos 70. Senna (1976) aponta possíveis viéses de estimação inerentes à formulação de Mincer. Em primeiro lugar, ao considerar a educação uma atividade estritamente de investimento, o modelo negligencia o componente de consumo na atividade educacional, ocasionando uma subestimação da taxa de retorno desse investimento, pois o fluxo de saída será superavaliado. Segundo, ao assumir que a taxa média de retorno à educação formal não varia entre indivíduos e, além disto, supor que o rendimento inicial é igual para todos os indivíduos, o modelo também negligencia as diferenças de habilidade natural entre indivíduos, isto é, assume que o desempenho individual, durante a escolarização ou no mercado de trabalho, não é afetado pela habilidade natural do indivíduo e/ou pela qualidade da educação.

Muito provavelmente, esses aspectos qualitativos dos efeitos da escolaridade nos rendimentos estariam positivamente correlacionados com os níveis salariais. Assim, por exemplo, a uma maior habilidade natural do indivíduo, maior sua chance de sucesso na escola ou no desempenho de certas atividades. Logo, maior produtividade esse indivíduo terá e, consequentemente, maior rendimento do trabalho. 
Contudo, se habilidade e escolaridade são correlacionadas positivamente, o fato de não se incluir na função uma variável que represente a habilidade, poderá produzir um viés para cima no coeficiente da variável escolaridade (Senna, 1976).

A dificuldade de obter variáveis que indiquem essas características

qualitativas tem levado os estudiosos a incorporar algumas proxies e dummies na tentativa de reduzir o viés de estimação.

Tentativa de englobar alguns efeitos da qualidade da mão-de-obra, foi desenvolvida também por Mincer (1974), como ilustrado a seguir.

\subsubsection{A função salário com investimento após a escola}

Conforme assinalado anteriormente, o modelo da escolaridade representado pela expressão (9) é a forma mais simples da função salário da teoria do capital humano. Ele pressupõe que após o término da educação formal, o fluxo de rendimento permanece constante e que após o ingresso do indivíduo no mercado de trabalho, este não mais investe em capital humano. De imediato, essas pressuposições mostram incoerência com o mundo real, à medida que qualificações individuais e o contínuo desenvolvimento de habilidades, com muita freqüência, são aprimoradas na própria execução das tarefas ou com treinamento após a escola ${ }^{15}$. Visando captar efeitos dos investimentos após a educação formal, Mincer (1974) apresenta o seu modelo ampliado.

Conforme o autor, admitindo que um indivíduo típico, com $S$ anos de educação formal, invista $C_{0}$ durante o primeiro ano de experiência no mercado de trabalho, seu salário durante este primeiro ano será

$$
Y_{0}=Y_{s}-C_{0}
$$

\footnotetext{
${ }^{15}$ Ver Becker (1993).
} 
Onde $Y_{s}$ é o rendimento potencial correspondente a $S$ anos de educação completa e experiência zero; $C_{0}$ é o custo do investimento, interpretado como parcela dos custos totais financiada pelo trabalhador. Como no modelo anterior, aqui se consideram somente os custos indiretos. $C_{0}$ é, portanto, a renda sacrificada pelo indivíduo por estar ampliando seu estoque de capital humano.

Se o investimento ocorrer somente durante o primeiro ano, no ano seguinte o indivíduo perceberá um salário igual ao salário inicial mais o retorno ao investimento realizado no período anterior, ou seja

$$
Y_{1}=Y_{s}+r_{0} C_{0}=E_{1}
$$

Contudo, se os investimentos continuarem também no ano seguinte, então o salário será

$$
Y_{1}=Y_{s}+r_{0} C_{0}-C_{1}=E_{1}-C_{1}
$$

onde $E_{l}$ é o salário potencial de um indivíduo com 1 ano de experiência.

Generalizando para $j$ períodos de experiência , a expressão resultante é

$$
\begin{gathered}
Y_{0}=Y_{s}-C_{0}=E_{0}-C_{0} \\
\therefore Y_{1}=Y_{s}+r_{0} C_{0}-C_{1}=E_{1}-C_{1} \\
\therefore Y_{2}=Y_{s}+r_{0} C_{0}+r_{1} C_{1}-C_{2}=E_{2}-C_{2} \\
\vdots \\
\therefore Y_{j}=Y_{s}+\sum_{t=0}^{j-1} r_{t} C_{t}-C_{j}=E_{j}-C_{j}
\end{gathered}
$$


$\mathrm{Na}$ equação (13), $Y_{j}$ representa o salário percebido pelo indivíduo no $j$ ésimo ano após sua entrada no mercado de trabalho. ${ }^{16}$.

Definindo $k_{j}$ como a razão entre os custos de investimento pós-escola e o salário potencial, ou seja, a fração do salário potencial que é destinada aquele investimento, $\left(k_{j}=c_{j} / E_{j}\right)$ e utilizando a equivalência para $E_{j}{ }^{17}$, tem-se que

$$
E_{j}=E_{j-1}+r C_{j-1}=E_{j-1}+r E_{j-1} k_{j-1}=E_{j-1}\left(1+r k_{j-1}\right)
$$

Assumindo $r_{0}=r_{1}=r_{2}=\cdots=r_{t} \quad$ e $\quad k \leq 1$ e $r$ relativamente pequeno, aplicando logaritmo natural tem-se

$$
\begin{aligned}
& \ln E_{j}=\ln E_{0}+\sum_{t}^{j-1} \ln \left(1+r_{t} k_{t}\right) \\
& \ln E_{j}=\ln E_{0}+\sum_{t=0}^{j-1} r_{t} k_{t}
\end{aligned}
$$

Desde que $Y_{j}=E_{j}\left(1-k_{j}\right)^{18}$ a equação (15) resulta em

$$
\ln Y_{j}=\ln E_{0}+\sum_{t=0}^{j-1} r_{t} k_{t}+\ln \left(1-k_{j}\right)
$$

16 A variação dos salários com o aumento da experiência é melhor ilustrada da seguinte maneira: $\Delta Y_{j}=Y_{j+1}-Y_{y}=\sum_{t=0}^{j} r_{t} C_{t}-C_{j+1}-\sum_{t=0}^{j-1} r_{t} C_{t}+C_{j} \mathrm{e}$

$\Delta Y_{j}=r_{j} C_{j}-\left[C_{j+1}+C_{j}\right]=r_{j} C_{j}-\left[C_{j+1}+C_{j}\right] \frac{C_{j}}{C_{j}} \quad$ de modo que $\Delta Y_{j}=C_{j}\left[r_{j}-i_{j}\right]$.

Assim o salário aumenta com a experiência sempre que a taxa de variação dos custos do investimento pósescola, $i_{j}$, for inferior a taxa de retorno desse investimento, $r_{j}$ (Mincer, 1974).

${ }^{17}$ A equivalência é dada por: $E_{j}=Y_{s}+\sum_{t=0}^{j-1} r_{t} C_{t} \Leftrightarrow E_{j}=Y_{s}+\sum_{t=0}^{j-2} r_{t} C_{t}+r_{j} C_{j-1} \Leftrightarrow$ $E_{j}=E_{j-1}+r C_{j-1}$ (ibid.).

${ }^{18}$ Da equação (14) tem-se $Y_{j}=E_{j}-C_{j} \Leftrightarrow Y_{j}=E_{j}-k_{j} E_{j} \Leftrightarrow Y_{j}=E_{j}\left(1-k_{j}\right)$ (ibid.). 


$$
\therefore \ln Y_{j}=\ln Y_{0}+r_{s} S+r_{t} \sum_{t=0}^{j-1} k_{t}+\ln \left(1-k_{j}\right)
$$

onde $r_{s}$ é a taxa de retorno a $S$ anos de educação formal, $r_{t}$ é a taxa de retorno aos investimentos em capital humano após a escola e $k$ é a fração do salário potencial dedicada a investimento após a escola.

Segundo Senna (1976) modelos de otimização de capital humano sugerem que a fração $k_{t}$ declina linearmente com o passar do tempo $(t)$ devido a dois motivos. Primeiro, à medida que a idade do indivíduo aumenta, o período de tempo que resta de sua vida útil para recuperar os custos de investimento diminui, fazendo com que tais investimentos se tornem menos atrativos. Segundo, com o aumento da idade e com a acumulação de experiência, a produtividade marginal e o salário do indivíduo aumentam, o que torna maior o seu custo de oportunidade, fazendo cair o incentivo a investir.

Baseado nessas hipóteses e supondo que $k_{t}$ seja uma função linear do tempo, a função salário foi aproximada, por uma expansão de Taylor, para uma forma quadrática, especificada como:

$$
\ln Y_{i}=a+b_{1} S_{i}+b_{2} J_{i}+b_{3} J_{i}^{2}+u_{i}
$$

onde:

ln $Y i=$ logaritmo natural do rendimento do indivíduo $i$;

$S i=$ anos de escolarização ou instrução formal do indivíduo $i$;

$J_{i}=$ anos de experiência no mercado de trabalho do $i$-ésimo indivíduo;

$a=$ constante;

$b_{1}=$ taxa de retorno à escolarização;

$b_{2}=$ taxa de retorno à experiência;

$b_{3}=$ coeficiente do quadrado da experiência, o qual produz um perfil rendimentoidade côncavo para baixo; e

$u_{i}=$ resíduo aleatório. 
De acordo com o modelo, anos adicionais de estudo e de experiência no trabalho proporcionam rendimento mais elevado, sujeito a retorno decrescente a partir de certo período. Portanto, equiivale afirmar que no inicio da vida útil do trabalhador, os salários aumentam de forma crescente devido ao maior nível de produtividade do trabalho, proveniente da educação e também da acumulação de experiência. Em segundo momento, em decorrência da obsolescência e da depreciação do estoque de capital humano do indivíduo, os aumentos ocorrem de forma decrescente. Em um terceiro estagio, o estoque de capital humano permanece praticamente constante.

A taxa de retorno ao investimento em educação, $b_{1}$, difere da encontrada no modelo da escolaridade, pois aqui capta-se a taxa de retorno à educação isoladamente dos efeitos da experiência, o que não se verifica no modelo da escolaridade.

Em resumo, esta formulação da teoria do capital humano sugere que os rendimentos são côncavos em relação à experiência, prevendo coeficientes positivos para $b_{1}$ e $b_{2}$ e negativo para $b_{3}$.

Segundo Senna (1976), deve ser enfatizado que esses modelos são essencialmente de longo prazo. A suposição de taxas de retorno à educação formal e ao investimento após a escola iguais para todos os indivíduos, eqüivale a admitir que no mercado de trabalho há informação perfeita, mobilidade total dos agentes e ausência de forças monopolistas e monopsonistas, ou seja, um mercado de trabalho em concorrência perfeita.

Esse autor faz também alguns comentários sobre os possíveis viéses de estimação, como a ausência de uma variável que capte a habilidade natural das pessoas e a qualidade da educação. Tais viéses podem ser reduzidos com a utilização de proxies dessas variáveis e variáveis binárias de controle. Com relação a inclusão de uma proxy para a habilidade, o maior problema reside na definição de uma medida que reflita realmente a habilidade do indivíduo para produzir e auferir renda no mercado de trabalho. A respeito da qualidade do ensino, por sua vez, o autor cita os trabalhos de 
Link-Ratledge $^{19}$ e Jonhson-Stafford ${ }^{20}$, que incorporaram ao modelo uma proxy para a qualidade de escolaridade.

\subsection{Breve revisão de estudos empíricos}

A influência da educação no rendimento do trabalho tem sido objeto de estudo de vários pesquisadores focalizando três importantes características. A maioria dos trabalhos tenta identificar a educação como principal determinante dos rendimentos sob a ótica do capital humano. Uma parte considerável procura testar a teoria do capital humano vis-a-vis a visão da escolas credencialista e da sinalização; enquanto a parte restante tem procurado aperfeiçoar os métodos de estimação das equações salários, visando corrigir o viés de estimação inerente aos modelos do capital humano.

Nesta seção encontram-se expostos somente alguns trabalhos relacionados à contribuição da educação e experiência na determinação do rendimento do trabalho e a uma forma alternativa de estimação da equação salário.

Utilizando a metodologia desenvolvida por Becker $(1964)^{21}$ e por Schultz $(1961)^{22}$, Gibbon (1975) mensura a taxa de retorno dos investimentos através de estimativas de uma taxa de desconto que iguala os valores presentes dos custos e dos benefícios (taxa interna de retorno), desagregando em setores e regiões para o sexo masculino e tomando três categorias de custos: renda sacrificada, custos totais corrigidos e custos totais.

Os resultados, segundo o autor, evidenciam a alta estabilidade dos investimentos em educação no Brasil, sendo que os maiores índices, em todas as regiões, correspondem ao ensino primário. Nota-se também pequena elevação das taxas quando a

\footnotetext{
${ }^{19}$ Link, Charles R., Ratledge, Edward C. Social returns to quantity and quality of education: a further statement. Journal of Human Resources, v.10, n.1, 1975.

${ }^{20}$ Johnson, George E., Stafford, Frank P. Social returns to quantity of schooling. Journal of Human Resources, v.8. n. 2, 1973.

${ }^{21}$ O "Human Capital" de Becker, foi reeditado em 1993.

${ }^{22}$ SCHULTZ T. W. Investment in human capital. American Economic Review, v. 51, mar. 1961.
} 
renda sacrificada é corrigida pelo percentual de estudantes que trabalham. Por fim, o autor enfatiza a contribuição do investimento em educação como instrumento de distribuição da renda.

Ribeiro (1979) combinando as técnicas cash-flow e função de produção, determinou taxas de retorno à educação para os membros da Cooperativa Agrícola de Cotia, em 1976, de acordo com o número médio de anos de educação formal do produtor e também para diferentes níveis de educação.

$\mathrm{O}$ autor considerou os custos privado e público. No custo privado foram considerados o ganho médio não realizado e a despesa média com livros e outros materiais escolares correspondentes a cada ano escolar. No custo público foi contabilizada a despesa anual por aluno, nas três esferas de poder executivo (nacional, estadual e municipal)

Para o número médio de anos de escolaridade do produtor $(7,9$ anos de educação formal) a taxa de retorno ao investimento em educação foi 24,78\%. As taxas internas de retorno relacionadas a níveis de educação variaram contrariamente a elevação do nível educacional. É bastante elevada para o nível mais baixo, devido sobretudo ao baixo custo, atingindo 25,49\% (duas vezes superior ao determinado para o nível mais elevado). Ribeiro destaca ainda a possibilidade das taxas estarem subestimadas, devido a alguns pressupostos e ao caso de migração de cooperados.

Trabalhando com uma amostra de 33 mil indivíduos participantes do mercado de trabalho de El Salvador, Anderson (1980) analisou a taxa de retorno à escolaridade com base na equação salário, concluindo que somente quando escolaridade e experiência são consideradas, a taxa de retorno estimada foi 19\%. Quando as variáveis explicativas foram ampliadas, de modo a incluir a experiência ao quadrado e uma variável cruzada (experiência x escolaridade), o valor da taxa de retorno diminuiu para $15 \%$.

Em análise dos efeitos do family background sobre o mercado de trabalho de homens com idade entre 30 e 55 anos, no Brasil, Lam \& Schoeni (1993) partem do pressuposto de que a omissão de variável relacionada ao family background nas estimativas do retorno à educação é parcialmente responsável por elevados coeficientes 
à escolaridade nas equações de salário. Com amostra de mais de 40 mil homens, procuram identificar a magnitude do viés de family background sobre o salário do indivíduo por meio da estimação de equação salário tradicional, comparando-a em seguida, com quatro equações de salário, incluindo: i) escolaridade dos pais; ii) escolaridade dos pais e dos pais da esposa do indivíduo; iii) escolaridade da esposa; e, iv) uma regressão com todas as variáveis anteriores. Resultados apontaram um declínio de $1 / 4$ a $\quad 1 / 3$ com a inclusão das variáveis relativa ao family background.

O surpreendente nos resultados encontrados, deve-se ao fato de o nível educacional do pai da esposa do indivíduo ter apresentado maior efeito sobre o rendimento do indivíduo do que o proporcionado pela educação do pai. Segundo os autores, isto serve de suporte ao uso de proxies à características não observáveis associadas ao rendimento do trabalho.

Kassouf (1995) trabalhando com amostra de indivíduos com idades entre 18 e 65 anos, diferenciando homens de mulheres e setor urbano de rural, utilizou o procedimento de Heckman para estimativas consistentes dos parâmetros na presença de seletividade amostral.

Os resultados mostraram que os retornos à escolaridade e ao treinamento foram bem maiores no setor urbano do que no rural, enquanto o retorno à escolaridade foi superior ao retorno do investimento em treinamento. Foi mostrado também que os trabalhadores urbanos atingem o pico de rendimento mais cedo do que os trabalhadores rurais. As taxas encontradas, considerando os indivíduos em sua totalidade e com 4 a 13 anos de experiência, variaram de $15,75 \%$ a $21,69 \%$ no setor urbano, e de $11,60 \%$ a $13,60 \%$ no setor rural.

Kassouf conclui que os residentes no setor urbano têm maiores incentivos ao investimento em educação e em treinamento do que os residentes no setor rural. Estes, quando atingem "um bom nível” de educação, migram às cidades em busca de maiores salários.

Blackburn \& Neumark (1995) examinam a evidência de serem viesadas as estimativas dos efeitos da escolaridade sobre os salários quando estimadas por mínimos quadrados ordinários, com a inclusão de teste de scores como proxies de 
habilidades não observadas ${ }^{23}$. Quando o teste de score foi incluído na equação salário básica, o coeficiente estimado para escolaridade foi menor que o estimado sem controle para habilidade. Isto indica que as estimativas tradicionais comportam um viés de alta de cerca de $40 \%$. O viés de alta permaneceu mesmo depois de considerar um vetor de variáveis do family background como instrumento para o teste de scores, sendo o novo estimador quase a metade do primeiro.

Segundo os autores, com a inclusão de proxies para habilidade nas equações convencionais de salário, o teste de especificação fornece pouca evidência sobre a questão da escolaridade ser endógena ou medida com erro.

A conclusão dos autores é que estimativas de mínimos quadrados ordinários que omitem as medidas de habilidades são sobrestimadas.

Ramos (1996), com amostra de homens ocupados, assalariados e com idade entre 25 e 65 anos, selecionados nas PNADs de 1976, 1981, 1985 e 1990, examina a natureza da relação entre educação e salários no Brasil, comparando os enfoques de capital humano e de sinalização. O autor estima, simultaneamente, retornos à educação diferenciados por níveis completos e a anos de escolaridade, com base em equações de salário tradicionais, para captar não linearidade nos retornos à educação e existência do "efeito-diploma" no mercado de trabalho. ${ }^{24}$

Os resultados mostram que os retornos à educação são diferenciados por grupo educacional, sendo mais elevados para os grupos de maior escolaridade, de aproximadamente $20 \%$ à educação superior e metade nos três níveis inferiores. Foi também comprovada a existência de um prêmio adicional ao término de cada nível ("efeito-diploma"), cuja dimensão é mais elevada para o curso superior. Portanto, o retorno associado à educação é substancialmente maior à educação superior, tanto em termos de anos de estudo, quanto à finalização de um estágio específico.

A evolução temporal dos retornos, segundo o nível de escolaridade, apresenta-se estável, enquanto as variações na magnitude do "efeito -diploma" são um

\footnotetext{
${ }^{23}$ Entende-se por habilidade características usualmente não captadas pelas variáveis do capital humano e que influenciam a escolaridade dos indivíduos.

${ }^{24}$ No estudo de Ramos (1996) são utilizados 16 anos de estudo e cinco níveis educacionais: analfabeto, primário, ginásio, colegial e superior.
} 
pouco mais pronunciadas, diminuindo de 29\% (1976) a 19\% (1990) no nível superior. A composição dos retornos a cada ano mais o "efeito-diploma" correspondente (retornos totais) mostrou-se estável no período. O nível superior apresenta ganhos salariais acima de $200 \%$, cerca de 4 vezes mais que os de estágios anteriores.

A conclusão de Ramos é que a educação no Brasil funciona tanto para elevar a produtividade dos indivíduos como para sinalizar oportunidades no mercado de trabalho. A natureza da relação educação-salários no Brasil condiz tanto com o enfoque de capital humano quanto com o de sinalização, sendo os retornos individuais (privados) superiores aos retornos sociais. Esses fatos demandam políticas educacionais que universalizem o acesso à escola, sobretudo nas fases iniciais, como “... o meio mais adequado de viabilizar a obtenção de uma distribuição de salários mais igualitária em conjunto com uma redução no contigente de pobres ...".

Trabalhando com amostra de homens da Finlândia, Uusitalo (1999) compara taxas de retornos à educação formal e experiência (medida como anos de trabalho após a escola), nos modelos padrões de equações de salário, por meio de duas estimativas de mínimos quadrados ordinários (simples e com controle por habilidade) com a obtida através de estimativas com variáveis instrumentais para o family background. O estudo parte do princípio que as diferenças entre grupos de salários com diferentes níveis de educação são influenciadas não somente pela educação do indivíduo, mas também por outras características observáveis e não observáveis que atuam na escolha e durante a educação.

Com base no modelo de equações salário, onde o salário do indivíduo é determinado por sua escolaridade, por um vetor de variáveis exógenas (no qual a experiência é mais importante) e um vetor de outras características que influenciam a decisão de estudar, formado por family background e army test scores ${ }^{25}$, mostrou que quando as diferenças individuais são ignoradas, o retorno à educação formal é sobrestimado, diminuindo de $8,9 \%$ para $7,4 \%$ com a introdução dessas medidas. A estimação por meio de variáveis instrumentais foi $12,9 \%$, indicando que o family ${ }^{25}$ Corresponde ao teste aplicado pelas forças armadas da Finlândia para medir habilidade dos homens em
idade de iniciar o serviço militar obrigatório. 
background exerce significativa influência sobre a escolaridade dos filhos e, por conseguinte, sobre o rendimento do trabalho.

Em trabalho recente, Herrera B. \& Madri-Aris (2000) analisam o perfil de salários e os retornos à educação no Panamá, em amostra de 6.668 observações, das quais $40 \%$ correspondiam ao sexo feminino. Os autores confirmam a relevância da educação na explicação dos diferenciais de salário e a tendência padrão deste diferencial aumentar com a idade até os 45 - 50 anos, para em seguida decrescer; a distribuição de salários por idade aumenta constantemente. Para as mulheres de nível universitário, a tendência padrão não foi verificada.

Com relação a taxa de retorno à educação, os autores mostram que ao contrário dos países menos desenvolvidos, o retorno é mais elevado no Panamá para níveis mais altos de escolaridade. Possivelmente, por ser a economia panamenha voltada à prestação de serviços, a demanda por trabalhadores não absorve todas as pessoas com educação elementar, concluem.

Taxa de retorno à educação por gênero, mostra que as mulheres apresentam taxas mais elevadas nos dois níveis educacionais inferiores, e menor que a verificada para os homens no nível de educação superior, da ordem de 12,6\% contra $14,6 \%$, respectivamente. 


\section{METODOLOGIA}

Para alcançar os objetivos deste trabalho serão estimadas taxas de retorno à educação tendo por base funções tradicionais de rendimento associadas ao paradigma do capital humano.

Segundo Ramos (1991) a teoria do capital humano postula a existência de uma relação positiva entre produtividade e escolaridade. Assim, ao adquirir um ano a mais de estudo, o indivíduo está aglutinando em torno de $S i$ mais recursos humanos, que permitirão o aumento de sua produtividade, tornando-a de maior valor no mercado de trabalho, e em última instância, elevando seu salário potencial de mercado. ${ }^{26}$ Colocada de forma mais clara, a abordagem do capital humano atribui causalidade à relação entre educação e salário. Este é o motivo pelo qual o estoque de educação incorporado ao indivíduo constitui capital humano. As outras fontes de capital humano são: migração; busca de informação sobre as oportunidades de emprego, nutrição e saúde. Segundo Schultz (1973b) são as diferentes dotações desses elementos possuídos pelos indivíduos os principais determinantes das diferenças salariais entre as pessoas.

Assim, conforme o exposto acima, a função de rendimento é

$$
Y=f(S, Z), \operatorname{com} d Y / d S>0,
$$

onde $Y$ representa a renda do trabalho, $S$ é o nível de escolaridade e $Z$ um vetor de outras variáveis relevantes. Para estimar os diferenciais de salários associados a distintos graus de escolaridade, alguns pontos merecem destaques, como apontam Ramos (1991) e Senna (1976). 
Primeiro, convém atentar para o fato de que somente os aspectos privados das decisões sobre investimento em capital humano são considerados, mesmo reconhecendo que políticas públicas educacionais desempenham importante papel na distribuição de escolaridade e contribuem para a melhoria dos índices educacionais.

Segundo, assume-se que o indivíduo tem amplos poderes para decidir o quantum de educação a ser adicionado ao seu capital humano. Esta hipótese é por demais simplista, pois à medida que torna o investimento em educação uma atitude intrínseca ao indivíduo, não contempla fatos reais, tais como decisões tomadas no âmbito da família, restrição financeira, facilidade de acesso ao sistema de ensino público, subsídio educacional e crédito educativo.

Ao considerar a decisão do investimento em educação algo que diz respeito unicamente ao indivíduo, surge uma implicação, a de tornar importante somente os custos decorrentes dessa decisão. Assim, somente o custo indireto ou renda sacrificada são considerados no estudo, constituindo o custo de oportunidade desse investimento.

De modo geral, esse custo de oportunidade representa parcela importante do custo total do investimento em educação. Contudo, é necessário lembrar que ele varia de acordo com o meio social no qual o indivíduo se encontra. Em alguns casos, o custo social de jovens adolescentes é muito baixo devido à pouca flexibilidade da demanda por trabalhadores adolescentes. Em outros, a renda sacrificada poderá representar valor expressivo, pois em algumas comunidades, sobretudo as mais pobres, o rendimento do trabalho infantil é parcela significativa da renda familiar. Além disso, note-se também que o custo de oportunidade poderá ser nulo, devido a restrições legais quanto ao emprego infantil.

Os demais componentes do custo total, tais como despesas com materiais, taxas e contribuições, são usualmente conhecidos como custos diretos da educação. Importante destacar que quando o setor público subsidia a educação, o custo total da educação passa a ser dividido em custo social e custo privado.

\footnotetext{
${ }^{26}$ Ramos (1991) enfatiza que apesar das fortes críticas que esta linha de raciocínio tem sofrido, nenhuma vertente teórica nega a relevância da educação, seja por esta elevar a produtividade individual, seja por servir de indicador de outras características de valor do trabalho.
} 
Um terceiro ponto, é que a relação funcional estabelece uma ordem de causalidade, visando medir quanto o salário de um indivíduo seria alterado se ele elevasse sua escolaridade até o nível imediatamente superior ao atual. A diferença entre o salário atual e o equivalente a um nível a mais de escolaridade, é baseada no salário médio observado para os trabalhadores que têm de fato o grau de instrução almejado pelo indivíduo em questão, sendo portanto, a variação marginal no rendimento da renda do trabalho, dada uma variação de uma unidade na escolaridade, em termos matemáticos, $d Y / d S$.

Outra questão diz respeito ao vetor de outras variáveis relevantes $(Z)$. Este vetor é constituído por variáveis de difícil observação e mensuração, como raça, habilidade, cultura da comunidade, vocação, experiência, educação dos pais, aporte financeiro da família, qualidade de ensino, região e setor econômico. Nesse conjunto de variáveis, também chamado de variáveis de controle, a difícil mensuração e computação, torna a contribuição do vetor $Z$ arbitrária, o que causa possíveis problemas ou distorções nas estimativas.

A experiência é uma variável desse conjunto que, a despeito de sua apresentação ser menos complicada quanto a mensuração e observação, acarreta problemas à estimação do retorno à educação, pois na ausência de informação direta sobre experiência, utilizam-se proxies. A proxy mais comum é a que define experiência como: (idade - escolaridade - 7). Lam \& Levison (1990a) e Cacciamali \& Freitas (1992) utilizaram como proxy à experiência a soma: (idade - escolaridade - seis). Há ainda os que consideram uma idade limite, a partir da qual a experiência no trabalho começa a somar ao capital humano acumulado (Lam \& Levison (1990a).

O principal efeito das diferentes definições de experiência é que elas modificam o tamanho das amostras e o retorno estimado à educação ${ }^{27}$. Finalmente, resta ainda outro problema, o da forma funcional mais apropriada para a função $f(S, Z)$.

O modelo econométrico a ser estimado neste trabalho é apresentado a seguir, em 4.1.

${ }^{27}$ Lam \& Levison (1990a) apresentam uma boa discussão desse conteúdo. 


\subsection{Modelo econométrico}

O padrão de estimativas do capital humano supõe que as variáveis explicativas sejam independentes umas das outras em relação à variável explicada, isto é, que elas não guardam correlação entre si. Essas variáveis compreendem educação, saúde, nutrição, informação acerca de oportunidades de emprego, migração, qualidade da educação, nível de escolaridade, renda da família e habilidade pessoal. Como enfatizado em vários estudos, para grande parte dessas variáveis as informações não permitem mensurar sua influência na formação da renda dos indivíduos. Por força dessas restrições, o modelo a ser estimado considera apenas a influência das variáveis escolaridade, idade, nível educacional dos pais e de um conjunto de variáveis binárias. A variável a ser explicada é o logaritmo neperiano do rendimento horário do trabalho principal.

A formulação assume que o rendimento anual de um indivíduo é equivalente ao produto marginal do trabalho e que seu produto marginal aumenta quando aumenta o capital humano acumulado. A taxa de retorno privado a um ano de estudo adicional será estimada com dados de rendimento individual.

Seguindo diversos pesquisadores, será utilizado aqui um modelo semilogaritmo que é uma extensão da função salário de Mincer, podendo ser escrita como

$$
Y=f(\text { anoesc, } \text { idade, nepai, nemae, } Z)
$$

onde $Y$ é o rendimento na ocupação principal; anoesc anos completos de estudo; idade corresponde a anos de idade do indivíduo; nepai e nemae são níveis de escolaridade do pai e da mãe, respectivamente, e $Z$ corresponde a um vetor de variáveis de controle ou binárias. Com base na função supra mencionada, três formulações específicas serão testadas, quais sejam: 


\section{Formulação (1)}

$$
\ln Y_{i}=\beta_{0}+\beta_{1} A N O E S C+\beta_{2} I D A D E+\beta_{3} I D Q U A D+\sum_{c=14}^{28} \beta_{c} V B C_{c}+u_{i}
$$

\section{Formulação (2)}

$$
\begin{aligned}
\ln Y_{i}=\beta_{0}+\beta_{1} A N O E S C+\beta_{2} I D A D E+ & \beta_{3} I D Q U A D+\beta_{4} N E P A I+ \\
& +\beta_{9} N E M A E+\sum_{c=14}^{28} \beta_{c} V B C_{c}+u_{i}
\end{aligned}
$$

\section{Formulação (3)}

$$
\begin{aligned}
\ln Y_{i}=\beta_{0}+\beta_{1} A N O E S C+\beta_{2} I D A D E & +\beta_{3} I D Q U A D+\sum_{p=5}^{8} \beta_{p} N E P A I_{p}+ \\
& +\sum_{m=10}^{13} \beta_{m} N E M A E_{m}+\sum_{c=14}^{28} \beta_{c} V B C_{c}+u_{i}
\end{aligned}
$$

em que:

$Y i$ : rendimento horário;

Anoesc: anos completos de estudo;

Idade: anos de idade do indivíduo;

Idquad: idade ao quadrado;

$V B C_{c}$ : variáveis binárias de controle para sexo, região, cor, condição na família e condição na ocupação, $c \in\{14, \ldots, 28\}$;

Nepai: nível de escolaridade do pai;

Nemae: nível de escolaridade da mãe;

$\beta_{n ; c ; p ; m}$ : parâmetros; $n \in\{0, \ldots, 3,4,9\} ; c \in\{14, \ldots, 28\} ; \quad p \in\{5, \ldots, 8\}$; $m \in\{10, \ldots, 13\}$

$u_{i}=$ resíduo aleatório.

Nas formulações acima prevalece a suposição de que o salário anual de um indivíduo é equivalente ao produto do trabalho e que o produto marginal aumenta 
quando aumenta o capital humano acumulado. Em outras palavras, o mercado de trabalho competitivo.

Ao mesmo tempo, com a inclusão dos níveis de escolaridade dos genitores, procura-se eliminar a hipótese de não haver níveis de desigualdade em fatores como inteligência, habilidade física e family background. As variáveis binárias de controle servirão para captar as diferenças estruturais nos mercados de trabalho considerados, tendo como base o mercado do nordeste rural.

Por outro lado, espera-se que a inclusão dos níveis de escolaridade dos pais, bem como de um conjunto de variáveis binárias, possa contribuir para a melhor especificação do modelo. Essas variáveis são consideradas proxies de habilidades não observadas dos indivíduos.

$\mathrm{Na}$ formulação (2) - eq. (21) - o nível de escolaridade dos pais assume valores discretos de 1 a 5, enquanto na formulação (3) tal nível educacional aparece como variável binária, tendo o nível elementar como base.

Apesar de não aparentar, há uma importante diferença entre essas duas formulações. Na primeira, está implícita linearidade da influência do nível educacional do pai (ou mãe) no rendimento, enquanto na segunda, o incremento no rendimento do trabalho individual devido ao nível educacional do pai (ou mãe) se diferencia conforme o nível de educação formal.

O questionamento das estimativas de retorno à educação tiveram destaque com Griliches em 1977 e continuam até períodos mais recentes. Segundo Herrera B. \& Madrid-Aris (2000), durante a década de 80 as críticas concentravam-se na questão de os rendimentos do trabalho não refletirem, de fato, a produtividade do trabalho. Durante a última década (anos 90), grande parte dos estudos busca identificar elementos causadores de viés nessa estimação, tais como seletividade amostral, heterogeneidade não observada nas variáveis independentes e endogeneidade das decisões de investimento em educação. Outros estudos têm procurado atenuar os viéses de estimação por meio de modelos alternativos de variável instrumental. 
Elemento comum dessas pesquisas é a conclusão que as estimativas de mínimos quadrados tradicionais, ao retorno à educação, são carregadas de erros econométricos, conhecidos como erros de especificação e de medidas.

Segundo Bedi e Gaston (1999), citados por Herrera \& Madrid-Aris (2000), enquanto fatores não observados sobre habilidade do indivíduo podem viesar as estimativas de mínimos quadrados para cima, a endogeneidade das decisões quanto ao investimento em educação causariam viés para baixo. Assim, nada se pode afirmar sobre sinal e magnitude do viés global nas estimativas de mínimos quadrados.

De acordo com Blackburn \& Neumark (1995), as formulações (1), (2) e (3) resultam em estimativas consistentes somente sobre a hipótese de a escolaridade não estar correlacionada com o erro na equação salário. Os autores apontam duas razões que podem invalidar essa hipótese: i) modelos de escolaridade do capital humano sugerem que indivíduos com salários mais baixos deveriam estar mais propensos a investir em educação que indivíduos de salários mais altos; e, ii) erros de medida na variável poderiam implicar uma correlação entre escolaridade e erro na equação salário.

Para contornar esse viés potencial, serão estimados também os retornos à escolaridade através do modelo de variável instrumental, conforme sugerido por Blackburn \& Neumark (1995). Essa formulação é dada por

\section{Formulação (4)}

$$
\begin{aligned}
& A N O E S C=\alpha_{0}+\alpha_{1} N E P A I+\alpha_{2} N E M A E+v_{i} \\
& \ln Y_{i}=\beta_{0}+\beta_{1} A N O E S C+\beta_{2} I D A D E+\beta_{3} I D Q U A D+\sum_{c=14}^{28} \beta_{c} V B C_{c}+u_{i}
\end{aligned}
$$

onde:

$Y i$ : rendimento horário;

Anoesc: anos completos de estudo;

Idade: anos de idade do indivíduo;

Idquad: idade ao quadrado; 
$V B C_{c}$ : variáveis binárias de controle para sexo, região, cor, condição na família e condição na ocupação; $c \in\{14, \ldots, 28\}$.

Nepai: nível de escolaridade do pai;

Nemae: nível de escolaridade da mãe;

$\alpha_{i}$ : parâmetros; $i \in\{1, \ldots, 2\}$;

$\beta_{n ; c}$ : parâmetro a ser estimado, $n \in\{0, \ldots, 3\}$ e $c \in\{14, \ldots, 28\}$;

$v_{i} ; \quad u_{i}=$ resíduo aleatório.

Essa última formulação se origina do método de variável instrumental apresentado no apêndice. Assume-se que nepai e nemae sejam independentes de $v_{i}$, e, por consequiência de $u_{i}$ e que nepai e nemae estão correlacionados com anoesc ${ }^{28}$.

\subsection{Definição e seleção da amostra}

Os dados utilizados neste trabalho foram extraídos dos microdados da Pesquisa sobre Padrões de Vida 1996/97 (PPV), realizada pela Fundação Instituto Brasileiro de Geografia e Estatística (IBGE), em convênio com o Banco Mundial. A PPV é uma pesquisa multitemática nas regiões nordeste e sudeste do Brasil, no período de março de 1996 a março de 1997. De grande diversidade social e econômica, a PPV permite qualificar e identificar determinantes do bem-estar social de diferentes grupos da sociedade brasileira.

Nos cerca de 5.000 domicílios pesquisados $^{29}$, com um total de 19.409 pessoas, cobrindo dez estratos geográficos (Regiões Metropolitanas de Fortaleza, Recife, Salvador, Belo Horizonte, Rio de Janeiro e São Paulo; restante da área urbana do

\footnotetext{
${ }^{28}$ As estimativas da eq. (24) são esperadas consistentes, mas não eficientes, pois, embora teoricamente haja um vasto número de instrumentos disponíveis, nada garante que epai e emae sejam de fato os que apresentam a mais alta correlação com a variável anoesc. Isto é, que elas sejam um instrumento ótimo. Consequentemente os estimadores poderão não ser o de variância mínima (eficientes).

${ }^{29}$ Ver Pesquisa sobre Padrões de Vida 1996 - 1997/IBGE.
} 
nordeste, restante da área urbana do sudeste, restante da área rural do nordeste e restante da área rural do sudeste). A PPV levantou diversas características dos indivíduos da amostra e seu respectivo fator de expansão (ou peso), que permite alcançar o total da população residente na área geográfica amostrada.

Além dos padrões estruturais de desenvolvimento regional, a pesquisa aponta importantes relações e diferenças entre eles. De acordo com IBGE (1999), 90,1\% dos domicílios no sudeste e $64,5 \%$ dos domicílios no nordeste situam-se em áreas urbanas. O nível de instrução do(a) chefe do domicílio está correlacionado positivamente com a classificação do domicílio segundo às condições de moradia ${ }^{30}$.

Nos domicílios, cujos chefes possuem pelo menos o primeiro grau completo, $50,5 \%$ foram considerados adequados e $15 \%$ classificaram-se como inadequados. Essas mesmas rubricas apresentam índices correspondentes a 17,3\% e $39,0 \%$, respectivamente, nos domicílios cujo chefe possui menos de um ano de escolaridade.

O número médio de anos de estudo completos das pessoas entrevistadas com 25 anos ou mais de idade era 2,3 anos no meio rural e 6,1 no meio urbano; 4,1 no nordeste e 6,1 no sudeste.

A PPV comprova que a região sudeste e as áreas urbanas apresentam condições de vida mais favoráveis que o nordeste e áreas rurais. As mulheres freqüentam, proporcionalmente, mais a escola do que os homens e permanecem as discriminações raciais, enquanto a renda familiar e a instrução dos pais são fortes determinantes da escolarização.

Dados como os da PPV, são levantados com forte influência de fatores que condicionam entrevistado e entrevistador, muitas vezes distantes socioeconomicamente, de sorte que as estatísticas podem ser inexatas. O exemplo mais comum de inexatidão no Brasil, diz respeito a subdeclaração de rendimentos, especialmente por parte das pessoas com renda relativamente mais elevada (Hoffmann,

\footnotetext{
${ }^{30}$ A classificação dos domicílios é feita com base em três indicadores de qualidade: estrutura física do imóvel; acesso aos serviços de utilidade pública e densidade populacional. Distinguem-se em adequado, semi-adequado e inadequado.
} 
2000). Entretanto, acredita-se que outras características, como nível de escolaridade, cor da pele e trabalho, comportam viés considerável.

Outra fonte de viés surge quando se faz a extrapolação de uma característica amostrada para uma população, sem se considerar particularidades intrínsecas a cada indivíduo. Assim, por exemplo, a comparação do nível educacional de diferentes indivíduos, em muitos casos, não permite identificar causas estruturais, como habilidade, renda familiar (durante o período de escolarização) e qualidade da escola.

Do escrito acima, pode-se concluir que observações aparentemente homogêneas são de fato heterogêneas. Na tentativa de tornar a amostra mais homogênea, serão fixadas algumas restrições aos microdados da PPV.

\subsubsection{Descrição das variáveis}

Os critérios utilizados para a seleção de observações foram estabelecidos segundo um conjunto de informações sobre rendimento do trabalho principal, idade, escolaridade, carga horária semanal na atividade principal e nível de escolaridade dos pais. Por praticidade, denominaremos essas informações variáveis chave. Na continuação desta seção descreveremos cada uma dessas variáveis chave e enfocaremos os critérios para seleção da amostra.

Idade

A amostra ficou restrita a pessoas que à época da entrevista declararam ter 15 anos ou mais de idade. O uso desta opção se deve ao fato de considerarmos, contrariando outras alternativas, que até essa idade a maioria dos indivíduos, embora já acumulando capital humano em termos de escolaridade e, em alguns casos, com 
experiência $^{31}$ em trabalho, não se encontra habilitada a interagir com o mercado de trabalho formal.

Casos dessa natureza podem ser ilustrados por cenas comuns ao cotidiano dos centros urbanos brasileiros. Quando uma jovem adolescente se estabelece como agregada em alguns domicílios para afazeres domésticos, ela está sendo subempregada (se seu estoque de capital humano a qualifica a prestar serviços mais complexos) ou, por vezes, onerada (se não a legalizam como empregada). $\mathrm{O}$ mesmo ocorre em algumas atividades que empregam menores de idade, como é o caso dos 'flanelinhas'. Fora dos centros urbanos há também fortes evidências de emprego ilegal de crianças em algumas atividades, sobretudo nas atividades agropecuárias e extrativistas naturais, como forma de complementação do orçamento familiar.

\section{Nível de instrução dos pais}

A PPV traz informações sobre o nível de escolarização dos pais dos entrevistados. $\mathrm{Na}$ amostra selecionaram-se somente os indivíduos que conheciam o nível de instrução do pai e da mãe. Em seguida, os níveis foram arrumados em cinco categorias, separadas por pai e por mãe, conforme os anos de escolaridade de cada um deles, a saber:

1 - pai/mãe com menos de quatro anos de estudos completos;

2 - pai/mãe com 4 a 7 anos de estudos completos;

3 - pai/mãe com 8 a 11 anos de estudos;

4 - pai/mãe com 12 a 15 anos de escolarização formal; e,

5 - os que concluíram mais de 15 anos de estudos

Essa variável foi ordenada em categorias para evitar um grande número de estimativas com valores muito baixos.

\footnotetext{
${ }^{31}$ Lam \& Levison (1990) apresentam uma breve discussão sobre a que idade se inicia de fato o acúmulo de experiência no mercado de trabalho.
} 


\section{Anos de estudo}

Foram consideradas somente as observações para as quais havia informações sobre a escolaridade dos indivíduos. O nível de escolaridade foi ordenado segundo anos de estudos completos, iniciando-se em 1, correspondente a menos de 1 ano de estudo, até atingir 16, relacionando os indivíduos que concluíram 15 anos ou mais de estudo.

\section{Posição na ocupação}

Quanto a posição na ocupação consideraram-se somente os indivíduos empregados, os que trabalhavam por conta própria ou empregadores, descartando-se os que declararam ser trabalhadores não remunerados.

\section{Horas trabalhadas por semana}

A PPV demonstra quantas horas semanais foram gastas exclusivamente na ocupação principal das pessoas nos sete dias que antecederam à pesquisa, por posição na ocupação. Isto tornou possível a utilização de critérios diferenciados por posição na ocupação. Foram desconsiderados os empregados que trabalhavam menos de 20 horas por semana na atividade principal. Para os que trabalhavam por conta própria ou eram empregadores foram selecionados os que dedicaram pelo menos 10 horas semanais.

\section{Rendimento}


Neste trabalho constam somente observações que apresentaram informação sobre remuneração na ocupação principal cujo vencimento não fosse negativo ou nulo. Mais precisamente, o rendimento líquido da empresa ou negócio para empregador e conta própria $^{32}$, enquanto para empregados foi considerado o salário bruto $^{33}$ do último pagamento.

O passo seguinte foi construir uma taxa para o rendimento horário, relacionando o número de horas semanais à ocupação principal de acordo com o montante e período de pagamento do último rendimento. Três formas de pagamento foram verificadas: semanal, quinzenal e mensal. A taxa de rendimento horário relativa ao modo semanal foi obtida dividindo o rendimento pela carga horária semanal. Com relação a forma de pagamento quinzenal obteve-se o quociente entre quatorze vezes o valor do último rendimento e trinta vezes a carga horária semanal. Por fim, a taxa de rendimento horário correspondente ao modo de pagamento mensal resultou da relação entre sete vezes o valor do rendimento mensal e trinta vezes o valor da carga horária semanal.

A padronização temporal das taxas de rendimento foi levada à efeito com base no IPCA-IBGE ${ }^{34}$, para valores de junho de 2000. A escolha do IPCA se deu devido a característica da amostra e também porque este índice apresentou variação acumulada no período muito próxima da variação verificada no salário mínimo, que à época do inicio da PPV correspondia a $\mathrm{R} \$ 120,00$ e, a partir de abril do ano 2000 passou a $\mathrm{R} \$$ 151,00 , variando cerca de $26 \%$.

\footnotetext{
${ }^{32}$ A PPV considera como rendimento líquido o 'rendimento bruto menos as despesas efetuadas com o empreendimento como, por exemplo, o pagamento de empregados, matéria-prima, energia elétrica, telefone, etc. da pessoa que explora um empreendimento como o conta própria ou empregador'. O salário bruto é definido pela PPV como o 'recebimento bruto em dinheiro ou produtos e/ou mercadorias' (PPV, microdados, 1998).

${ }^{33} \mathrm{O}$ salário bruto é definido pela PPV como o 'recebimento bruto em dinheiro ou produtos e/ou mercadorias' (PPV, microdados, 1998).

${ }^{34}$ O Índice Nacional de Preços ao Consumidor Amplo - IPCA, é produzido pelo IBGE deste 1980. O IPCA 'Mede a variação de preços ao consumidor de famílias com rendimentos mensais compreendidos entre 1 (hum) e 40 (quarenta) salários mínimos, qualquer que seja a fonte de rendimentos, e residentes nas áreas urbanas das regiões metropolitanas do Rio de Janeiro, Porto Alegre, Belo Horizonte, Recife, São Paulo, Belém, Fortaleza, Salvador e Curitiba, além do Distrito Federal e de Goiânia', IBGE(2000) in:http://www.ibge.gov.br.
} 
Construiu-se também um indicador de rendimento mensal para cada indivíduo na amostra, por meio do produto entre valor total do rendimento e razão correspondente a forma de pagamento. Quando a forma de pagamento declarada foi semanal, a taxa de rendimento mensal resultou do valor do vencimento vezes a razão 30/7. Para a forma quinzenal, o produto entre o montante do rendimento e 30/14.

\section{Idade de ingresso no mercado de trabalho}

Nas observações com ausência de registro da idade de ingresso no mercado de trabalho ou cujo registro apontava isto ter ocorrido com menos de quinze anos, foi considerado o número limite 15, que corresponde a idade limite para o indivíduo pertencer à $\operatorname{amostra}^{35}$.

\section{Experiência}

Representa a diferença entre a idade atual e a idade que o indivíduo começou a trabalhar. Ressalte-se que apesar de serem desconsiderados os períodos de ausência do indivíduo no mercado de trabalho, esta medida corresponde a uma proxy para experiência global no mercado de trabalho, semelhante a aplicações de pesquisadores como Cacciamalli \& Freitas (1992) e Soares \& Gonzaga (1998).

As variáveis descritas anteriormente foram denominadas variáveis chave por terem sido aplicadas com algum nível de restrição e/ou critério à base de microdados da PPV. Além das variáveis chave, na seleção final foi possível identificar um conjunto

\footnotetext{
${ }^{35}$ Lam \& Levison (1990) apresentam uma breve discussão sobre a que idade se inicia de fato o acúmulo de experiência no mercado de trabalho.
} 
de variáveis que determinam uma relação de pertinência de cada indivíduo a determinada situação como sexo, cor, região, estrato geográfico, classe salarial e anos de estudo.

Nestas últimas variáveis, a inserção do indivíduo amostrado intra-variável se dá de forma exclusiva, enquanto inter-variável ocorre uma relação de aditividade. Por exemplo, um indivíduo só pertencerá ao estrato geográfico 1 ( Rg. Metropolitana de Fortaleza) se, e somente se, não estiver relacionado em nenhum outro estrato geográfico; entretanto, esse indivíduo pode ser homem, de cor branca, etc. A descrição desse grupo de variáveis será aqui suprimida, pois, além da própria denominação o fazer, há com bastante clareza na PPV.

\subsubsection{Amostra selecionada}

As variáveis descritas anteriormente, denominadas variáveis chave, permitiram dimensionar uma seleção final que resultou numa amostra de $15 \%$ do total das observações, já considerando os valores expandidos, correspondente a uma população de 15.624.470 de habitantes distribuídos nos dez estratos geográficos cobertos pela PPV.

A Tabela 1 mostra a participação relativa e acumulada na seleção final por estrato geográfico. Nela se observa que as restrições impostas causaram grandes alterações na estrutura de contribuição amostral por estrato geográfico. Variações negativas mais acentuadas ocorreram nos estratos 5 (Nordeste rural), 10 (Sudeste rural) e 4 ( Nordeste urbano), respectivamente. As variações positivas ficaram por conta de seis estratos geográficos, cuja variação média foi de $36 \%$. À exceção da região metropolitana do Recife (2), que teve sua contribuição diminuída em 4,3\%, as demais apresentaram um aumento na participação em média de 38\%, destacando-se os estratos 6 (Belo Horizonte) e 7 (Rio de Janeiro), cuja participação foi acrescida em aproximadamente uma vez e meia. 
Na última coluna da Tabela 1 consta a mudança na composição por estrato após a submissão dos microdados às variáveis chave. Observa-se que as populações rurais, em média, foram as mais atingidas pelas restrições impostas. Isto, porque informações levantadas de maneira simples no meio urbano (emprego e escolaridade dos pais), no meio rural são obtidas com certa dificuldade devido ao menor nível de instrução dos moradores e também às características do meio.

Tabela 1 - Estrato geográfico e participação percentual na população total, na amostra selecionada e variação na participação.

\begin{tabular}{|c|c|c|c|c|c|}
\hline & Estrato Geográfico & $\begin{array}{c}\text { Participação na } \\
\text { Pop. Total }\end{array}$ & $\begin{array}{c}\text { Participação na } \\
\text { Seleção }\end{array}$ & $\begin{array}{c}\text { Participação da } \\
\text { Seleção na Pop. } \\
\text { Total }\end{array}$ & $\begin{array}{l}\text { Variação na } \\
\text { Participação }\end{array}$ \\
\hline 1 & $\begin{array}{l}\text { Reg. Metropolitana de } \\
\text { Fortaleza }\end{array}$ & 2,56 & 3,38 & 0,51 & 32,0 \\
\hline 2 & $\begin{array}{l}\text { Reg. Metropolitana de } \\
\text { Recife }\end{array}$ & 2,54 & 2,43 & 0,37 & $-4,3$ \\
\hline 3 & $\begin{array}{l}\text { Reg. Metropolitana de } \\
\text { Salvador }\end{array}$ & 2,57 & 3,40 & 0,51 & 32,3 \\
\hline 4 & $\begin{array}{l}\text { Restante do Nordeste } \\
\text { Urbano }\end{array}$ & 18,18 & 12,60 & 1,90 & $-30,7$ \\
\hline 5 & $\begin{array}{l}\text { Restante do Nordeste } \\
\text { Rural }\end{array}$ & 14,68 & 4,37 & 0,66 & $-70,2$ \\
\hline 6 & $\begin{array}{l}\text { Reg. Metropolitana de } \\
\text { Belo Horizonte }\end{array}$ & 3,34 & 5,06 & 0,76 & 51,5 \\
\hline 7 & $\begin{array}{l}\text { Reg. Metropolitana de } \\
\text { Rio de Janeiro }\end{array}$ & 8,59 & 12,68 & 1,91 & 47,6 \\
\hline 8 & $\begin{array}{l}\text { Reg. Metropolitana de } \\
\text { São Paulo }\end{array}$ & 14,82 & 18,81 & 2,84 & 26,9 \\
\hline 9 & $\begin{array}{l}\text { Restante do Sudeste } \\
\text { Urbano }\end{array}$ & 26,68 & 33,30 & 5,02 & 24,8 \\
\hline 10 & $\begin{array}{l}\text { Restante do Sudeste } \\
\text { Rural }\end{array}$ & 6,04 & 3,98 & 0,60 & $-34,1$ \\
\hline & Total & 100 & 100 & 15,08 & ---- \\
\hline
\end{tabular}

Fonte: Pesquisa sobre padrões de vida 1996-1997 [CD-ROM].Microdados. Rio de Janeiro: IBGE 1998. 


\section{PERFIL SOCIOECONÔMICO DA AMOSTRA SELECIONADA}

A Tabela 2 descreve a composição da amostra segundo algumas variáveis. À exceção da variável condição na família, cuja freqüência é bem distribuída, as outras variáveis apresentam elevada desproporcionalidade de freqüência nas categorias intra-variável. Das observações que satisfizeram todos os critérios adotados, $38,5 \%$ se referem a pessoas do sexo feminino; quase metade são chefes de família e $91 \%$ estão domiciliados em ambiente urbano.

Destacam-se ainda, na Tabela 2, a distribuição de freqüência segundo a cor da pele, grandes regiões e condição na ocupação. Segundo estas variáveis, grosso modo, $70 \%$ residem no sudeste, são de cor branca e atuam no mercado de trabalho como empregado. Com respeito aos grupos étnicos, a segunda categoria mais presente é a dos pardos, com aproximadamente $28 \%$ da amostra. Esse fato, talvez, seja um forte indício de que há relações preconceituosas na sociedade brasileira.

Na Tabela 3, são observados valor médio obtido das variáveis chave. Combinando as informações das Tabelas 2 e 3, o indivíduo típico da amostra é assim caracterizado: sexo masculino, de cor branca e aproximadamente 33 anos de idade, filho de pais com instrução entre 4 e 7 anos de estudo (correspondente ao nível 2) e residente na região sudeste do Brasil. Com relação a seus atributos produtivos e sua relação com o mercado de trabalho, esse indivíduo têm em média 10 anos de estudo (equivalente ao atual ensino médio incompleto), ingressou no mercado de trabalho aos 16 anos e conta com 16 anos de experiência, é empregado e percebe taxa de rendimento horário de $\mathrm{R} \$$ 6,48 e rendimento mensal de $\mathrm{R} \$ 1.089$, o equivalente a 7,2 salários mínimos. 
Tabela 2 - Distribuição da amostra selecionada segundo sexo, condição na família, região, situação do domicílio, cor da pele e condição na ocupação.

\begin{tabular}{|c|c|c|}
\hline \multicolumn{2}{|c|}{ Variável } & \multirow{2}{*}{$\begin{array}{c}\text { Freqüência relativa }(\%) \\
61,53\end{array}$} \\
\hline Seyo & Homem & \\
\hline SeXV & Mulher & 38,47 \\
\hline \multirow{2}{*}{ Condição na Família } & Chefe de domicílio & 45,91 \\
\hline & Outros & 54,09 \\
\hline \multirow{2}{*}{ Grande Região } & Nordeste & 26,17 \\
\hline & Sudeste & 73,83 \\
\hline \multirow{2}{*}{ Situação do Domicílio } & Rural & 9,03 \\
\hline & Urbano & 90,97 \\
\hline \multirow{4}{*}{ Cor da Pele } & Branca & 68,49 \\
\hline & Preta & 2,96 \\
\hline & Parda & 27,86 \\
\hline & Amarela + indígena & 0,69 \\
\hline \multirow{3}{*}{ Condição na ocupação } & Empregado & 72,94 \\
\hline & Conta própria & 19,94 \\
\hline & Empregador & 7,12 \\
\hline
\end{tabular}

Fonte: Pesquisa sobre padrões de vida 1996-1997 [CD-ROM].Microdados. Rio de Janeiro: IBGE 1998. 
Tabela 3 - Média e coeficiente de variação de variáveis chave na amostra selecionada.

\begin{tabular}{|c|c|c|c|c|}
\hline Variável & Média & $\begin{array}{l}\text { Coeficiente de } \\
\text { variação }(\mathrm{CV})\end{array}$ & Mínimo & Máximo \\
\hline Nível de escolaridade do pai & 2,18 & 53,7 & 1 & 5 \\
\hline Nível de escolaridade da mãe & 2,10 & 51,0 & 1 & 5 \\
\hline Rendimento mensal (R\$) & $1.089,1$ & 211,4 & 11,95 & 75.876 \\
\hline Anos de estudo completo & 10,09 & 39,9 & 1 & 17 \\
\hline $\begin{array}{l}\text { Taxa de rendimento horário } \\
(\mathrm{R} \$)\end{array}$ & 6,48 & 265,0 & 0,06 & 590,20 \\
\hline Idade (anos) & 32,87 & 34,8 & 15 & 88 \\
\hline $\begin{array}{l}\text { Idade de ingresso no mercado } \\
\text { de trabalho (anos) }\end{array}$ & 16,76 & 17,5 & 15 & 51 \\
\hline $\begin{array}{l}\text { Experiência no mercado de } \\
\text { trabalho (anos) }\end{array}$ & 16,11 & 73,7 & 0 & 70 \\
\hline
\end{tabular}

A imposição de uma idade limite resultou numa amostra com distribuição muito próxima entre três classes etárias, conforme dispõe a Figura 2. Os percentuais crescem à medida que aumentam as idades das classes, até a penúltima classe, refletindo o envelhecimento da população, como revelado em alguns estudos. As pessoas com 56 anos ou mais de idade correspondem a 4\%, enquanto os menores de 18 anos representam 8,5\% das observações. Indivíduos com idade entre 19 e 55 anos representam 87,6\% das observações. 


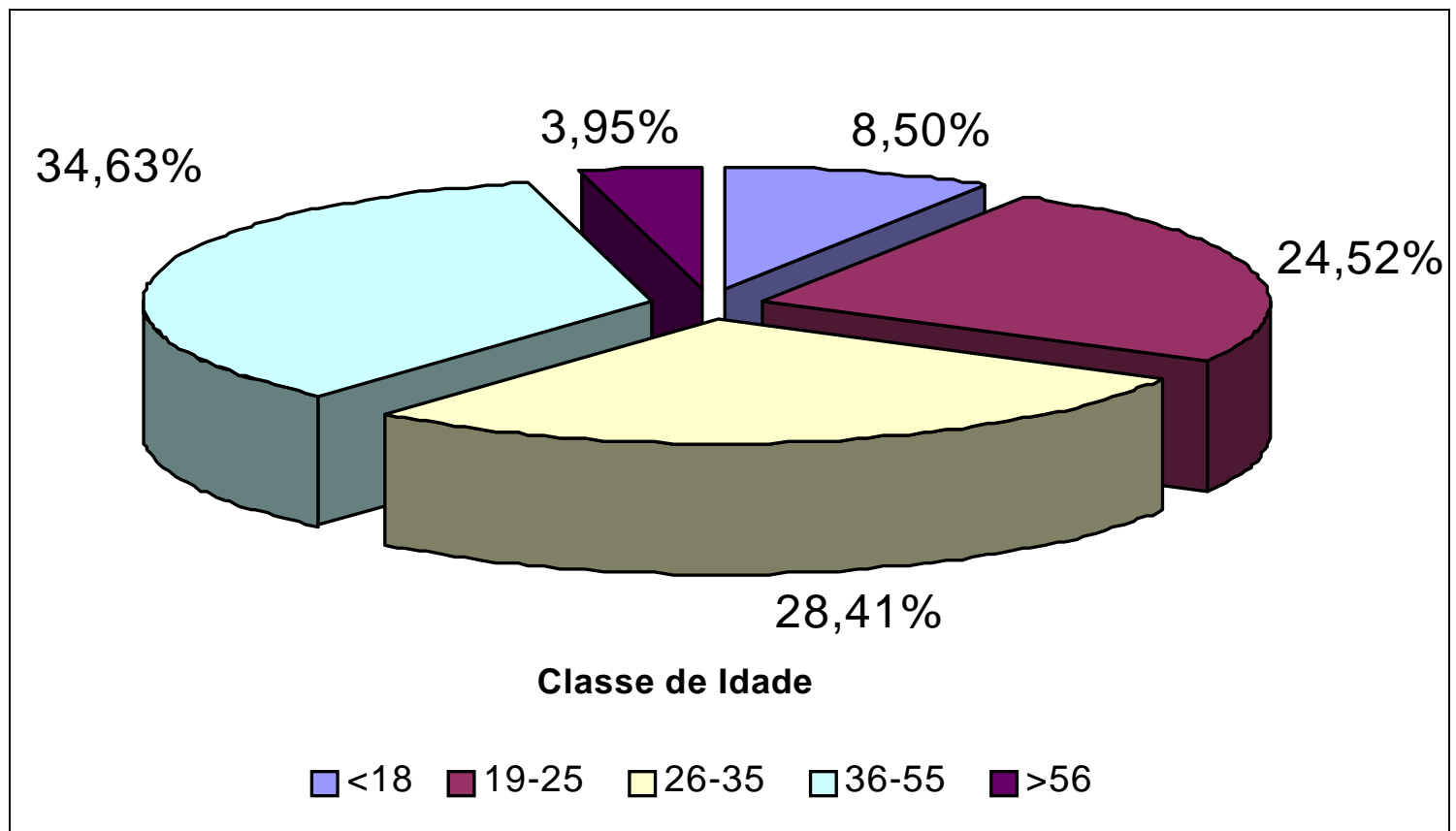

Fonte: Pesquisa sobre padrões de vida 1996-1997 [CD-ROM].Microdados. Rio de Janeiro: IBGE 1998.

Figura 2 - Composição da amostra selecionada segundo classes etárias dos indivíduos de 15 anos ou mais de idade e com rendimento positivo no trabalho principal.

Com referência ao nível de escolaridade, a Figura 3 exibe a distribuição na amostra selecionada e dentro de cada faixa etária. De acordo com a referida Figura, $29 \%$ dos brasileiros residentes nas regiões nordeste e sudeste e que apresentam as características essenciais a este estudo, possuem menos de oito anos de estudo completo, dos quais cerca de $8 \%$ têm nível de instrução inferior a quatro anos de estudo. Por outro lado, metade dos indivíduos amostrados possui escolaridade mínima de onze anos e, desses, somente $6 \%$ iniciaram curso superior e não o concluíram.

Também na Figura 3, a porcentagem de pessoas com instrução com até 12 anos de estudo e com idade entre 19 - 25 é superior ao das pessoas de 25 anos ou mais de idade, enquanto a porcentagem de pessoas com menos de quatro anos de estudo nesta classe é a menor observada. Entretanto, esse indicador é ainda bastante elevado para os mais jovens na amostra, praticamente igual aos $10 \%$ entre os mais velhos, 
evidenciando que a sociedade brasileira, sobretudo nas camadas mais pobres, carece ainda de um sistema educacional abrangente e democrático.

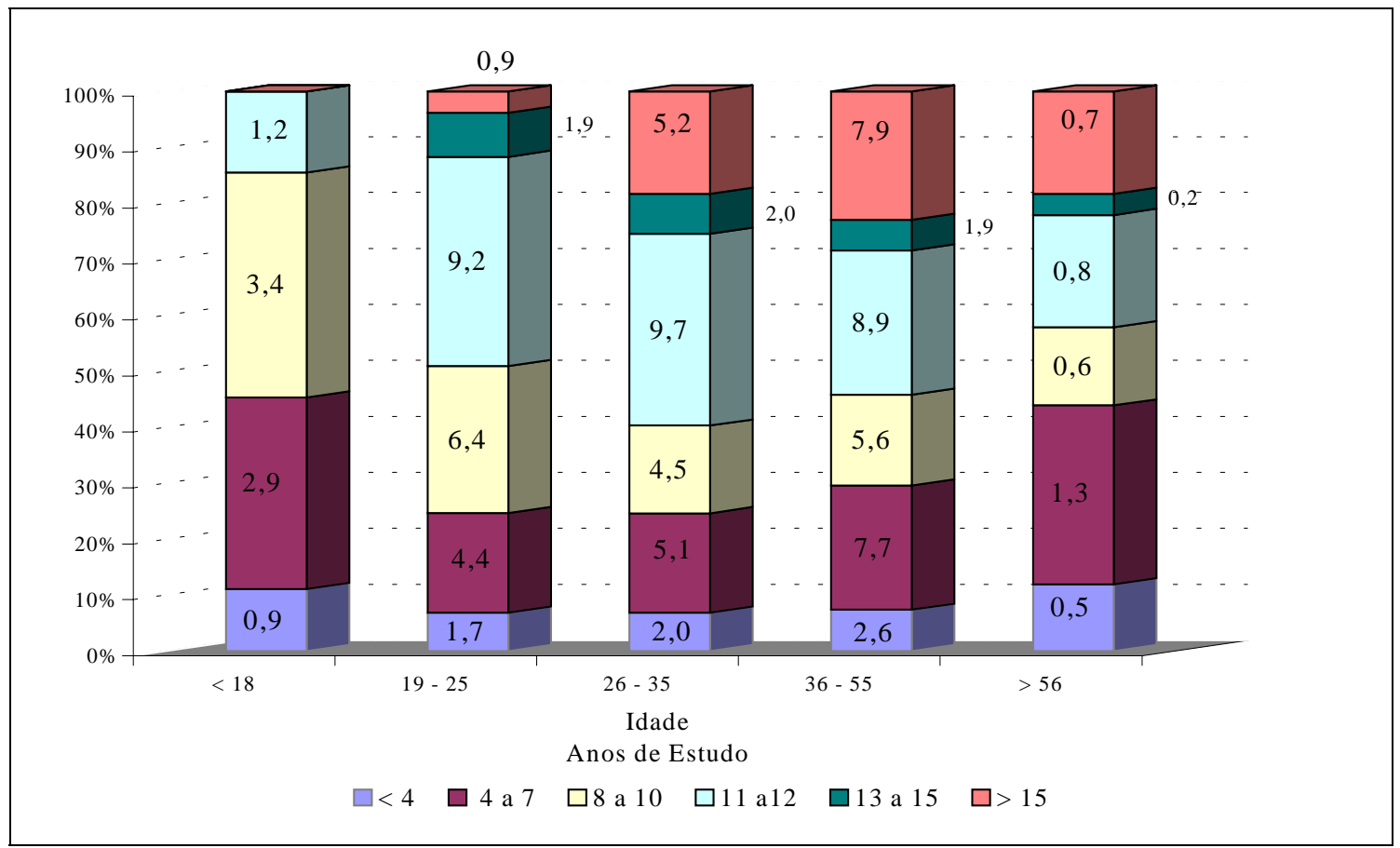

Fonte: Pesquisa sobre padrões de vida 1996-1997 [CD-ROM].Microdados. Rio de Janeiro: IBGE 1998.

Figura 3 - Distribuição de anos de estudo por faixa etária, amostra selecionada.

A participação relativa de indivíduos com instrução superior cresce com a elevação da idade até a penúltima faixa etária. Nesta, é mais expressiva, o que pode ser um forte indicio de as pessoas sentirem-se mais estimuladas a continuar os estudos após sua inserção no mercado de trabalho.

Medidas de posição e de dispersão para as variáveis chave por classes de idade e classes de ano de estudo são mostradas nas Tabelas 4 e 5. A média indica a característica presente nos indivíduos em cada categoria, enquanto o coeficiente de variação é um indicador de quão dispersas do valor médio estão as observações. Na Tabela 4 pode-se observar que as faixas intermediárias apresentam nível de escolaridade 
mais elevado e menor dispersão. As médias do nível de escolaridade dos pais são muito similares entre as classes, com pequenas diferenças nos coeficientes de variação.

Tabela 4 - Média e coeficiente de variação (CV) de variáveis chave por faixa etária.

\begin{tabular}{|c|c|c|c|c|c|c|c|c|c|}
\hline \multirow{2}{*}{ Faixa } & & \multicolumn{8}{|c|}{ VARIÁVEL } \\
\hline & etária & $\begin{array}{c}\text { Taxa de } \\
\text { rendimento } \\
\text { mensal }\end{array}$ & $\begin{array}{l}\text { Anos } \\
\text { de } \\
\text { estudo }\end{array}$ & $\begin{array}{l}\text { Nível de } \\
\text { escolari- } \\
\text { dade do } \\
\text { pai }\end{array}$ & $\begin{array}{l}\text { Nível de } \\
\text { escolari- } \\
\text { dade da } \\
\text { mãe }\end{array}$ & $\begin{array}{c}\text { Anos de } \\
\text { experiência } \\
\text { no } \\
\text { trabalho }\end{array}$ & $\begin{array}{c}\text { Anos } \\
\text { de } \\
\text { idade }\end{array}$ & $\begin{array}{c}\text { No. de } \\
\text { pessoas } \\
\text { no } \\
\text { domicílio }\end{array}$ & $\begin{array}{c}\text { Idade } \\
\text { começou a } \\
\text { trabalhar }\end{array}$ \\
\hline \multirow{2}{*}{$<18$} & Média & 232,92 & 7,67 & 2,04 & 2,04 & 1,47 & 16,83 & 5,28 & 13,57 \\
\hline & $\mathrm{CV}(\%)$ & 76,2 & 33,1 & 47,5 & 48,5 & 69,4 & 6,1 & 38,1 & 19,7 \\
\hline \multirow{2}{*}[19,25]{} & Média & 469,19 & 9,76 & 2,24 & 2,21 & 5,19 & 21,96 & 4,70 & 15,35 \\
\hline & $\mathrm{CV}(\%)$ & 99,6 & 33,8 & 54,5 & 52,0 & 54,1 & 9,2 & 45,5 & 25,6 \\
\hline \multirow{2}{*}[26,35]{} & Média & 981,44 & 10,74 & 2,27 & 2,15 & 13,57 & 30,54 & 3,98 & 15,37 \\
\hline & $\mathrm{CV}(\%)$ & 141,5 & 37,9 & 54,6 & 52,1 & 29,6 & 9,5 & 46,7 & 29,1 \\
\hline \multirow{2}{*}[36,55]{} & Média & $1.685,48$ & 10,48 & 2,09 & 2,02 & 26,20 & 43,05 & 4,21 & 14,85 \\
\hline & $\mathrm{CV}(\%)$ & 178,1 & 42,1 & 52,6 & 48,5 & 23,4 & 11,8 & 387 & 34,5 \\
\hline \multirow{2}{*}{$>55$} & Média & $2.325,02$ & 9,23 & 2,31 & 1,99 & 45,32 & 62,75 & 3,50 & 15,02 \\
\hline & $\mathrm{CV}(\%)$ & 240,4 & 50,1 & 57,1 & 45,7 & 19,4 & 10,4 & 51,4 & 44,3 \\
\hline
\end{tabular}

Fonte: Pesquisa sobre padrões de vida 1996-1997 [CD-ROM].Microdados. Rio de Janeiro: IBGE 1998. 
Tabela 5 - Média e coeficiente de variação (CV) de variáveis chave na amostra selecionada, segundo as classes de estudo.

\begin{tabular}{rrrrrrrrrr}
\hline & & \multicolumn{7}{c}{ VARIÁVEL } \\
Classe de estudo \\
(anos)
\end{tabular}

Fonte: Pesquisa sobre padrões de vida 1996-1997 [CD-ROM].Microdados. Rio de Janeiro: IBGE 1998.

A Figura 4 ilustra os valores médios por faixa etária. Observa-se um aumento marginal ao longo dos anos do nível de escolaridade (anoesc) da população brasileira representada pela amostra. Constam também nesta Figura o valor médio do rendimento mensal (renms) - em unidades de salário mínimo (SM) e do nível de escolaridade dos pais de cada indivíduo amostrado (nepai, nemae). As mães apresentam nível de escolaridade ligeiramente inferior ao dos pais e o rendimento mensal do trabalho apresenta-se com significativa elevação entre as faixas etárias.

A variável renms apresenta crescimento contínuo de acordo com a faixa etária (Figura 4 e Tabela 4), sendo que o grau de dispersão, medido pelo CV, mostra que entre os indivíduos mais velhos o rendimento do trabalho apresenta-se mais disperso. 


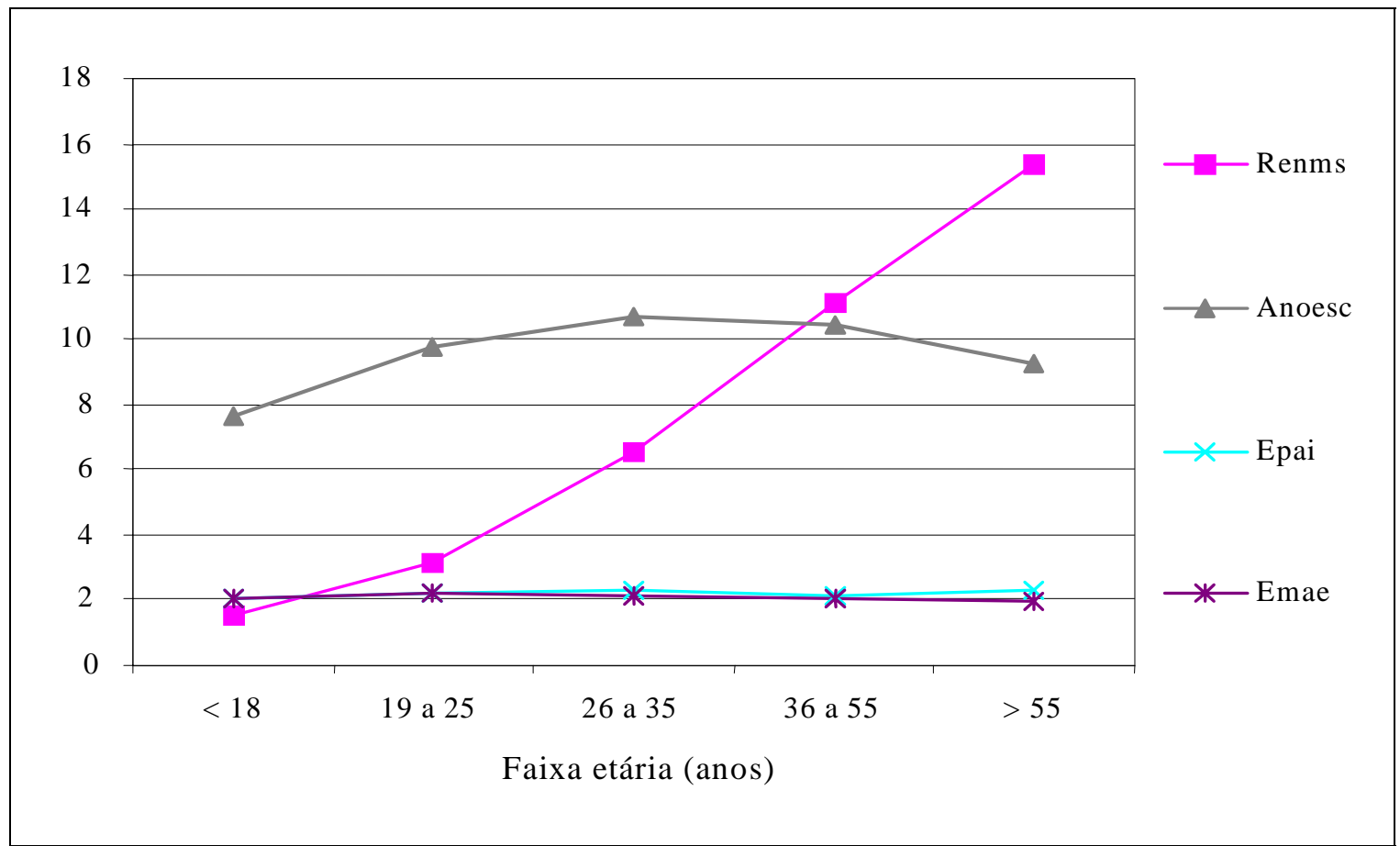

Fonte: Pesquisa sobre padrões de vida 1996-1997 [CD-ROM].Microdados. Rio de Janeiro: IBGE 1998.

Figura 4 - Média de rendimento mensal (em SM), anos de estudo e nível de escolaridade dos pais por classes de idade.

Conforme mostram a Tabela 5 e a Figura 5, a escolaridade está relacionada positivamente com o nível de escolaridade dos pais e com o rendimento do trabalho. Destaca-se, nessa Tabela, o CV de anos de estudo (anoesc), que diminui consideravelmente à medida que aumenta o nível de escolaridade. A dispersão relativa no primeiro grupo é cerca de quatro vezes maior que no quarto e sexto grupos, significando que o número de indivíduos forçados a abandonar a escola nos primeiros anos é muito superior ao verificado nas séries subsequentes. Nesse sentido, talvez seja possível inferir que o sistema educacional no Brasil, além de concentrado, pode estar contribuindo para a má distribuição de renda ${ }^{36}$.

Na Figura 5, vê-se que o aumento da escolaridade está acompanhado de um declínio no número de pessoas no domicílio (pessoas), e de uma elevação do

${ }^{36}$ Ver Reis \& Barros (1990) Barros \& Mendonça (1996) e Mendonça (1994). 
rendimento mensal (renms). Isto se torna mais acentuado a partir dos 10 anos de estudos. Nota-se também relação de mesmo sentido entre nível de instrução dos pais e escolaridade e entre idade de ingresso no mercado de trabalho (idinicio) e escolaridade (anoesc).

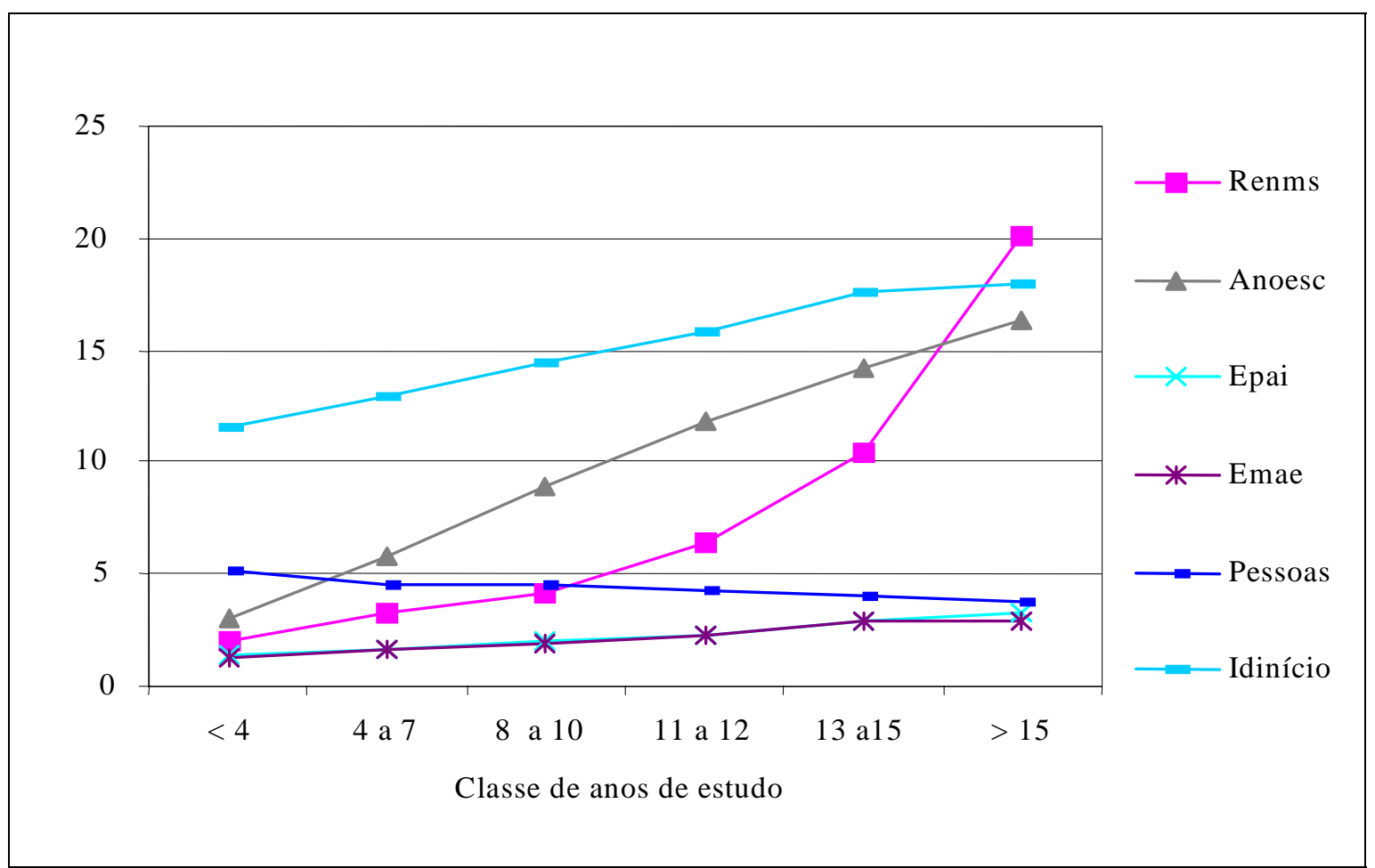

Fonte: Pesquisa sobre padrões de vida 1996-1997 [CD-ROM].Microdados. Rio de Janeiro: IBGE 1998.

Figura 5 - Média de rendimento mensal (em SM), anos de estudo, pessoas no domicílio, idade de ingresso no mercado de trabalho e nível de escolaridade dos pais, por classes de anos de estudo.

A Figura 6 mostra a proporção relativa entre as observações amostradas segundo grupo de anos de estudo e nível educacional dos genitores. De acordo com a ilustração, o nível educacional dos pais está relacionado com anos de estudo do indivíduo. Provavelmente, esta relação é conseqüência da associação entre o maior nível 
de escolaridade e maior remuneração do trabalho, o que permite aos pais investir mais na educação dos filhos, tanto em termos de quantidade como de qualidade do ensino.

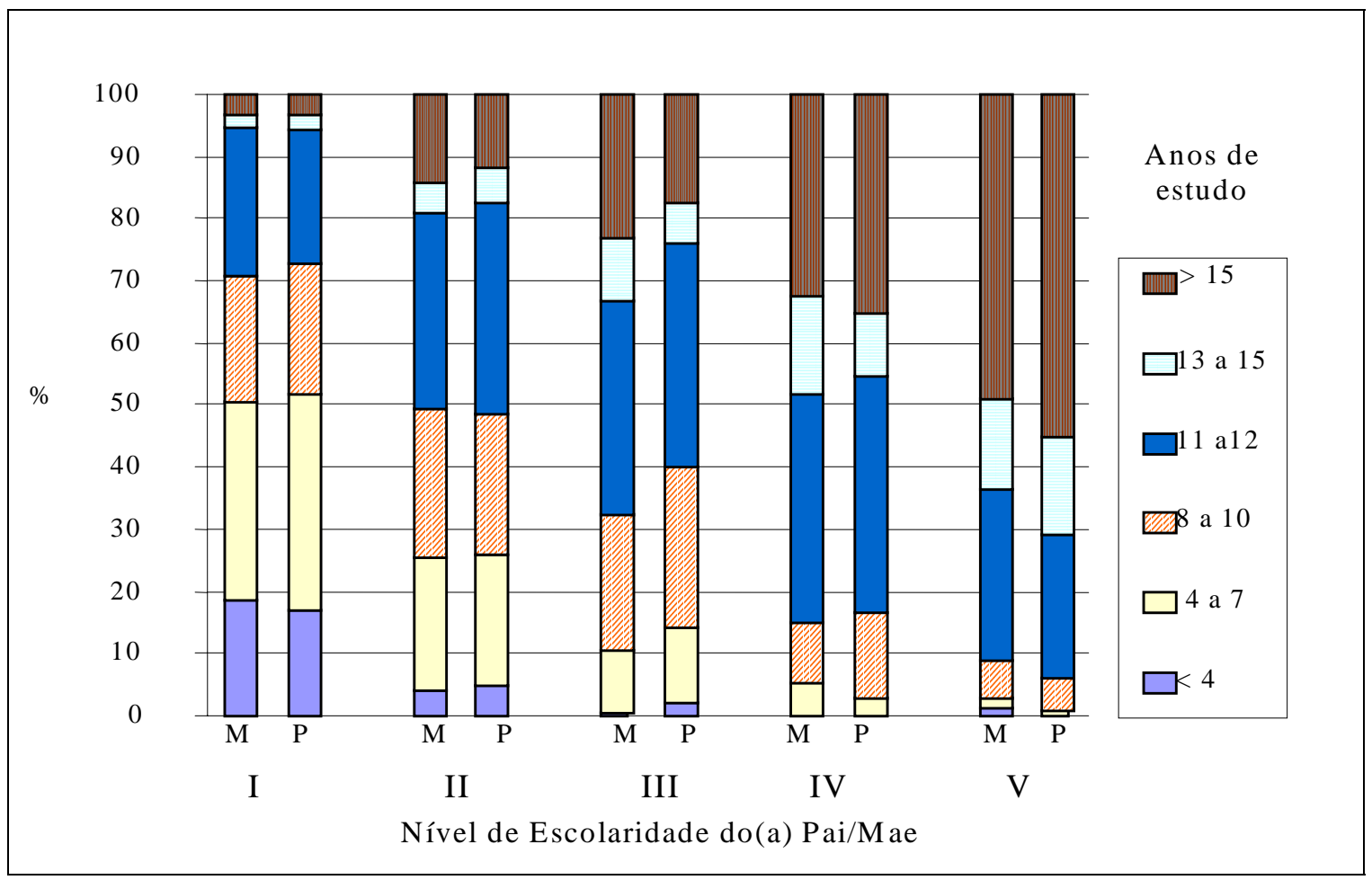

Fonte: Pesquisa sobre padrões de vida 1996-1997 [CD-ROM].Microdados. Rio de Janeiro: IBGE 1998.

Figura 6 - Distribuição de grupo de anos de estudo segundo o nível de escolaridade da mãe e do pai.

Ainda de acordo com a Tabela 5, pode-se observar que todos os grupos de escolaridade mostram elevados valores para o coeficiente de variação da variável renms, ocorrendo maior dispersão entre os indivíduos com escolaridade entre 13 - 15 anos de estudo. A maior dispersão não constitui um problema, pois, a partir desse nível de instrução as oportunidades de emprego tornam-se mais numerosas. Logo, parece natural que se verifique grande diferencial na remuneração dos indivíduos cuja escolaridade é 
mais elevada. Contudo, essa dispersão reduz-se à metade entre os indivíduos com instrução superior ${ }^{37}$.

O rendimento médio do trabalho cresce $60 \%$ (de $\mathrm{R} \$ 312,97$ para $\mathrm{R} \$$ 500,40 ) entre os dois primeiros grupos e de $93 \%$ (de $\mathrm{R} \$ 1.581,01$ a $\mathrm{R} \$ 3.036,39$ ) entre as duas últimas classes de anos de estudo. O crescimento verificado entre os grupos extremos é da ordem de $870 \%$ a favor do extremo superior, muito próximo aos $898 \%$ verificados entre as faixas de idade de mesma posição.

A desigualdade de renda na economia brasileira fica evidenciada na Figura 7, que mostra a distribuição da amostra segundo classes de rendimento mensal e o percentual de apropriação, em relação ao montante de rendimento do trabalho, correspondente a cada classe salarial. Observa-se que menos de $3 \%$ dos indivíduos percebem rendimento acima de 35 salários mínimos mensal e que, a despeito de constituir reduzida parcela da amostra, esses indivíduos, em conjunto, se apropriam de $28,4 \%$ do montante pago à amostra. Isto eqüivale afirmar que esta pequena parcela detém 1 de cada 3,5 SM destinados à remuneração do trabalho. Não menos acentuadas são as diferenças verificadas entre classes intermediárias, cuja relação salário apropriado e montante de salários pagos varia de 0,25 a 0,09, entre a penúltima classe de rendimento e a segunda, onde estão cerca de $83 \%$ das observações individuais e $70 \%$ do montante de rendimento em salários mínimos.

\footnotetext{
${ }^{37}$ Fernandes \& Narita (2000) verificam que o retorno 'pecuniário' do ensino superior no Brasil é alto e crescente, e mesmo as formações com menor retorno no mercado de trabalho possuem retorno econômico razoável.
} 


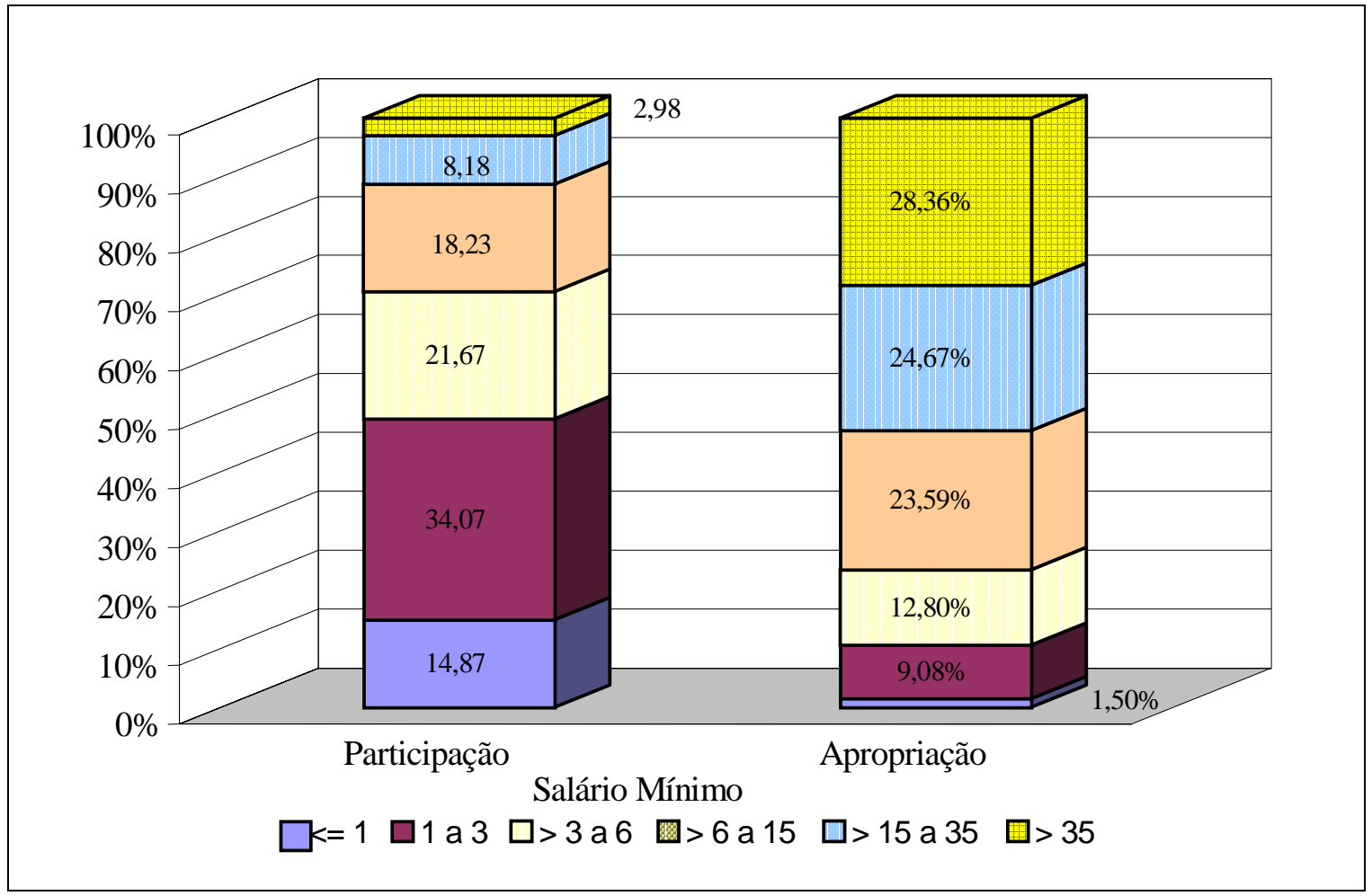

Fonte: Pesquisa sobre padrões de vida 1996-1997 [CD-ROM].Microdados. Rio de Janeiro: IBGE 1998.

Figura 7 - Distribuição amostral e apropriação de rendimento do trabalho, em SM, segundo classe de rendimento mensal.

Valores médios e os respectivos coeficientes de variação das variáveis chave, segundo as classes de rendimento mensal, estão dispostos na Tabela 6. Todas as variáveis apontam crescimento nas médias verificadas à medida que se desloca para classe de maior rendimento, exceção feita a pessoas no domicílio, que diminui cerca de uma unidade na última classe e idinicio que cresce e atinge o máximo na penúltima classe. Classes de maior rendimento apresentam menor variabilidade entre as observações para as variáveis relacionadas à formação educacional, anos de idade e experiência no mercado de trabalho, denotando que indivíduos de classes com mais alta renda apresentam tais características de forma mais homogênea que a verificada em classes de baixo rendimento. 
Tabela 6 - Média e coeficiente de variação (CV) de variáveis chave, segundo as classe de rendimento mensal na amostra selecionada.

\begin{tabular}{|c|c|c|c|c|c|c|c|c|c|}
\hline \multirow{2}{*}{\multicolumn{2}{|c|}{$\begin{array}{c}\text { Classe de Salário } \\
\text { Mínimo } \\
\text { SM }=\mathrm{R} \$ 151,00 \\
\text { jun/2000 }\end{array}$}} & \multicolumn{8}{|c|}{ VARIÁVEL } \\
\hline & & $\begin{array}{c}\text { Taxa de } \\
\text { rendimento } \\
\text { mensal }\end{array}$ & $\begin{array}{c}\text { Anos } \\
\text { de } \\
\text { estudo }\end{array}$ & $\begin{array}{l}\text { Nível de } \\
\text { escolari- } \\
\text { dade do } \\
\text { pai }\end{array}$ & $\begin{array}{l}\text { Nível de } \\
\text { escolari- } \\
\text { dade da } \\
\text { mãe }\end{array}$ & $\begin{array}{c}\text { Anos de } \\
\text { experiência } \\
\text { no } \\
\text { trabalho }\end{array}$ & $\begin{array}{c}\text { Anos } \\
\text { de } \\
\text { idade }\end{array}$ & $\begin{array}{c}\text { No. de } \\
\text { pessoas } \\
\text { no } \\
\text { Domicíli }\end{array}$ & $\begin{array}{c}\text { Idade } \\
\text { começou a } \\
\text { trabalhar }\end{array}$ \\
\hline \multirow{2}{*}{$<=1$} & Média & 109,64 & 7,37 & 1,73 & 1,72 & 11,50 & 27,91 & 4,98 & 13,99 \\
\hline & $\mathrm{CV}(\%)$ & 29,7 & 43,4 & 51,4 & 48,5 & 105,7 & 43,0 & 44,6 & 35,3 \\
\hline \multirow{2}{*}{$(1,3]$} & Média & 290,28 & 8,73 & 1,95 & 1,94 & 13,34 & 29,93 & 4,51 & 14,71 \\
\hline & $\mathrm{CV}(\%)$ & 28,6 & 39,3 & 52,8 & 51,0 & 87,7 & 38,2 & 46,3 & 30,0 \\
\hline \multirow{2}{*}{$(3,6)$} & Média & 643,58 & 10,53 & 2,22 & 2,17 & 16,72 & 33,35 & 4,11 & 14,89 \\
\hline & $\mathrm{CV}(\%)$ & 19,6 & 35,2 & 50,5 & 48,4 & 64,5 & 31,9 & 39,9 & 29,8 \\
\hline \multirow{2}{*}{$(6,15]$} & Média & $1.409,40$ & 11,90 & 2,44 & 2,29 & 19,62 & 36,40 & 3,97 & 15,29 \\
\hline & $\mathrm{CV}(\%)$ & 25,1 & 31,3 & 51,2 & 49,3 & 54,7 & 28,5 & 40,6 & 28,4 \\
\hline \multirow{2}{*}{$(15,35]$} & Média & $3.282,92$ & 13,76 & 2,95 & 2,63 & 22,98 & 41,11 & 3,98 & 17,19 \\
\hline & $\mathrm{CV}(\%)$ & 24,5 & 23,8 & 44,7 & 43,7 & 44,9 & 23,3 & 36,4 & 29,0 \\
\hline \multirow{2}{*}{$>35$} & Média & $10.374,3$ & 14,84 & 3,18 & 2,87 & 26,06 & 43,76 & 3,81 & 16,99 \\
\hline & $\mathrm{CV}(\%)$ & 75,7 & 16,7 & 41,2 & 42,9 & 35,0 & 19,7 & 46,7 & 23,5 \\
\hline
\end{tabular}

Fonte: Pesquisa sobre padrões de vida 1996-1997 [CD-ROM].Microdados. Rio de Janeiro: IBGE 1998.

A Figura 8 exibe o comportamento dos valores médios das variáveis anoesc, nepai, nemae, pessoas e idinicio entre classe de rendimento. Observa-se que somente a variável pessoas diminui sua média à medida que aumentam as classes de rendimento. $\mathrm{O}$ gráfico indica que indivíduos com rendimentos maiores, como esperado, convivem com famílias menores, são filhos de pais mais escolarizados e se permitem retardar o ingresso no mercado de trabalho. 


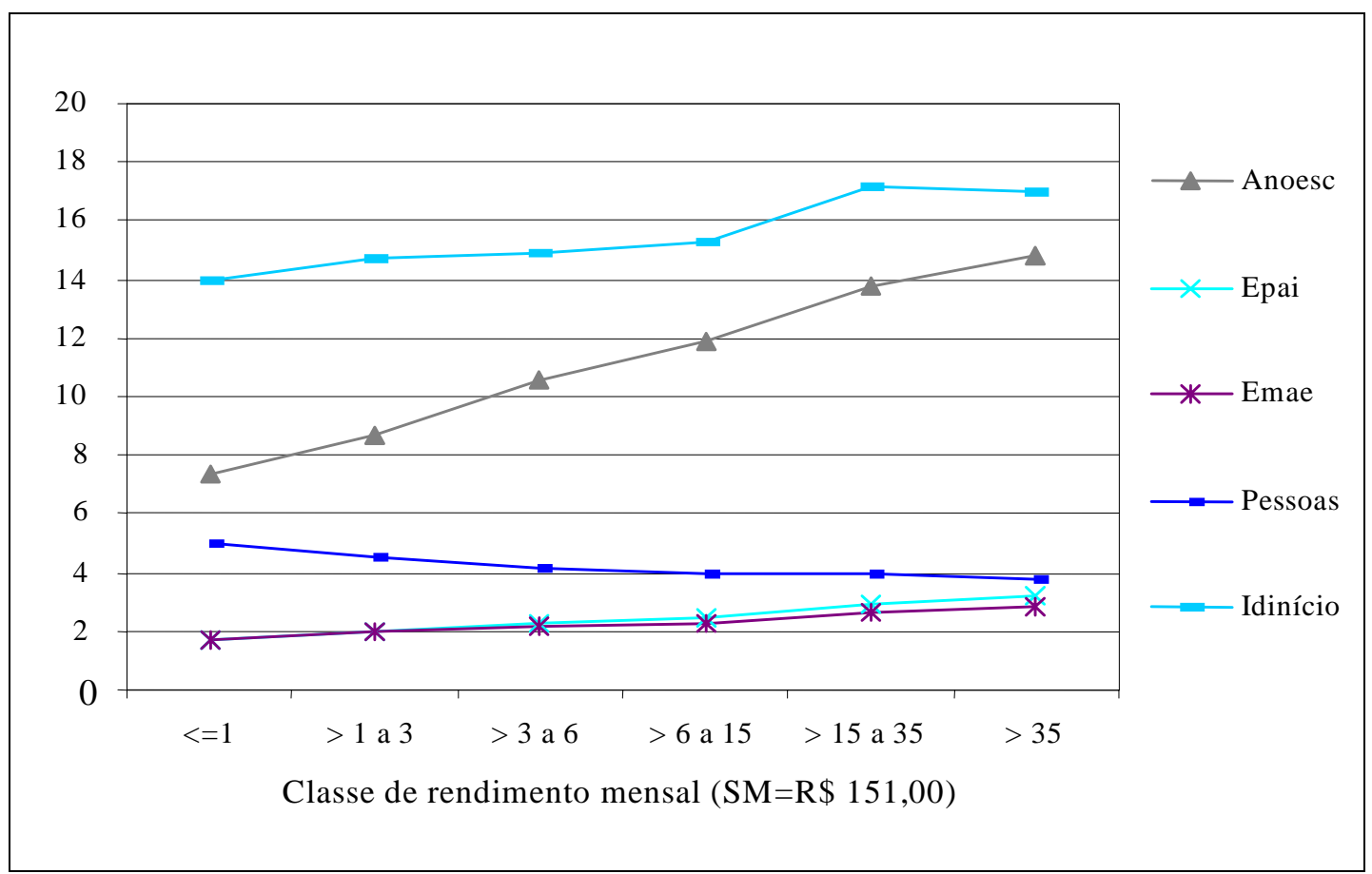

Fonte: Pesquisa sobre padrões de vida 1996-1997 [CD-ROM].Microdados. Rio de Janeiro: IBGE 1998.

Figura 8 - Média de anos de escolaridade, nível de instrução dos pais, pessoas no domicílio e idade de ingresso no mercado de trabalho, por classe de rendimento mensal.

As Tabelas 7 e 8 exibem média e coeficiente de variação das variáveis anteriores para cada categoria de posição na ocupação e gênero. As diferenças entre valor médio encontrado, conforme ilustrado na Figura 9, são maiores entre empregados e empregadores. Nas variáveis relacionadas à idade, experiência no trabalho e rendimento mensal os valores médios variam entre $36 \%$ e $230 \%$ a favor dos empregadores. 
Tabela 7 - Média e coeficiente de variação de variáveis chave segundo a condição na ocupação, amostra selecionada.

\begin{tabular}{|c|c|c|c|c|c|c|c|c|}
\hline \multirow[b]{2}{*}{$\begin{array}{c}\text { Condição na } \\
\text { ocupação }\end{array}$} & \multicolumn{8}{|c|}{ VARIÁVEL } \\
\hline & $\begin{array}{c}\text { Taxa de } \\
\text { rendimento } \\
\text { mensal }\end{array}$ & $\begin{array}{c}\text { Anos } \\
\text { de } \\
\text { estudo }\end{array}$ & $\begin{array}{l}\text { Nível de } \\
\text { escolari- } \\
\text { dade do } \\
\text { pai }\end{array}$ & $\begin{array}{l}\text { Nível de } \\
\text { escolari- } \\
\text { dade da } \\
\text { mãe }\end{array}$ & $\begin{array}{c}\text { Anos de } \\
\text { experiência } \\
\text { no } \\
\text { trabalho }\end{array}$ & $\begin{array}{l}\text { Anos } \\
\text { de } \\
\text { idade }\end{array}$ & $\begin{array}{c}\text { No. de } \\
\text { pessoas } \\
\text { no } \\
\text { domicílio }\end{array}$ & $\begin{array}{c}\text { Idade } \\
\text { começou a } \\
\text { trabalhar }\end{array}$ \\
\hline Empre- $\quad$ Média & 947,10 & 10,19 & 2,19 & 2,13 & 14,04 & 30,88 & 4,42 & 15,32 \\
\hline gado $\quad \mathrm{CV}(\%)$ & 172,5 & 38,4 & 53,9 & 50,7 & 78,6 & 35,6 & 43,9 & 28,7 \\
\hline Conta Média & 888,53 & 9,13 & 2,07 & 1,93 & 20,56 & 36,98 & 4,16 & 13,99 \\
\hline Própria $\quad \mathrm{CV}(\%)$ & 176,6 & 45,7 & 53,6 & 50,8 & 59,0 & 32,3 & 45,0 & 35,0 \\
\hline Empre- Média & $3.105,15$ & 11,68 & 2,43 & 2,35 & 24,82 & 41,74 & 3,82 & 14,87 \\
\hline gador $\mathrm{CV}(\%)$ & 192,7 & 35,6 & 50,6 & 48,1 & 48,6 & 27,9 & 42,7 & 35,9 \\
\hline
\end{tabular}

Fonte: Pesquisa sobre padrões de vida 1996-1997 [CD-ROM].Microdados. Rio de Janeiro: IBGE 1998.

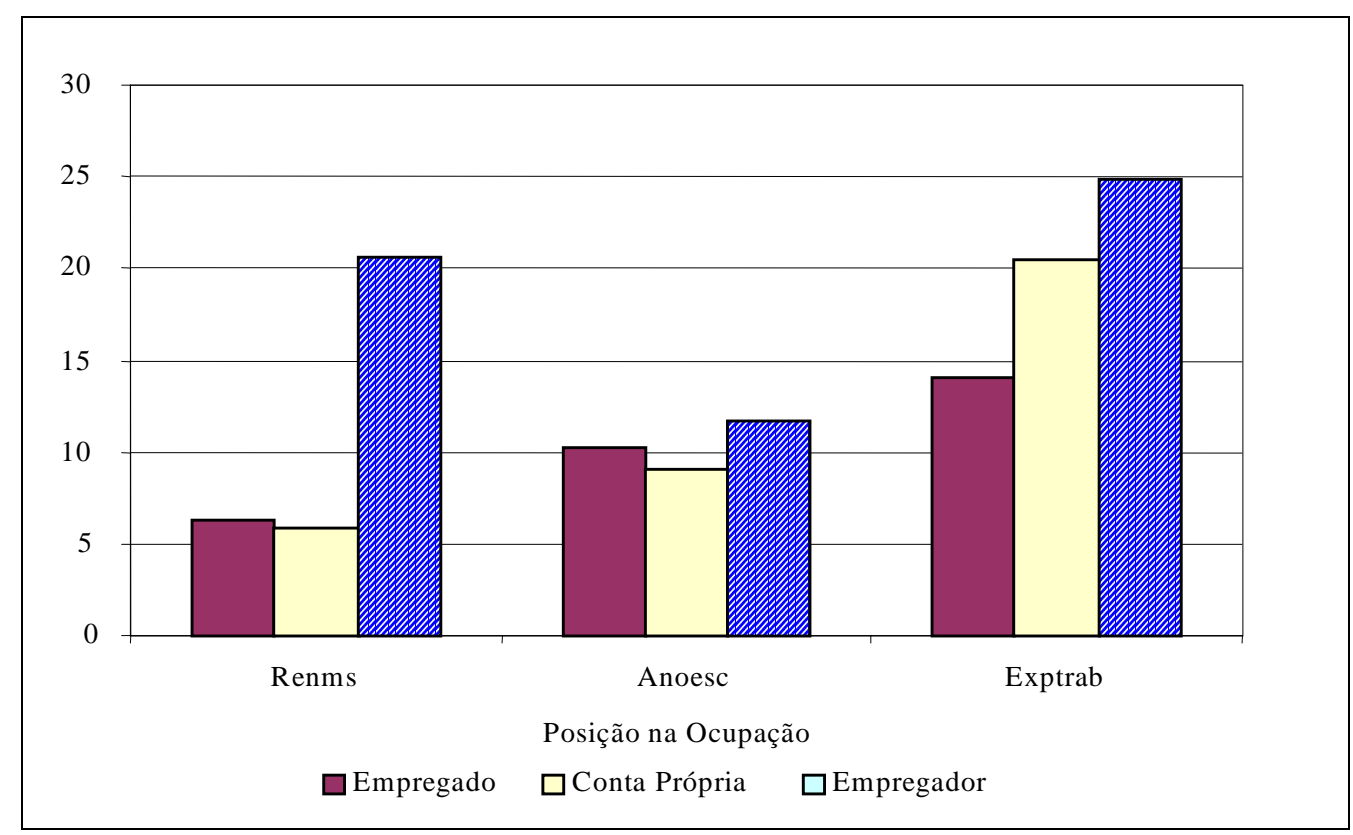

Fonte: Pesquisa sobre padrões de vida 1996-1997 [CD-ROM].Microdados. Rio de Janeiro: IBGE 1998.

Figura 9 - Média de rendimento mensal (em SM), escolaridade e experiência no trabalho segundo a posição na ocupação, amostra selecionada. 
A descrição da amostra segundo o gênero ou sexo, na Tabela 8, mostra que o mercado de trabalho é mais favorável aos homens, como enfatizado por diversos estudos $^{38}$. Os homens percebem rendimento do trabalho cerca de $74 \%$ superior ao rendimento médio percebido pelas mulheres. Duas outras variáveis apresentam-se também com diferenças marginais, anoesc, com 1 ano a mais a favor das mulheres, e exptrab, com diferença de 3 anos para os homens, como pode ser visto na Tabela 8 e Figura 10.

Tabela 8 - Média e coeficiente (CV) de variação de variáveis chave segundo o gênero, amostra selecionada.

\begin{tabular}{|c|c|c|c|c|c|c|c|c|c|}
\hline \multirow[b]{2}{*}{ Gên } & & \multicolumn{8}{|c|}{ VARIÁVEL } \\
\hline & ero & $\begin{array}{c}\text { Taxa de } \\
\text { rendimento } \\
\text { mensal }\end{array}$ & $\begin{array}{l}\text { Anos } \\
\text { de } \\
\text { estudo }\end{array}$ & $\begin{array}{l}\text { Nível de } \\
\text { escolari- } \\
\text { dade do } \\
\text { pai }\end{array}$ & $\begin{array}{l}\text { Nível de } \\
\text { escolari- } \\
\text { dade da } \\
\text { mãe }\end{array}$ & $\begin{array}{c}\text { Anos de } \\
\text { experiência } \\
\text { de } \\
\text { trabalho }\end{array}$ & $\begin{array}{l}\text { Anos } \\
\text { de } \\
\text { idade }\end{array}$ & $\begin{array}{c}\text { No. de } \\
\text { pessoas } \\
\text { no } \\
\text { domicílio }\end{array}$ & $\begin{array}{l}\text { Idade } \\
\text { começou a } \\
\text { trabalhar }\end{array}$ \\
\hline \multirow{2}{*}{ Homem } & Média & $1.301,67$ & 9,68 & 2,15 & 2,11 & 17,19 & 33,37 & 4,38 & $\overline{14,01}$ \\
\hline & $\mathrm{CV}(\%)$ & 208,7 & 42,0 & 52,6 & 50,7 & 72,0 & 36,7 & 44,1 & 29,6 \\
\hline \multirow{2}{*}{ Mulher } & Média & 749,11 & 10,74 & 2,24 & 2,10 & 14,39 & 32,08 & 4,25 & 16,63 \\
\hline & $\mathrm{CV}(\%)$ & 178,2 & 36,0 & 55,4 & 50,5 & 74,9 & 33,8 & 44,5 & 29,0 \\
\hline
\end{tabular}

Fonte: Pesquisa sobre padrões de vida 1996-1997 [CD-ROM].Microdados. Rio de Janeiro: IBGE 1998.

\footnotetext{
${ }^{38}$ Soares (2000) mostra que mulheres brancas têm remunerações 35\% inferiores àquelas recebidas pelos homens brancos.
} 


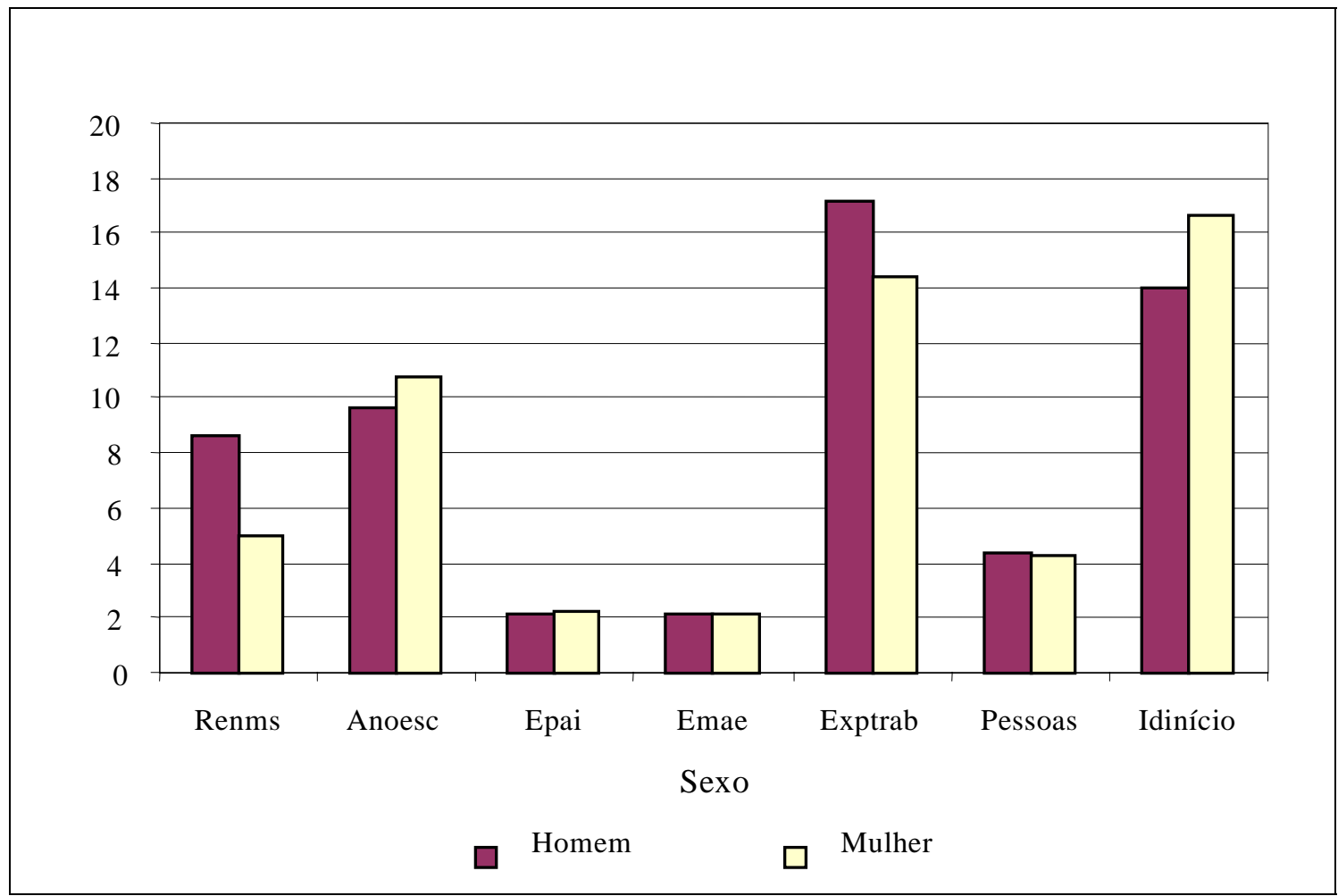

Fonte: Pesquisa sobre padrões de vida 1996-1997 [CD-ROM].Microdados. Rio de Janeiro: IBGE 1998.

Figura 10 - Valor médio de variáveis chave, por sexo.

Média das variáveis chave por estrato geográfico são vistas na Tabela 9 e na Figura 11. Destaca-se na Figura 11 o perfil semelhante das variáveis renms, idinicio, anoesc, nepai e nemae, que alcançam valores picos no Recife ou em Salvador, no nordeste, e no Rio de Janeiro ou São Paulo, na região sudeste. Valores mínimos sempre ocorrem no meio rural das respectivas regiões. Observa-se que os valores médios de rendimento mensal são mais elevados nas regiões metropolitanas situadas no sudeste brasileiro do que nas metrópoles nordestinas. Os maiores rendimentos aparecem também na região sudeste. 
Tabela 9 - Média e coeficiente de variação (CV) de variáveis chave, por estrato geográfico na amostra selecionada.

\section{VARIÁVEL}

\begin{tabular}{|c|c|c|c|c|c|c|c|c|c|}
\hline Metrópo & / Região & $\begin{array}{c}\text { Taxa de } \\
\text { rendimento } \\
\text { mensal }\end{array}$ & $\begin{array}{l}\text { Anos } \\
\text { de } \\
\text { estudo }\end{array}$ & $\begin{array}{l}\text { Nível de } \\
\text { escolari- } \\
\text { dade do } \\
\text { pai } \\
\end{array}$ & $\begin{array}{l}\text { Nível de } \\
\text { escolari- } \\
\text { dade da } \\
\text { mãe }\end{array}$ & $\begin{array}{c}\text { Anos de } \\
\text { experiência } \\
\text { no } \\
\text { trabalho } \\
\end{array}$ & $\begin{array}{l}\text { Anos } \\
\text { de } \\
\text { idade }\end{array}$ & $\begin{array}{c}\text { No. De } \\
\text { pessoas } \\
\text { no } \\
\text { domicílio } \\
\end{array}$ & $\begin{array}{c}\text { Idade } \\
\text { começou } \\
\text { a } \\
\text { trabalhar } \\
\end{array}$ \\
\hline \multirow{2}{*}{ Fortaleza } & Méd & 815,87 & $\overline{9,8}$ & 2,10 & 2,01 & 16,91 & 33,82 & 4,98 & 14,99 \\
\hline & $\mathrm{CV}(\%)$ & 235,5 & 44,3 & 61,9 & 56,2 & 73,7 & 35,5 & 42,4 & 32,8 \\
\hline \multirow{2}{*}{ Recife } & $\mathrm{N}$ & 980,16 & 10,41 & 2,35 & 2 & 15,91 & 33 , & 4,42 & 16,83 \\
\hline & $\mathrm{CV}(\%)$ & 225,2 & 37,3 & 46,8 & 43,8 & 76,2 & 35,7 & 44,1 & 28,7 \\
\hline \multirow{2}{*}{ Salva } & & 2 & 10,19 & 2,23 & 2 & 15,81 & 5 & 4,95 & 15,98 \\
\hline & $\mathrm{CV}(\%)$ & 163,5 & 37,0 & 53,8 & 49,5 & 72,3 & 33,5 & 54,9 & 26,3 \\
\hline$\overline{\mathrm{NE}}$ & fvicu & 110,41 & 10,50 & 1,95 & 2,06 & 15,12 & $32, \angle 0$ & 4,70 & 15,55 \\
\hline Urbano & $\mathrm{CV}(\%)$ & 143,9 & 39,6 & 57,4 & 55,3 & 76,6 & 35,4 & 42,6 & 30,0 \\
\hline \multirow{2}{*}{ NE R } & $\mathrm{N}$ & 508,28 & 1,0 & 1,71 & 1,88 & 14,01 & 30,68 & 5,07 & 13,68 \\
\hline & $\mathrm{CV}(\%)$ & 255,0 & 55,1 & 63,7 & 54,8 & 85,3 & 37,8 & 46,5 & 40,6 \\
\hline$\overline{\text { Belo }}$ & Média & 107,02 & 9,66 & 2,06 & 2,08 & 16,20 & 32,88 & 4,65 & $\overline{15,03}$ \\
\hline $\mathrm{H}$ & $\mathrm{CV}$ & 392,2 & 38,6 & 51,0 & 50,0 & 74,0 & 2 & 47,5 & 31,03 \\
\hline Rio de & Média & $1.442,32$ & 10,87 & 2,65 & 2,33 & 17,92 & 35,44 & 3,95 & $\overline{16,74}$ \\
\hline . & $\mathrm{CV}(\%)$ & 247 & 2 & 47,5 & 46,4 & 67,9 & 34,4 & 43,3 & 24,9 \\
\hline \multirow{2}{*}{ São 1} & Médi & $1.828,30$ & 11,06 & 2,41 & 2,27 & 16,18 & 32,91 & 3,99 & $\overline{15,51}$ \\
\hline & $\mathrm{CV}(\mathrm{o}$ & 158,0 & 3 & 50,2 & 49,8 & 71,4 & 35,1 & 41,6 & 25,7 \\
\hline \multirow{2}{*}{ SE Urbano } & $\bar{M}$ & 887,31 & 9,99 & 2,12 & 2,06 & 16,14 & 32,48 & 4,22 & $\overline{14,15}$ \\
\hline & $\mathrm{CV}(\%)$ & 123,0 & 37,9 & 51,9 & 48,5 & 73,0 & 35,5 & 41,0 & 31,4 \\
\hline \multirow{2}{*}{ SE Rur } & $\bar{M}$ & 360,75 & , & 1,45 & 1,46 & 14,78 & 30,73 & 4,42 & $\overline{12,44}$ \\
\hline & $\mathrm{CV}(\%)$ & 132,6 & 50,4 & 44,8 & 45,2 & 85,0 & 40,7 & 48,9 & 41,0 \\
\hline
\end{tabular}

Fonte: Pesquisa sobre padrões de vida 1996-1997 [CD-ROM].Microdados. Rio de Janeiro: IBGE 1998. 


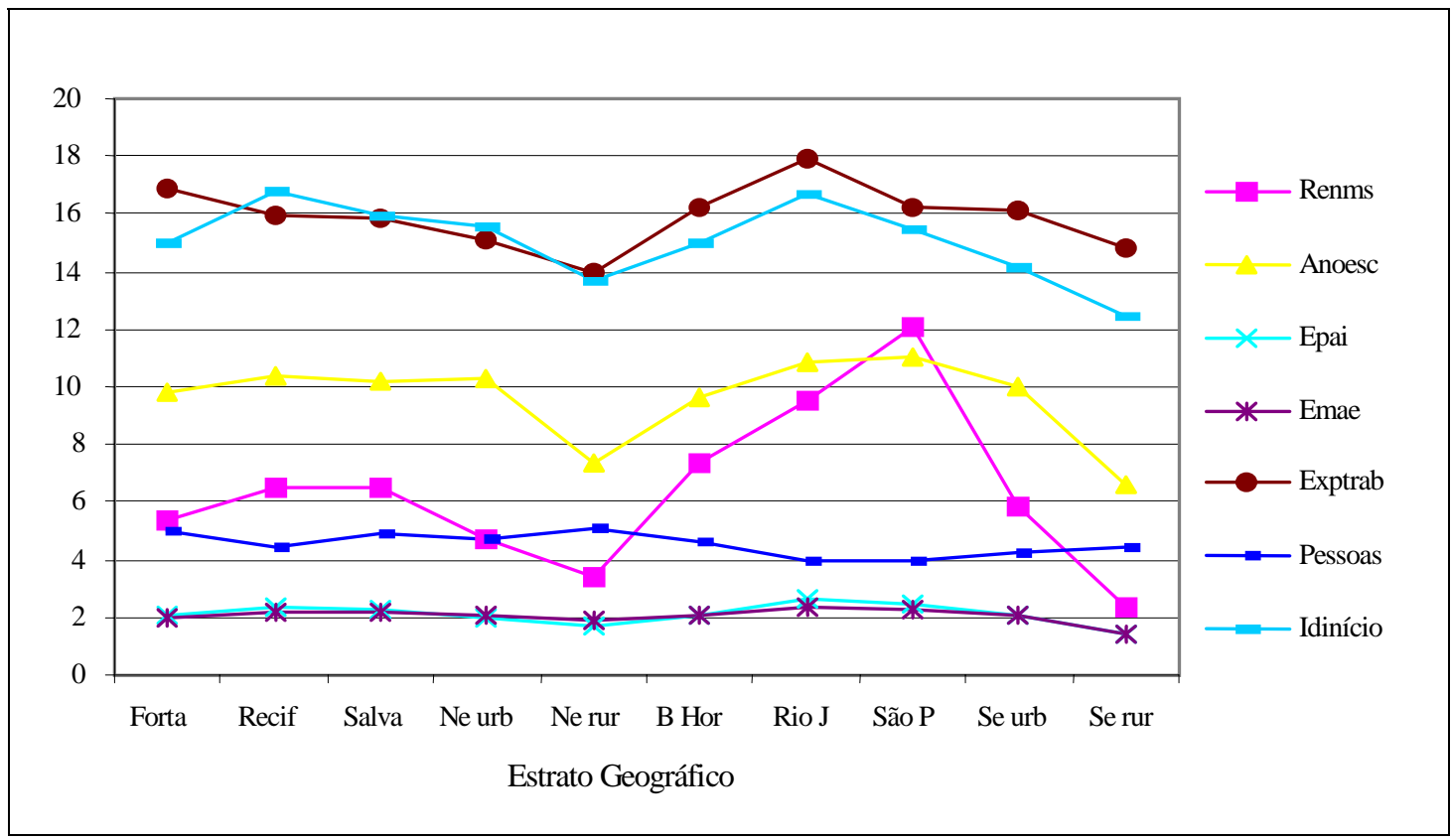

Fonte: Pesquisa sobre padrões de vida 1996-1997 [CD-ROM].Microdados. Rio de Janeiro: IBGE 1998.

Figura 11 - Valor médio de rendimento mensal (SM), anos de estudo, nível de escolaridade dos pais, anos de experiência no mercado de trabalho, número de pessoas no domicílio e idade de ingresso no mercado de trabalho, por estrato geográfico, amostra selecionada.

O rendimento médio mensal do trabalho principal (renms) nas áreas rurais não apresentou o comportamento esperado, de forma que o valor médio no nordeste rural foi $41 \%$ superior ao verificado no sudeste rural (serura). A amostra selecionada, infelizmente, não possibilita uma explicação razoável para tais estatísticas. Acredita-se que o viés seja resultante dos diversos filtros impostos à base de microdados da PPV, que alterou a distribuição inicial das observações. Outra possibilidade poderia ser a subdeclaração de rendimentos, tendo em vista que o rendimento máximo declarado no sudeste rural foi $30 \%$ do levantado no nordeste rural (Tabela 10). 
Tabela 10 - Participação setorial e taxa de rendimento mensal por região na amostra selecionada.

\begin{tabular}{|c|c|c|c|c|}
\hline \multirow{2}{*}{ Regiões } & \multicolumn{2}{|c|}{ Nordeste } & \multicolumn{2}{|c|}{ Sudeste } \\
\hline & PPV & Seleção & PPV & Seleção \\
\hline Regiões Metropolitanas & 18,92 & 35,13 & 44,98 & 49,51 \\
\hline Regiões Urbanas & 44,86 & 48,17 & 44,86 & 45,10 \\
\hline Regiões Rurais & 36,22 & 16,70 & 10,16 & 5,39 \\
\hline Renms (máximo) & \multicolumn{2}{|c|}{$12.602,24$} & \multicolumn{2}{|c|}{3.755 .55} \\
\hline Renms (mínimo) & \multicolumn{2}{|c|}{19,14} & \multicolumn{2}{|c|}{14,29} \\
\hline
\end{tabular}

Fonte: Pesquisa sobre padrões de vida 1996-1997 [CD-ROM].Microdados. Rio de Janeiro: IBGE 1998.

Outro argumento é que a região sudeste detém grande parte dos centro urbanos do país, formados não só por grandes cidades, mas também por cidades de porte médio e pequeno. Isto leva a crer que mesmo no meio rural, a maioria dos domicílios é classificada como urbana. Por outro lado, no nordeste, as cidades médias e pequenas apresentam ainda características típicas da vida rural, com reduzido índice de utilização de bens e serviços do cotidiano urbano, como saneamento básico, eletrificação, telefonia e bens duráveis (eletrodomésticos e eletroeletrônicos), resultando na elevada participação dos domicílios rurais.

Essa evidência pode ser corroborada pela taxa de participação do estrato geográfico intra-região. Considerando a amostra expandida, 16,7\% dos indivíduos no nordeste estão domiciliados em ambiente rural, percentual três vezes maior que o similar na região sudeste, onde há somente $5,4 \%$.

As variáveis exptrab e pessoas não apresentam um perfil bem delineado entre as regiões estudadas, inibindo uma razoável explicação. Exceto o fato do meio rural de cada grande região, exibir sempre maior número médio de pessoas por domicílio. 
Por outro lado, não se pode refutar a idéia de que as duas amostras selecionadas, com base nos critérios adotados, estejam de fato refletindo os cenários regionais em estudo.

Tudo leva a crer que os diversos filtros impostos à base de microdados da PPV geraram amostra que sintetiza as características socioeconômicas das regiões nordeste e sudeste do país. Os importantes contrastes regionais e setoriais constatados em estatísticas oficiais e em diversos estudos são revelados neste estudo. Os resultados sugerem também a existência de discriminações contra a mulher no mercado de trabalho. 


\section{RESULTADOS E DISCUSSÃO DOS MODELOS}

Foram estimadas as formulações descritas pelas equações (20), (21) e (22) e também as propostas (23) e (24), cujos regressores são relacionados com o capital humano acumulado pelo indivíduo, variáveis relacionadas ao family background e uma série de variáveis binárias de controle. ${ }^{39}$

De modo genérico, as formulações podem ser representadas pela expressão abaixo:

$$
Y_{i}=\alpha+\sum_{j} \beta_{j} X_{j i}+u_{i}
$$

onde $Y i$ é o logaritmo do rendimento horário do indivíduo $i ; \alpha$ e $\beta$ são parâmetros; $u_{j}$ são erros aleatórios e $X_{j i}$ um vetor com as seguintes variáveis explicativas: ${ }^{40}$

a) anoesc - Anos de escolaridade. É uma variável discreta cujos valores variam de 1 (no caso da pessoa não ter instrução escolar ou ter menos de 1 ano de estudo) a 16 (quando a pessoa tem 15 anos ou mais de estudo). O coeficiente dessa variável fornecerá uma estimativa para a taxa de retorno privado da educação formal.

b) idade - Anos de idade do indivíduo.

c) idquad - Quadrado da idade do indivíduo. Os coeficientes de idade e idquad indicam a tendência do rendimento crescer até certa idade, atingir um pico e decrescer com aproximação da velhice. Se $\beta_{2}$ e $\beta_{3}$ forem os parâmetros para idade e idquad, respectivamente, deve-se esperar que $\beta_{2}>0$ e $\beta_{3}<0$. Assim, o valor de $Y i$ será máximo quando a idade da pessoa for igual a $-\beta_{2} /\left(2 \beta_{3}\right)$.

\footnotetext{
${ }^{39}$ Com auxílio do PROC GLM e do PROC SYSLIN do SAS ( Procedimentos do Statistical Analysis Software- SAS).
} 
d) chfam - Variável binária que assume valor 1 se o indivíduo for chefe de família e valor 0 em caso contrário.

e) sexo - Binária que assume valor 1 para mulheres visando captar a existência de diferenciais de rendimento por gênero. Espera-se que o coeficiente correspondente a binária sexo seja negativo.

f) pretpard e amare - São duas variáveis binárias para distinguir três tonalidades de cor da pele: branca (tomada como base), preta e parda (pretpard) e amarela mais indígenas ${ }^{41}$ (amare). É esperado um coeficiente maior que zero para a variável amare e menor que zero para a variável pretpard.

g) ctpro e empgdr - Três posições na ocupação são especificadas nesta pesquisa por estas duas binárias: empregado, tomado como base; pessoa que trabalha por conta própria (ctpro) e empregadores, captada através de empgdr.

h) Dez estratos geográficos são diferenciados entre si pela utilização de nove variáveis binarias. O estrato geográfico denominado como restante do nordeste rural será tomado como base, os demais compreendem: rmfort - região metropolitana de Fortaleza; rmrecif - região metropolitana de Recife; rmsalv - região metropolitana de Salvador; neurba nordeste urbano; rmbh - região metropolitana de Belo Horizonte; rmrio - região metropolitana do Rio de Janeiro; rmsaop - região metropolitana de São Paulo; serura sudeste rural e seurba - Sudeste urbano.

i) nepai e nemae - Variáveis discretas que variam de 1 (quando o pai ou a mãe tem menos de 4 anos de estudos completos) a 5 (quando o pai ou a mãe tem mais de 15 anos completos de estudos). Essas variáveis são proxies para o family background.

Pode-se esclarecer o uso das variáveis binárias utilizando um exemplo de Hoffmann (1998b). Com muita clareza o autor destaca a finalidade dos regressores binários:

\footnotetext{
${ }^{40}$ Pela clareza de exposição, os itens são baseados em Hoffmann (1998b).

${ }^{41} \mathrm{Na}$ PPV a classificação amarela inclui tanto descendentes asiáticos quantos indígenas.
} 
“...se, por exemplo, o coeficiente para a binária de situação urbana for $b$, então o rendimento esperado das pessoas com domicílio urbano supera o rendimento esperados das pessoas com domicilio rural em 100( $\left.e^{b}-1\right) \%$, já considerados os efeitos das demais variáveis explanatórias incluídas na regressão”.

Portanto, as binárias indicam a diferença entre a característica base e a apresentada pelo indivíduo.

Para analisar os efeitos da escolaridade sobre o rendimento dos indivíduos, foi estimada uma sequiência de equações de rendimento por mínimos quadrados ponderados, em que o peso ou fator de expansão associado a cada pessoa, divulgado junto a PPV, é o fator de ponderação. A Tabela 11 dispõe as estimativas e respectivas estatísticas $t$ - student, o número de elementos considerados na análise e os valores do teste $F$ e do coeficiente de determinação.

A regressão (1), cujos resultados estão na primeira coluna da Tabela 11, mostra os coeficientes da equação de rendimento onde a variável dependente é o logaritmo do rendimento hora e as variáveis explicativas são anos de escolaridade (anoesc), idade e idade ao quadrado do indivíduo. As demais variáveis refletem a inserção do indivíduo numa série de situações, como descrito anteriormente. São as binárias chfam, pretpard, amare, ctpro e empgdr além das nove binárias para diferenciação geográfica.

A regressão (2) (na segunda coluna) tem como regressores as mesmas variáveis da regressão (1) acrescidas das variáveis nepai e nemae. A última coluna da mesma tabela mostra os parâmetros estimados para a regressão (3), com as mesmas variáveis da regressão (2), só que as variáveis referentes ao family background foram dissociadas por nível de escolaridade, ficando o nível 1 como base. 
Tabela 11 - Coeficientes, valores de $t$, número de observações, coeficientes de determinação e estatística $F$ por regressão.

\begin{tabular}{|c|c|c|c|}
\hline Variável & $\begin{array}{c}\text { Regressão } 1 \\
\text { (ln do rend. horário) }\end{array}$ & $\begin{array}{c}\text { Regressão } 2 \\
\text { (ln do rend. horário) }\end{array}$ & $\begin{array}{c}\text { Regressão } 3 \\
\text { (ln do rend. horário) }\end{array}$ \\
\hline \multirow[b]{2}{*}{ Constante } & $-2,208136$ & $-2,431699$ & $-2,283108$ \\
\hline & $(-17,691)$ & $(-19,152)$ & $(-18,308)$ \\
\hline \multirow{2}{*}{ Anoesc } & 0,136015 & 0,117320 & 0,117506 \\
\hline & $(34,507)$ & $(26,252)$ & $(26,202)$ \\
\hline \multirow{2}{*}{ Idade } & 0,068119 & 0,073356 & 0,073705 \\
\hline & $(10,973)$ & $(11,884)$ & $(11,940)$ \\
\hline \multirow{2}{*}{ Idquad } & $-0,000579$ & $-0,000636$ & $-0,000639$ \\
\hline & $(-7,311)$ & $(-8,103)$ & $(-8,141)$ \\
\hline \multirow{2}{*}{ Chfam } & 0,188491 & 0,202520 & 0,198552 \\
\hline & $(5,009)$ & $(5,430)$ & $(5,319)$ \\
\hline \multirow{2}{*}{ Sexo } & $-0,329771$ & $-0,312571$ & $-0,315881$ \\
\hline & $(-9,666)$ & $(-9,252)$ & $(-9,331)$ \\
\hline \multirow{2}{*}{ Pretpard } & $-0,074372^{*}$ & $-0,054403^{\mathrm{ns}}$ & $-0,058110^{* *}$ \\
\hline & $(-2,096)$ & $(-1,547)$ & $(-1,654)$ \\
\hline \multirow{2}{*}{ Amare } & $0,263713^{\mathrm{ns}}$ & $0,273900^{\mathrm{ns}}$ & $0,321772 * *$ \\
\hline & $(1,523)$ & $(1,600)$ & $(1,877)$ \\
\hline \multirow{2}{*}{ Ctpro } & $-0,044336^{\mathrm{ns}}$ & $-0,055400^{\mathrm{ns}}$ & $-0,059879 * *$ \\
\hline & $(-1,194)$ & $(-1,508)$ & $(1,630)$ \\
\hline \multirow{2}{*}{ Empgdr } & 0,417699 & 0,400364 & 0,398165 \\
\hline & $(7,227)$ & $(7,004)$ & $(6,973)$ \\
\hline \multirow{2}{*}{ Rmfort } & $0,192259^{* *}$ & $0,185780 * *$ & $0,184012 * *$ \\
\hline & $(1,864)$ & $(1,822)$ & $(1,806)$ \\
\hline \multirow{2}{*}{ Rmrecif } & $0,226754 *$ & $0,203471^{* *}$ & $0,218151^{*}$ \\
\hline & $(1,990)$ & $(1,805)$ & $(1,931)$ \\
\hline \multirow{2}{*}{ Rmsalv } & 0,378787 & 0,359114 & 0,363358 \\
\hline & $(3,669)$ & $(3,518)$ & $(3,557)$ \\
\hline \multirow{2}{*}{ Neurba } & $0,191246^{*}$ & 0,210354 & 0,208559 \\
\hline & $(2,409)$ & $(2,679)$ & $(2,656)$ \\
\hline
\end{tabular}


Tabela 11 - Coeficientes, valores de $t$, número de observações, coeficientes de determinação e estatística $F$ por regressão. (continuação)

\begin{tabular}{|c|c|c|c|}
\hline \multirow{2}{*}{$R m b h$} & 0,529147 & 0,525560 & 0,541739 \\
\hline & $(5,691)$ & $(5,719)$ & $(5,878)$ \\
\hline \multirow{2}{*}{ Rmrio } & 0,429906 & 0,380098 & 0,383684 \\
\hline & $(5,357)$ & $(4,4774)$ & $(4,796)$ \\
\hline \multirow{2}{*}{ Rmsaop } & 0,845891 & 0,833142 & 0,832120 \\
\hline & $(10,788)$ & $(10,741)$ & $(10,679)$ \\
\hline \multirow{2}{*}{ Serura } & $0,069769^{\mathrm{ns}}$ & $0,105658^{\mathrm{ns}}$ & $0,102477^{\mathrm{ns}}$ \\
\hline & $(0,703)$ & $(1,075)$ & $(1,043)$ \\
\hline \multirow{2}{*}{ Seurba } & 0,480215 & 0,485629 & 0,494219 \\
\hline & $(6,472)$ & $(6,618)$ & $(6,709)$ \\
\hline \multirow{2}{*}{ Nepai } & --- & 0,104086 & --- \\
\hline & --- & $(6,408)$ & --- \\
\hline \multirow{2}{*}{ Nemae } & $\begin{array}{l}-- \\
\end{array}$ & $0,033820^{*}$ & --- \\
\hline & --- & $(1,950)$ & --- \\
\hline \multirow{2}{*}{ Nepai2 } & --- & --- & 0,127408 \\
\hline & --- & --- & $(3,340)$ \\
\hline \multirow{2}{*}{ Nepai3 } & --- & --- & $0,103571 * *$ \\
\hline & --- & --- & $(1,725)$ \\
\hline \multirow{2}{*}{ Nepai4 } & --- & --- & 0,286985 \\
\hline & --- & --- & $(4,670)$ \\
\hline \multirow{2}{*}{ Nepai5 } & --- & --- & 0,484825 \\
\hline & --- & --- & $(6,462)$ \\
\hline \multirow{2}{*}{ Nemae2 } & --- & --- & $-0,019645^{\mathrm{ns}}$ \\
\hline & --- & --- & $(-0,524)$ \\
\hline \multirow{2}{*}{ Nemae3 } & --- & --- & 0,161172 \\
\hline & --- & --- & $(2,673)$ \\
\hline \multirow{2}{*}{ Nemae4 } & --- & --- & $0,027390^{\mathrm{ns}}$ \\
\hline & --- & --- & $(0,457)$ \\
\hline \multirow{2}{*}{ Nemae5 } & --- & --- & $0,170160 * *$ \\
\hline & --- & --- & $(1,841)$ \\
\hline
\end{tabular}


Tabela 11 - Coeficientes, valores de $t$, número de observações, coeficientes de determinação e estatística $F$ por regressão. (continuação)

\begin{tabular}{lrrr}
\hline No. Observações & 3.169 & 3.169 & 3.169 \\
\hline Valor $F$ & 182,396 & 171,925 & 133,276 \\
\hline$R^{2}$ & 0,5103 & 0,5221 & 0,5245 \\
\hline$R^{2}$ ajustado & 0,5075 & 0,5190 & 0,5205 \\
\hline
\end{tabular}

* Estatisticamente significativo a 5\%.

**Estatisticamente significativo a $10 \%$.

ns Estatisticamente não significativo.

Os demais são estatisticamente significativos a $1 \%$.

É importante observar os valores da estatística $F$ e enfatizar a similaridade entre coeficientes de determinação de cada uma das equações. Os valores da estatística $F$ são estatisticamente significativos ao nível de $1 \% \mathrm{em}$ todas as regressões, o que eqüivale dizer que o conjunto de variáveis tomadas em cada equação é estatisticamente significativo.

Na primeira regressão observa-se uma forte relação entre as variáveis explicativas e o logaritmo do rendimento das pessoas, com um $R^{2}$ de 0,5103 , o que indica que ao menos $51 \%$ da variação da variável dependente, neste caso, o logaritmo do rendimento da ocupação principal, pode ser explicado pela variação conjunta dos regressores.

Na regressão (2) vemos que o poder de explicação é ligeiramente maior (1 ponto percentual) que o anterior. A despeito das fortes evidências quanto a relação do family background com o rendimento dos indivíduos, constata-se nesta pesquisa que o coeficiente de determinação aumentou muito pouco com adição de tais proxies. Apesar disto, os coeficientes estão muito próximos daqueles obtidos em estudos anteriores. Entre eles o de Lam \& Schoeni (1993), que utilizando um conjunto de 17 binárias para o grau de instrução do indivíduo e 6 para o nível de instrução de seus genitores, separadamente, chegam a um $R^{2}$ igual a 0,54 . O valor de $R^{2}$ para a última regressão na Tabela 10, com binárias para os níveis educacionais dos pais, permanece praticamente inalterado em relação ao ajustamento anterior, sendo 0,5245. O coeficiente de 
determinação ajustado apresenta comportamento semelhante ao seu homônimo simples, variando de 0,5075 a 0,5205 nos três ajustamentos.

Os coeficientes de determinação aqui encontrados são em média $12 \%$ menores que os estimados por Hoffmann (2000), utilizando um conjunto de variáveis binárias para distinguir diversas características dos indivíduos, sem, no entanto, fazer uso de proxies relativas ao family background. Embora esses coeficientes guardem uma distância significativa entre si, acredita-se que a inclusão de variáveis binárias semelhantes as utilizadas por Hoffmann (2000 e 1998b) conduziria a maiores valores de $\mathrm{R}^{2}$.

Considerando as variáveis relacionadas ao nível educacional dos pais, o coeficiente de determinação é significativamente satisfatório, mesmo se comparado a estudos com foco central diferente. Ademais, merece atenção o fato de a determinação da escolaridade no Brasil estar condicionada a diversos fatores além da escolarização dos pais, como concluem Souza \& Silva (1994).

Na Tabela 11, verifica-se que a maioria dos coeficientes é estatisticamente diferente de zero ao nível de $1 \%$ (coeficientes sem indicação). Os coeficientes assinalados com um asterisco são estatisticamente significativos ao nível de significância de 5\%, os assinalados com dois asteriscos o são ao nível de 10\%, enquanto os que são acompanhados com a rubrica " $n s$ " não são estatisticamente diferentes de zero nos níveis mencionados acima.

As variáveis relacionadas com o acúmulo de capital humano - anoesc, idade e idquad - todas estimadas com o sinal correto. Os coeficientes relativos as categorias amare, ctpro e serura, foram estatisticamente não significativos aos níveis usuais; de até $10 \%$. Contudo, todas as estimativas resultaram em valores para os quais os sinais obtidos são os esperados.

A variável amare indica que, em média, as pessoas de cor amarela esperam obter um rendimento $30 \%$ maior que as pessoas de cor branca (tomada como base), já descontados os efeitos das demais variáveis ${ }^{42}$. A reduzida participação dos

\footnotetext{
${ }^{42}$ Em recente trabalho com pessoas ocupadas no Brasil, considerando o rendimento de todos os trabalhos, com base na PNAD 1999, Hoffmann (2000) estima um retorno médio para os indivíduos de cor amarela,
} 
indivíduos de cor amarela (somente $0,7 \%$ dos selecionados) pode ter contribuído para que o parâmetro estimado não fosse estatisticamente diferente de zero, ao nível de $10 \%$ de significância.

As variáveis ctpro e serura, têm maior participação na amostra, aproximadamente $20 \%$ e $4 \%$, respectivamente. Como fora citado antes, os sinais esperados foram verificados, entretanto, as reduzidas magnitudes dos parâmetros estimados levam a crer que na amostra selecionada, os indivíduos que trabalham por conta própria, em média, não percebem rendimentos, estatisticamente falando, diferentes das pessoas empregadas.

Por sua vez, o coeficiente estimado para a binária serura, enquanto estatisticamente não significativo, sugere que a população rural do sudeste não obtém rendimentos do trabalho estatisticamente diferentes dos indivíduos residentes no nordeste rural. Esta estimativa vem a ser surpreendente, tendo em vista os contrastes socioeconômicos entre as duas regiões, conforme destacado em diversos estudos e relatórios oficiais. ${ }^{43}$

As demais variáveis binárias de diferenciação regional são todas significativas ao nível de significância de $1 \%$. Exceto o coeficiente estimado para a região metropolitana de Fortaleza, significativo ao nível de 10\%; os de Recife e nordeste urbano são estatisticamente diferentes de zero ao nível de significância de $5 \%$.

De acordo com a primeira coluna da Tabela 12, verifica-se uma tendência de elevação do rendimento, em relação ao trabalhador situado no nordeste rural, no sentido norte-sul. O acréscimo no rendimento médio esperado na região metropolitana de Fortaleza é cerca de três vezes menor que o rendimento esperado na região metropolitana de Belo Horizonte. O mesmo fenômeno se verifica quando se compara as metrópoles de Salvador e São Paulo. É claro que não se pretende estabelecer uma

${ }^{43}$ Ver comentários sobre as estatísticas da Tabela 9. 
relação de causa-efeito, geograficamente falando, e que fatores históricos devem explicar tais resultados. ${ }^{44}$.

O maior diferencial de rendimento, conforme esperado, está associado a metrópole de São Paulo, onde as pessoas tendem a ganhar 133\% a mais do que as residentes no nordeste rural. $\mathrm{O}$ estrato urbano do sudeste tem incremento no rendimento esperado em $61,6 \%$, contra os $21,1 \%$ do nordeste urbano.

No nordeste, o maior diferencial está associado a metrópole de Salvador, com uma taxa de incremento no rendimento esperado de $46,1 \%$, bem maior que a verificada na região metropolitana de Recife $(25,5 \%)$, e inferior ao diferencial associado à região metropolitana do Rio de Janeiro, que com 53,7\% é o menor incremento do sudeste urbano.

Ainda de acordo com a Tabela 12, as pessoas pretas e pardas, identificadas pela variável pretpard, têm rendimento esperado inferior ao dos brancos, mesmo depois de descontados os efeitos das demais variáveis incluídas na regressão, de $7,2 \%$. O coeficiente estimado para a binária sexo indica que as mulheres obteriam na ocupação principal rendimento $28,1 \%$ menor que o rendimentos de seus pares do sexo masculino. Este resultado é praticamente igual ao encontrado por Hoffmann (2000).

${ }^{44} \mathrm{O}$ livro de Furtado Retrata de forma simples diversos aspectos que ajudam a compreender os disparates regionais no Brasil: FURTADO, C. Formação econômica do Brasil. 12 ed. São Paulo: Nacional, 1974. 248p. 
Tabela 12 - Percentual de acréscimo no rendimento esperado, idade de máximo rendimento e variação relativa, por regressão.

\begin{tabular}{|c|c|c|c|c|c|c|}
\hline Variável & $\begin{array}{l}\text { Regressão } 1 \\
\text { (ln. rend. hora) }\end{array}$ & $\begin{array}{c}\text { Regressão } 2 \\
\text { (ln. rend. hora) }\end{array}$ & $\begin{array}{c}\text { Regressão } 3 \\
\text { (ln. Rend. hora) }\end{array}$ & $\begin{array}{c}\text { Var \% } \\
\text { Reg 2/reg 1 }\end{array}$ & $\begin{array}{c}\text { Var \% } \\
\text { reg 3/reg } 1\end{array}$ & $\begin{array}{c}\text { Var } \% \\
\text { Reg 3/reg } \\
2 \\
\end{array}$ \\
\hline Anoesc & 14,6 & 12,4 & 12,5 & $-15,1$ & $-14,4$ & 0,8 \\
\hline Chfam & 20,7 & 22,4 & 22,0 & 8,2 & 6,3 & $-1,8$ \\
\hline Sexo & $-28,1$ & $-26,8$ & $-27,1$ & $-4,6$ & $-3,6$ & 1,1 \\
\hline Pretpard & $-7,2$ & $-5,3$ & $-5,6$ & $-26,4$ & $-22,2$ & 5,7 \\
\hline Amare & 30,2 & 31,5 & 38,0 & 4,3 & 25,8 & 20,6 \\
\hline Ctpro & $-4,3$ & $-5,4$ & $-5,8$ & 25,6 & 34,9 & 7,4 \\
\hline Empgdr & 51,8 & 49,2 & 48,9 & $-5,0$ & $-5,6$ & $-0,6$ \\
\hline Rmfort & 21,2 & 20,4 & 20,2 & $-3,8$ & $-4,7$ & $-1,0$ \\
\hline Rmrecif & 25,5 & 22,6 & 24,4 & $-11,4$ & $-4,3$ & 8,0 \\
\hline Rmsalv & 46,1 & 43,2 & 43,8 & $-6,3$ & $-5,0$ & 1,4 \\
\hline Neurba & 21,1 & 23,4 & 23,2 & 10,9 & 10,0 & $-0,9$ \\
\hline$R m b h$ & 69,7 & 69,1 & 71,9 & $-0,9$ & 3,2 & 4,1 \\
\hline Rmrio & 53,7 & 46,2 & 46,8 & $-14,0$ & $-12,8$ & 1,3 \\
\hline Rmsaop & 133,0 & 130,1 & 129,8 & $-2,2$ & $-2,4$ & $-0,2$ \\
\hline Serura & 7,2 & 11,1 & 10,8 & 54,2 & 50,0 & $-2,7$ \\
\hline Seurba & 61,6 & 62,5 & 63,9 & 1,5 & 3,7 & 2,2 \\
\hline Nepai & --- & 11,0 & --- & --- & --- & --- \\
\hline Nemae & --- & 3,4 & --- & --- & --- & -- \\
\hline Nepai2 & --- & --- & 13,6 & --- & --- & --- \\
\hline Nepai3 & --- & -- & 10,9 & -- & --- & -- \\
\hline Nepai4 & --- & --- & 33,2 & -- & --- & -- \\
\hline Nepai5 & --- & --- & 62,4 & --- & --- & --- \\
\hline Nemae2 & --- & --- & $-1,9$ & --- & --- & --- \\
\hline Nemae3 & --- & --- & 17,5 & --- & --- & -- \\
\hline Nemae4 & --- & --- & 2,8 & --- & --- & --- \\
\hline Nemae5 & --- & --- & 18,5 & --- & --- & --- \\
\hline $\begin{array}{l}\text { idade } \mathrm{p} / \mathrm{max} \\
\text { rendimento }\end{array}$ & 58,8 & 57,7 & 57,7 & $-1,9$ & $-1,9$ & 0 \\
\hline
\end{tabular}

Fonte: Baseado nos coeficientes da Tabela 11. 
O rendimento esperado dos chefes de família, captado pela variável chfam, também apresenta significativa diferença em relação aos demais membros do domicilio, sendo $21,7 \%$ superior.

Convém destacar que as variáveis associadas a cor da pele, sexo e condição na família, são carregadas de elementos heterogêneos individuais inobserváveis, os quais, provavelmente, não foram captados pelas variáveis. Estas, restringem-se somente a caracterizar os indivíduos de forma discriminada, pela cor da pele, sexo ou condição na família, sem considerar as idiossincrasias individuais, como traços culturais, ambição, perfil social e vocacional.

Como mostrado na Figura 3, a forte relação entre educação dos pais e educação e rendimento dos filhos, induziu a estimativa de uma regressão com os mesmos regressores da regressão anterior, adicionando as variáveis nepai e nemae. Como ocorreu com a regressão (1), a grande maioria dos coeficientes é estatisticamente significativa ao nível de $1 \%$. Os coeficientes estimados nesta regressão não diferem muito dos seus pares estimados na primeira regressão. A quinta coluna da Tabela 12 mostra a variação percentual nos coeficientes estimados ocasionada pela adição das duas variáveis relativas ao family background. As maiores variações são verificadas nos coeficientes das variáveis serura, pretpard, ctpro, anoesc e rmrio.

Os coeficientes para as variáveis nepai e nemae são estatisticamente significativos aos níveis de $1 \%$ e de $10 \%$, respectivamente. Os resultados indicam maior influência da educação do pai no logaritmo do rendimento do filho em relação ao nível de escolaridade da mãe. As estatísticas mostram que cada nível de escolaridade do pai acrescenta em média $11 \%$ ao rendimento esperado do filho ou filha, enquanto a cada nível de escolaridade alcançado pela mãe, o rendimento esperado é acrescido de 3,4\%, já descontados, em ambos os casos, os efeitos das demais variáveis.

Na primeira regressão o retorno ao investimento em educação indica que a cada ano adicional de escolaridade corresponde, em média, uma elevação no rendimento da ocupação principal da ordem de 14,6\%, enquanto na segunda regressão o 
retorno é inferior em dois pontos percentuais, sugerindo que as estimativas de mínimos quadrados são de fato viesadas para cima ${ }^{45}$.

Os demais coeficientes estimados na segunda regressão, se analisados em conjunto, delineiam o mesmo padrão de comportamento de seus correlatos na primeira estimação. Se analisados singularmente, verifica-se que alguns estimadores sofreram variações significativas. A variável pretpard, por exemplo, tem seu nível de significância modificado de 5\% para $13 \%$.

O padrão de diferenciação regional não apresenta mudanças significativas. Os coeficientes estimados para as regiões metropolitanas apresentam percentual de redução de até $14 \%$, verificado no Rio de Janeiro. No entanto, a variação não é suficientemente forte para causar modificação na hierarquia dos diferenciais regionais. Os demais estratos geográficos, indicados pelas variáveis neurba, serura e seurba, apresentam variações positivas de 10,9\%, 54,2\% e 1,5\%, respectivamente.

Os resultados determinados com a adição dos níveis de escolaridade dos pais como regressores, de maneira genérica, não foram capazes de modificar a estrutura de participação, causando apenas algumas modificações nos parâmetros isolados. Como esperado, a taxa de retorno ao investimento em educação diminuiu de 14,6\% para $12,4 \%$. A explicação é que na primeira regrssão a variável anoesc computa não somente os anos de escolaridade do indivíduo, este de forma direta, mas também, de maneira indireta, variáveis inobserváveis que influenciam a educação formal da pessoa, como educação dos pais, status social, nível de renda, qualidade da escola, meio social, habilidade e outras. Grande parte dessas variáveis ficou sendo conhecida na literatura como variáveis relacionadas ao family background. Ao adicionar o nível de escolaridade dos pais como proxies do family background, fica mais restrito o conjunto de fatores que influenciam a escolaridade, de forma que a variável anoesc passou a sofrer menor influência de características heterogêneas de difícil mensuração.

\footnotetext{
${ }^{45}$ Recentemente várias aplicações foram propostas no sentido de provar que as estimativas de mínimos quadrados para as equações mincerianas de rendimento fornecem estimativas viesadas, dentre elas Blackburn \& Neumark (1995) e Vella \& Feeberk (1997).
} 
As variáveis condição na família (chfam) e gênero (sexo) sofreram variações moderadas, indicando que mesmo depois de descontados os efeitos das demais variáveis e do nível educacional dos pais, as pessoas do sexo feminino continuam a ter rendimento na ocupação principal $27 \%$ inferior ao obtido pelos homens. O rendimento esperado para os chefes de família aumentou $8 \%$ com a adição dos dois novos regressores.

As variáveis relacionadas a cor da pele, pretpard e amare, continuaram com os sinais esperados, porém, o nível de significância estatística ficou aquém do intervalo usual. Variáveis binárias relacionadas à condição na ocupação, empgdr e ctpro, também apresentam variações contrárias. O diferencial aumentou cerca de $26 \%$ para os indivíduos cuja ocupação principal era por conta própria e reduziu cinco pontos percentuais na categoria dos empregadores.

Nos resultados da terceira regressão (Tabela 11) o nível de escolaridade dos pais foi aplicado no ajustamento como variáveis binárias, tendo como variável base o nível de escolaridade elementar, ou seja, o nível 1. O melhor ajustamento, conforme indicado pelo coeficiente de determinação ajustado (0,5203), foi obtido neste terceiro modelo. Os coeficientes não sofreram grandes mudanças em relação aos estimadores de regressão (2).

Como ocorreu nas duas regressões (1) e (2), serura não tem seu parâmetro significativo, enquanto ctpro, é estatisticamente significativa (a 10\%). As variáveis relacionadas a cor da pele alcançam o nível de significância de $10 \%$, sendo que o acréscimo esperado no rendimento do trabalho relativo a variável amare é cerca de $21 \%$ superior ao estimado na regressão (2) (Tabela 12). Isto corresponde afirmar que em média o rendimento dos indivíduos de cor amarela esteja $38 \%$ acima das expectativas dos indivíduos de cor branca.

Os diferenciais regionais restantes resultaram em estimativas com nível de significância de 1\%, exceto os referentes às variáveis rmrecif e rmfort, cujos níveis de significância estatística são $5 \%$ e $10 \%$, respectivamente.

Os efeitos diretos da localização regional no rendimento esperado na ocupação principal está representado na Figura 12. A Figura mostra o acréscimo 
percentual no rendimento esperado de um indivíduo situado numa determinada região, em relação ao indivíduo situado na região nordeste rural, sem considerar a influência das demais características. Tudo indica que o padrão de diferenciação regional não é alterado pela adição das variáveis relativas ao nível de escolaridade dos pais.

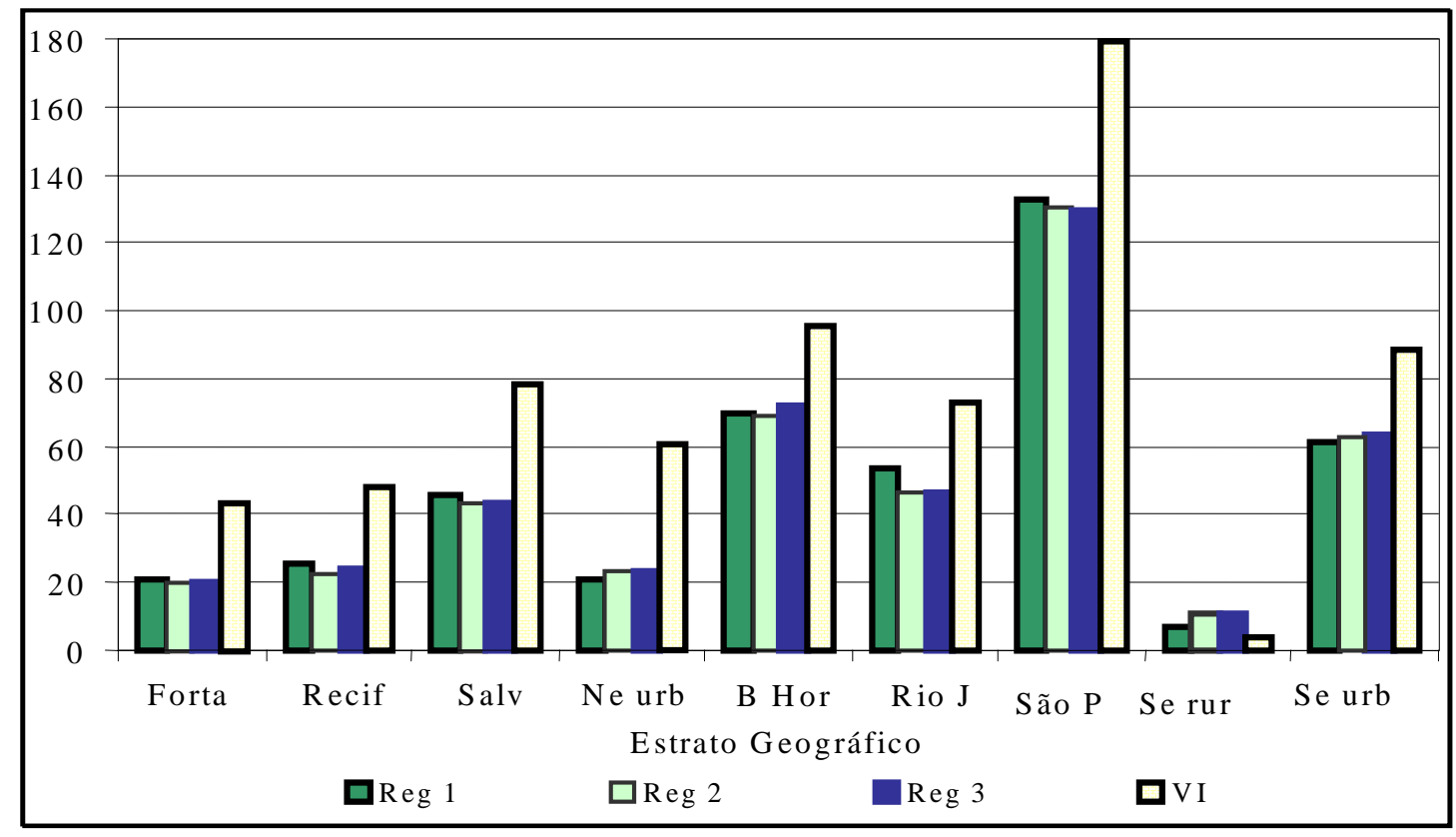

Fonte: Tabelas 12 e 15.

Figura 12 - Estrato geográfico e estimativas de acréscimo no rendimento esperado em relação ao residente no nordeste rural segundo as regressão ajustada.

O efeito direto dessas variáveis sobre o rendimento esperado dos filhos pode ser visto na Tabela 13 e na Figura 13. As quatro primeiras linhas da Tabela 13 mostram o efeito total da variação no nível de escolaridade do(a) pai(mãe) sobre o rendimento esperado dos filhos, em relação a filhos cujo(a) pai(mãe) apresenta escolaridade básica (nível 1). Considere, por exemplo, um indivíduo cujo nível 
educacional do pai é 4. Esse indivíduo terá um rendimento esperado 33,2\% superior a qualquer outro indivíduo cujo pai tenha menos de 4 anos de estudos (nível 1).

Tabela 13 - Percentual de incremento no rendimento esperado associado ao nível de escolaridade dos pais.

\begin{tabular}{cccc}
\hline Nível de escolaridade & $\begin{array}{c}\text { Intervalo de anos } \\
\text { de estudo }\end{array}$ & PAI & MÃE \\
\hline 2 & $4-7$ & 13,59 & $-1,95$ \\
\hline 3 & $8-11$ & 10,91 & 17,49 \\
\hline 4 & $12-15$ & 33,24 & 2,78 \\
\hline 5 & $>15$ & 62,39 & 18,55 \\
\hline$(2-3)$ & $(11-8) /(4-7)$ & $-2,36$ & 19,82 \\
\hline$(2-4)$ & $(12-15)) /(4-7)$ & 17,30 & 4,82 \\
\hline$(2-5)$ & $(12-15) /(8-11)$ & 42,96 & 20,90 \\
\hline$(3-4)$ & $(>15) /(8-11)$ & 20,13 & $-12,52$ \\
\hline$(3-5)$ & $(>15) /(12-15)$ & 46,41 & 0,90 \\
\hline$(4-5)$ & 21,88 & 15,35 \\
\hline
\end{tabular}

Fonte: Percentuais levantados com base nos coeficientes da regressão (3), (Tabela 11). 


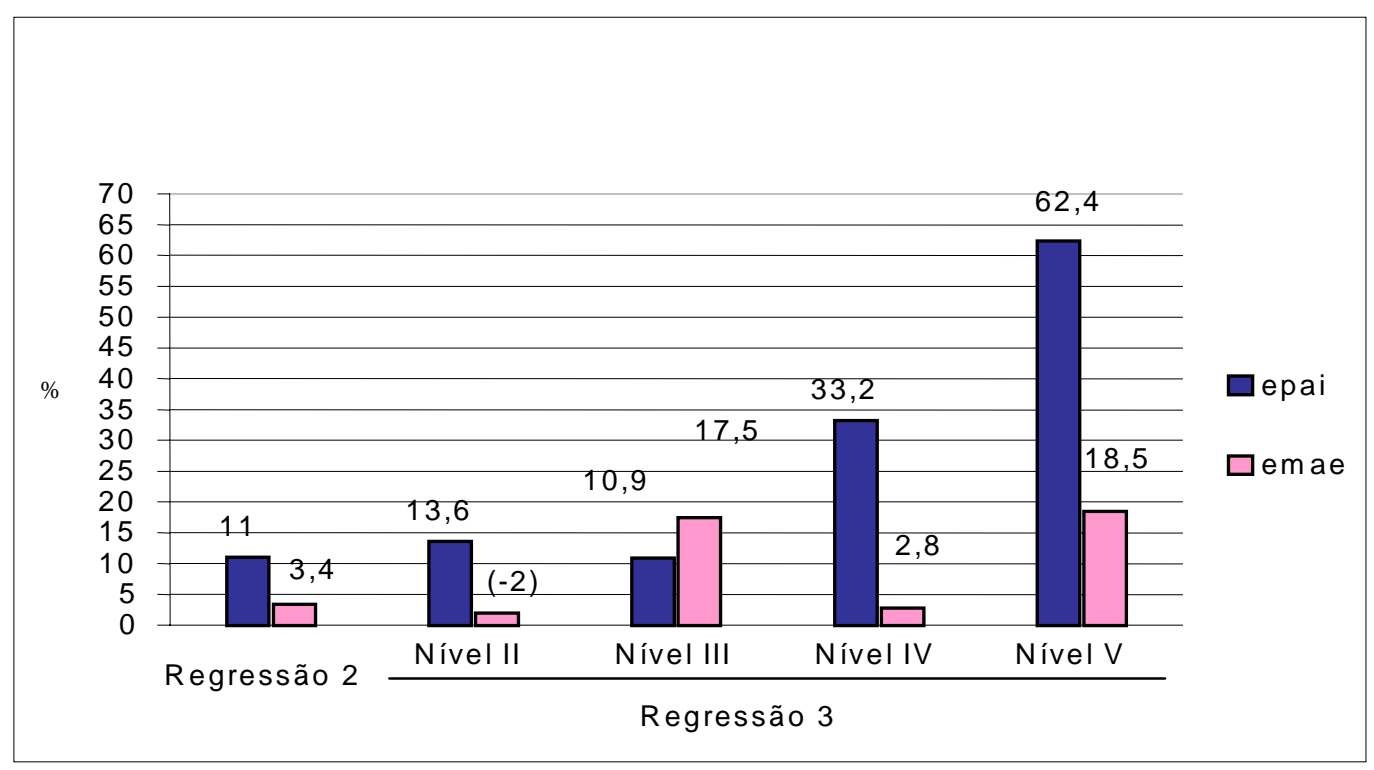

Fonte: Percentuais levantados com base nas regressões 1, 2 e 3 (Tabela 11).

Figura 13 - Percentual de incremento no rendimento do trabalho principal segundo o nível de escolaridade dos pais.

A estimação da equação salário pelo método da variável instrumental poder ser vista na Tabela 14. De acordo com as estatísticas $F$, pode-se rejeitar a hipótese de serem os coeficientes simultaneamente, iguais a zero. O coeficiente de determinação, apesar de ser inferior ao das regressões anteriores, é satisfatório $(0,43)$.

Da instrumentalização da equação salário resultam sinais corretos para os coeficientes e nível de significância estatística de $1 \%$, exceto para o parâmetro da variável serura, não significativo. 
Tabela 14 - Coeficientes, valores $t$, número de observações, coeficiente de determinação e estatística $F$ estimado no modelo de variável instrumental.

\begin{tabular}{|c|c|c|}
\hline Variável & $\begin{array}{c}\text { Instrumento } \\
\text { (anos de estudo) }\end{array}$ & $\begin{array}{c}\text { Regressão } \\
\text { (ln do rend. horário) }\end{array}$ \\
\hline \multirow[b]{2}{*}{ Constante } & 5,700027 & $-3,462943$ \\
\hline & $(40,295)$ & $(-22,822)$ \\
\hline \multirow{2}{*}{ Anoesc } & --- & 0,175805 \\
\hline & --- & $(23,089)$ \\
\hline \multirow{2}{*}{ Idade } & --- & 0,106386 \\
\hline & --- & $(16,529)$ \\
\hline \multirow{2}{*}{ Idquad } & --- & $-0,001021$ \\
\hline & --- & $(-12,423)$ \\
\hline \multirow{2}{*}{ Chfam } & --- & 0,169908 \\
\hline & --- & $(4,289)$ \\
\hline \multirow{2}{*}{ Sexo } & --- & $-0,223140$ \\
\hline & --- & $(-6,232)$ \\
\hline \multirow{2}{*}{ Pretpard } & --- & $-0,187864$ \\
\hline & --- & $(-5,071)$ \\
\hline \multirow{2}{*}{ Amare } & --- & 0,550097 \\
\hline & --- & $(3,023)$ \\
\hline \multirow{2}{*}{ Ctpro } & --- & $-0,167981$ \\
\hline & --- & $(-4,326)$ \\
\hline \multirow{2}{*}{ Empgdr } & --- & 0,464182 \\
\hline & --- & $(7,631)$ \\
\hline \multirow{2}{*}{ Rmfort } & --- & 0,362804 \\
\hline & --- & $(3,348)$ \\
\hline \multirow{2}{*}{ Rmrecif } & --- & 0,394357 \\
\hline & --- & $(3,293)$ \\
\hline \multirow{2}{*}{ Rmsalv } & --- & 0,580315 \\
\hline & --- & $(5,357)$ \\
\hline \multirow{2}{*}{ Neurba } & --- & 0,472381 \\
\hline & --- & $(5,695)$ \\
\hline
\end{tabular}


Tabela 14 - Coeficiente, valor t, número de observação, coeficiente de determinação e estatística $F$ estimado pelo modelo de variável instrumental. (continuação)

\begin{tabular}{lrr}
\hline Rmbh & --- & 0,670967 \\
& --- & $(6,868)$ \\
\hline Rmrio & --- & 0,546474 \\
& --- & $(6,476)$ \\
Rmsaop & --- & 1,026282 \\
& --- & $(12,486)$ \\
\hline Serura & --- & $(0,381)$ \\
\hline Seurba & --- & 0,634676 \\
\hline Nepai & --- & $(8,148)$ \\
\hline Nemae & --- & -- \\
& 1,133508 & -- \\
\hline$N$ & $(17,360)$ & -- \\
\hline Valor $F$ & 0,886953 & 3.169 \\
\hline$R^{2}$ & $(12,369)$ & 134,517 \\
\hline$R^{2}$ ajustado & 3.169 & 0,4346 \\
\hline ns: Estatisticamente não significativo. & 585,368 & 0,4314 \\
\hline ns & 0,2700 & -- \\
\hline
\end{tabular}

${ }^{\text {ns: }}$ Estatisticamente não significativo.

A Tabela 15 exibe os índices de acréscimo no rendimentos esperado e a variação de cada índice em relação aos estimados na primeira regressão. Três variáveis binárias apresentaram diminuição no diferencial do rendimento esperado a elas associados, chfam, sexo e serura, enquanto as demais sofreram variação positiva, destacando-se as variáveis relacionadas a cor da pele, condição na ocupação e estratos geográficos neurba e rmfort. 
Tabela 15 - Percentual de acréscimo no rendimento esperado e idade para máximo rendimento, segundo o modelo de variável instrumental.

\begin{tabular}{|c|c|c|}
\hline Variável & Variável Instrumental & $\begin{array}{l}\text { Variação percentual dos índices } \\
\text { em VI em relação a regressão } 1\end{array}$ \\
\hline$\overline{\text { Anoesc }}$ & 19,2 & 31,5 \\
\hline Chfam & 18,5 & $-10,6$ \\
\hline Sexo & $-20,0$ & $-28,8$ \\
\hline Pretpard & $-17,1$ & 137,5 \\
\hline Amare & 73,3 & 142,7 \\
\hline Ctpro & $-15,5$ & 260,5 \\
\hline Empgdr & 59,1 & 14,1 \\
\hline Rmfort & 43,7 & 106,1 \\
\hline Rmrecif & 48,3 & 89,4 \\
\hline Rmsalv & 78,7 & 70,7 \\
\hline Neurba & 60,4 & 186,3 \\
\hline Rmbh & 95,6 & 37,2 \\
\hline Rmrio & 72,7 & 35,4 \\
\hline Rmsaop & 179,1 & 34,7 \\
\hline Serura & 4,1 & $-43,1$ \\
\hline Seurba & 88,6 & 43,8 \\
\hline Idade $\mathrm{p} /$ max rendimento & 52,1 & 11,4 \\
\hline
\end{tabular}

Fonte: Baseado nas Tabelas 12 e 14.

As variações regionais, como ocorreu nas regressões (2) e (3), não foram suficientes para modificar a estrutura de diferenciação regional. A metrópole de São Paulo permanece associada ao maior diferencial de rendimento.

As estimativas de retorno à educação com base nas diferentes estimações, apontam que a omissão de variáveis relacionadas às características individuais não observáveis nas estimativas de mínimos quadrados, determina retorno superestimado, enquanto a estimativa segundo o modelo de variável instrumental, utilizando a educação dos pais como instrumento à escolaridade, superestimou ainda mais este retorno. 
Verifica-se que o retorno à educação formal, foi aumentado em cerca de $32 \%$ por ano de estudo (Tabela 15) e, se considerados os períodos de escolarização, o acréscimo verificado atinge $100 \%$ no nível superior (Tabela 16). O aumento do retorno à educação reduz a idade com que as pessoas alcançam o rendimento máximo do trabalho de 58 para 52 anos.

Tabela 16 - Percentual de aumento no rendimento esperado associado ao aumento da escolaridade do próprio indivíduo, amostra selecionada.

\begin{tabular}{crrrr}
\hline $\begin{array}{c}\text { Variação na } \\
\text { escolaridade }\end{array}$ & Regressão 1 & Regressão 2 & Regressão 3 & $\begin{array}{c}\text { Variável } \\
\text { Instrumental }\end{array}$ \\
\hline $0-4$ & 97,40 & 79,79 & 79,95 & 140,86 \\
\hline $0-8$ & 240,12 & 187,45 & 187,93 & 386,59 \\
\hline $0-11$ & 411,50 & 308,71 & 309,63 & 724,54 \\
\hline $0-15$ & 781,31 & 553,47 & 555,41 & $1.565,78$ \\
\hline $4-8$ & 72,30 & 59,88 & 60,00 & 102,02 \\
\hline $4-11$ & 159,12 & 127,33 & 127,63 & 242,34 \\
\hline $4-15$ & 346,45 & 263,47 & 264,21 & 591,61 \\
\hline $8-11$ & 50,39 & 42,19 & 42,26 & 69,45 \\
\hline $8-15$ & 159,12 & 127,33 & 127,63 & 242,34 \\
\hline $11-15$ & 72,30 & 59,88 & 60,00 & 102,02 \\
\hline
\end{tabular}

Fonte: Percentuais levantados com base nos coeficientes da tabela 11.

Conhecer as estimativas que reflitam com fidelidade o retorno à educação tem sido, e deverá ser no futuro, objeto de muitos estudos. Nesta pesquisa, os modelos testados indicam taxas de retorno que se situam no intervalo de $12 \%$ a $19 \%$.

Dada a complexidade e multiplicidade de fatores que caracterizam e influenciam a relação entre escolaridade e rendimento do trabalho, parecem bastante razoáveis as estimativas aqui analisadas. Outro importante resultado aponta a 
escolaridade dos pais como fator essencial para conhecer a direção e analisar a magnitude dessa relação. Com efeito, o modelo de variável instrumental eleva de modo substantivo a taxa de retorno obtida nos modelos de regressão múltipla. 


\section{CONCLUSÃO}

A amostra selecionada manteve as características socioeconômicas de cada região, bem como suas diferenças principais. Os contrastes regionais mais evidentes ficaram por conta das estatísticas sobre rendimento do trabalho.

As médias de anos de escolaridade da amostra situam-se muito além das estatísticas oficiais, sugerindo que o mercado de trabalho utiliza e valoriza a escolaridade como balizamento das capacidades do trabalhador. A despeito do maior nível educacional das mulheres, o rendimento do trabalho não reflete essa vantagem, o que sugere a existência de discriminação à mulher no mercado de trabalho.

Com base nas formulações propostas, foram estimados retornos à educação formal, idade, nível educacional dos pais e a uma série de variáveis binárias sobre características individuais. Em todas as formulações, o conjunto de variáveis mostrou-se relevante e o coeficiente de determinação satisfatório.

$\mathrm{O}$ retorno à escolaridade diminui de $14 \%$ para $12 \%$ da primeira à terceira formulação. O rendimento esperado é acrescido em pelo menos $11 \%$ e 3\% por nível educacional de pai e mãe, respectivamente. Quanto maior esse nível educacional, maior é o acréscimo no rendimento esperado. Pai com educação superior eleva o rendimento esperado em $62 \%$ contra $18 \%$ da mãe. Provavelmente, o maior percentual da educação superior do pai resulta da discriminação à mulher no mercado de trabalho.

Outras características devem ser consideradas, dentre elas traços culturais da comunidade e acesso à educação pública. Tais características, porém, não puderam ser captadas pelas variáveis em estudo, mas exercem papel relevante no processo de distribuição da educação. Vale destacar, por exemplo, o resultado indicando a existência de elevado diferencial de rendimento, associado às pessoas de origem asiática: $38 \%$. 
Nesse sentido, é possível supor que a cultura asiática atribui maior valor à educação, em seus aspectos quantitativos e qualitativos.

Os diferenciais de escolaridade e rendimento estão de acordo com a importância relativa das duas regiões analisadas. Eles refletem uma parte não desprezível das características econômicas do nordeste e sudeste do país. Pode-se admitir que fatores econômicos como oferta de emprego, estoque de capital físico, tecnologia e custo de vida, tiveram significativa importância na diferenciação do rendimento esperado por região. A metrópole de São Paulo atribui maior "prêmio" aos serviços produtivos do fator trabalho. Nesta metrópole, o rendimento esperado é $30 \%$ superior ao de Belo Horizonte e mais que o dobro do esperado no nordeste rural.

O perfil côncavo da equação salário com respeito à idade, é também constatado neste estudo. A idade entre 52 - 58 anos é aquela em que o rendimento do trabalho atingiria valor máximo. Em outras palavras, aquela em que o indivíduo alcançaria sua maior produtividade no trabalho.

Mesmo considerando a significativa influência do nível educacional dos pais e das demais variáveis no rendimento esperado das pessoas, a educação individual é o principal fator indutor de melhores expectativas de rendimento, elevando de 6 a 7 vezes a renda das pessoas de nível superior, quando comparada com a renda das pessoas sem nenhum estudo. Portanto, como relação de causa e efeito, anos adicionais de estudo elevam tanto a produtividade do trabalhador como seu rendimento, conforme as previsões de T. W. Schultz e Jacob Mincer.

A inclusão da escolaridade dos pais nas regressões múltiplas diminuiu as taxas de retorno à educação, enquanto o modelo de variável instrumental elevou essas taxas. Ademais, do ajustamento deste modelo resultaram alterações significativas na magnitude dos parâmetros; sem que fossem, no entanto, modificados seus respectivos sinais.

Dada a importância da heterogeneidade de fatores - econômicos, sociais e culturais - não captados na amostra selecionada, acredita-se que a utilização do nível educacional dos pais, como proxy de tais fatores, proporcione melhores estimativas das 
relações entre escolaridade e rendimento do trabalho. Assim sendo, a taxa de retorno à educação formal no Brasil deve situar-se no intervalo de $12 \%$ a $19 \%$ por ano de estudo.

De acordo com as evidências obtidas nesta pesquisa, entre as recomendações de políticas públicas educacionais merecem destaque aquelas voltadas para a massificação do acesso à escola. Os policymakers deveriam conceder estímulos econômicos, inclusive pecuniários, às famílias mais pobres, com objetivo de manter o jovem na escola. 


\section{REFERÊNCIAS BIBLIOGRÁFICAS}

ALVES, E. L. G.; SOARES, Fábio V. Ocupação e escolaridade: tendências recentes na grande. São Paulo Rio de Janeiro: IPEA, 1996. 57p. (Texto para discussão, 428)

ANDERSON, L. Rate of return to human capital: a test using El Salvador data. American Economic Review, v.70, n.2, p.138-141, May 1980.

ÁVILA, A. F. D. at al. Formação do capital humano e retorno dos investimentos em treinamento na EMBRAPA. Brasília: EMBRAPA, 1983.

AZEVEDO, P. F. Esforço tecnológico através de investimento em capital humano nas empresas do setor de bens de capital brasileiro. São Paulo, 1992. 139p. Dissertação (Mestrado) - Faculdade de Economia e Administração - Universidade de São Paulo.

BARROS, A. R.; BARROS, M. R. Fatores determinantes dos salários relativos: um estudo empírico com dados primários. In: ENCONTRO NACIONAL DE ECONOMIA, 23, Salvador, 1995. Anais. Brasília: ANPEC, 1995. p.43-57.

BARROS, R. P.; MENDONÇA, R. S. P. Os determinantes da desigualdade no Brasil. Rio de Janeiro: IPEA, 1995. 63p. (Texto para discussão, 377)

BARROS, R. P., MENDONÇA, R. Os determinantes da desigualdade no Brasil. In: INSTITUTO DE PESQUISA ECONÔMICAS APLICADA. A economia brasileira em perspectiva. Rio de Janeiro: IPEA, 1996. v.2, parte 3, cap.19, p.421-474: Políticas sociais, distribuição de renda e pobreza.

BARROS, R. P.; MENDONÇA, R. Investimentos em educação e desenvolvimento econômico. Rio de Janeiro: IPEA, 1997. 8p. (Texto para discussão, 525) 
BARROS, R. P.; MENDONÇA, R. S. P. Determinantes da participação de menores na força de trabalho. Rio de Janeiro: IPEA, 1990. 16p. (Texto para discussão, 200)

BARROS, R. P.; MACHADO, A. F.; MENDONÇA, R. S. P. A desigualdade da pobreza: estratégias ocupacionais e diferenciais por gênero. Rio de Janeiro: IPEA, 1997. 40p. (Texto para discussão, 453)

BECKER, G. S. Human capital: a theoretical and empirical analysis, with special reference to education. 3 ed. Chicado: The University of Chicago Press, 1993. 390p.

BLACKBURN, M. L.; NEUMARK, D. Are OLS estimates of the return to schooling biased downward? another look. The Review of Economics and Statistics, v.77, n.2, p.217-230, 1995.

BLAUG, M. Jacob Mincer, schooling, experience and earning reviews. Economic Development and Cultural Change, v.25, n.1, p.166-171, Oct. 1976.

CACCIAMALLI, M. C.; FREITAS, P. S. Do capital humano ao salário-eficiência: uma aplicação para analisar os diferenciais de salários em cinco ramos manufatureiros da Grande São Paulo. Pesquisa e Planejamento Econômico, v.22, n.2, p.343-368, ago. 1992.

CALLAN, T.; HARMON, C. The economic return to schooling in Ireland. Labour Economics, v.6, n.4, p.543-550, nov. 1999./ Artigo em Elsivier Science Inc.: http://www.probe.br/sciencedirect.html.(set/2000)

CASTRO, C. M. Investimento em educação no Brasil: comparação de três estudos. Pesquisa e Planejamento Econômico, v.1, n.1, p.141-152, jun. 1971.

CORRÊA, A. J. Distribuição de renda e pobreza na agricultura brasileira. Piracicaba: UNIMEP, 1998. 260p.

CRAWFORD, R. Na era do capital humano: o talento, a inteligência e o conhecimento como forças econômicas, seu impacto nas empresas e nas decisões de investimento. São Paulo: Atlas: 1994. 186p. 
FERNANDES, R.; MENEZES FILHO, N. A evolução da desigualdade no Brasil metropolitano entre 1983 e 1992. Estudos Econômicos, v.30, n.4, p.549-569. 2000.

FERNANDES, R.; TEDESCO NARITA, R. Instrução superior e mercado de trabalho no Brasil. Ribeirão Preto: FEA, 2000. 14p. (Texto para discussão, 9)

FERREIRA, F. H. G. Os determinantes da desigualdade de renda no Brasil: luta de classes ou heterogeneidade educacional? Rio de Janeiro: PUC-RIO, 2000. (Texto para discussão, 415)

FIGUEREDO NETO, L. Retornos privados aos investimentos em capital humano: evidências da PNAD-1995. Piracicaba, 1997. 97p. Dissertação (mestrado) - Escola Superior de Agricultura “Luiz de Queiroz”, Universidade de São Paulo.

FUNDAÇÃO INSTITUTO BRASILEIRO DE GEOGRAFIA E ESTATÍSTICA. Pesquisa sobre padrões de vida 1996/1997. Microdados (compact disc). Rio de Janeiro: IBGE, 1998.

FUNDAÇÃO INSTITUTO BRASILEIRO DE GEOGRAFIA E ESTATÍSTICA. Pesquisa sobre padrões de vida 1996/1997. Rio de Janeiro: IBGE, 1999. 149p.

FUNDAÇÃO INSTITUTO BRASILEIRO DE GEOGRAFIA E ESTATÍSTICA. Pesquisa Mensal de Emprego. http://www.sidra.ibge.gov.br (26/02/2001)

FUNDAÇÃO INSTITUTO BRASILEIRO DE GEOGRAFIA E ESTATÍSTICA. Pesquisa Nacional por amostra de Domicílio 1999. http:// www.Ibge.gov.br/ ibge/estatistica/condiçoesdevida (26/02/2001)

FUNDAÇÃO INSTITUTO BRASILEIRO DE GEOGRAFIA E ESTATÍSTICA. Síntese dos indicadores sociais 1999. http//:www.ibge.gov.br (abril/2000)

GARCIA, F. et al. Distribuição da educação: o círculo vicioso da desigualdade na América Latina. São Paulo: FGV, 1999. 16p. (Texto para discussão, 73)

GIBBON, V. H. Taxas de retorno dos investimentos em educação no Brasil: uma análise desagregada. Revista Brasileira de Economia, v.29, n.3, p.109-133. jul-set. 1975. 
GUJARATI, D. N. Basic econometrics. 3. ed. Nova York: Mcgraw-Hill, 1995. 838p.

HERRERA B., V. H., MADRI-ARIA, M. Earnings profiles and return to education in Panama. In: LATIN AMERICAN AND CARIBBEAN ASSOCIATION, 5 (compact disc). Rio de Janeiro, Oct. 2000.

HOFFMANN, R.; VIEIRA, S. Análise de regressão: uma introdução à econometria. 3 ed. São Paulo: Hucitec, 1998a. 379p.

HOFFMANN, R. Equações de rendimento para pessoas ocupadas no Brasil: contrastes regionais e setoriais. In: CONGRESSO BRASILEIRO DE ECONOMIA E SOCIOLOGIA RURAL, 36. O agronegócio brasileiro: desafios e perspectivas, Poços de Caldas, 1998. Anais. Brasília: SOBER, 1998b. v.2, p.707-718.

HOFFMANN, R. Distribuição de Renda no Brasil. In: LATIN AMERICAN AND CARIBBEAN ASSOCIATION, 5. (compact disc). Rio de Janeiro, Oct. 2000.

KASSOUF, A. L. Retornos à escolaridade e treinamento nos setores rurais e urbanos do Brasil. In: CONGRESSO BRASILEIRO DE ECONOMIA E SOCIOLOGIA RURAL, 34, Aracaju, 1996. Anais. Brasília: SOBER, 1996. v.1, p.771-785.

KASSOUF, A. L. Retornos à escolaridade e ao treinamento nos setores urbanos e rural do Brasil. Revista de Economia e Sociologia Rural, v.35, n.2, p.59-76, abril/ 1997.

KMENTA, J. Elementos de Econometria: teoria econométrica básica. $2^{a}$ ed. São Paulo: Atlas, 1988.

LAM, D.; LEVISON, D. Idade, experiência, escolaridade e diferenciais de renda: Estados Unidos e Brasil. Pesquisa e planejamento Econômico, v.1, n.1, p.219-256, ago. 1990a.

LAM, D.; LEVISON, D. O declínio na desigualdade da escolaridade no Brasil e seus efeitos na desigualdade de rendimentos. Revista Brasileira de Econometria, v.10, n.2, p.243-278, nov. 1990 b. 
LAM, D.; SCHOENI, R. F. Effects of family background on earnings and returns to schooling: evidence from Brazil. Journal of Political Economy, v.101, n.4, out. 1993.

LEAL, C. I. S.; WERLANG, S. R. C. Educação e distribuição de renda. Ensaios Econômicos da EPGE, n.148, 1989.

LEAL, C. I. S.; WERLANG, S. R. C. Retornos em educação no Brasil: 1976-1986. Pesquisa e Planejamento Econômico, v.21, n.3, p.559-574, dez. 1991.

MANHANI, D. C. Uma avaliação do programa de formação de hovens empresários rurais. - projovem Piracicaba, 2000. 118p. Dissertação (mestrado) - Escola Superior de Agricultura “Luiz de Queiroz”, Universidade de São Paulo.

MEDEIROS, J. A. Alcance e limitações da teoria do capital humano: diferença de ganhos em 1973. São Paulo: IPE, 1982. 187p.

MENDONÇA, R. S. P. Qualidade do ensino básico e igualdade de oportunidades. In: MENDONÇA, R. S. P.; URANI, A. Estudos do Trabalho. Rio de Janeiro: IPEA, 1994. v.1, cap.4, p.69-89: Qualidade do ensino básico e igualdade de oportunidades.

MINCER, J. B. Schooling, experience and earnings. New York: NBER, 1974. 152p.

MYINT, H. Educação e desenvolvimento: um balanço teórico. In: PEREIRA, L. Desenvolvimento, trabalho e educação. Rio de Janeiro: Zahar, 1967. Parte 2, cap.9. p.130-147: Desenvolvimento e educação: fundamentos econômicos.

PINHEIRO, A.; RAMOS, L. Diferenciais intersetoriais de salários no Brasil. Revista do BNDES, v.2, n.3, p.19-220, jun. 1995.

RAMOS, L. Educação, desigualdade de renda e ciclo econômico no Brasil. Rio de Janeiro: IPEA, 1991. 26p. (Texto para discussão, 219)

RAMOS, L. R. A.; REIS., J. G. A. Distribuição da renda: aspectos teóricos e o debate no Brasil. In: CAMARGO, J. M.; GIAMBIAGI, F. (org.). Distribuição de renda no Brasil. Rio de Janeiro: Paz e Terra, 1991. cap.1, p.21-45: Distribuição da renda: aspectos teóricos e o debate no Brasil. 
RAMOS, L.; VIEIRA, M. L. A relação entre educação e salários no Brasil. In: A economia brasileira em perspectiva. Rio de Janeiro: IPEA, 1996. v.2, parte 3, cap.21, p.493-510: Políticas sociais, distribuição de renda e pobreza.

REIS, J. G. A.; BARROS, R. P. Desigualdade salarial e distribuição de educação: a evolução das diferenças regionais no Brasil. Pesquisa e Planejamento Econômico, v.20, n.3, p.415-478, dez. 1990.

RIBEIRO, J. L. A contribuição da educação na produção agrícola. Revista de Economia e Sociologia Rural, v.17, n.4, p.85-118, out. 1979.

SCHUH, G. E.; BRANDÃO, A. S. P. The theory, empirical evidence, and debate on agricultural development issues in Latin America: a selective survey. s.l.: s.n, 1990. cap. 10

SCHULTZ, T. W. O valor econômico da educação. Rio de Janeiro: Zahar, 1973a. $101 \mathrm{p}$.

SCHULTZ, T. W. O capital humano: investimentos em educação e pesquisa Rio de Janeiro: Zahar, 1973b. 250p.

SENNA, J. J. Escolaridade, experiência no trabalho e salários no Brasil. Revista Brasileira de Economia, v.30, n.2, p.163-193, abr. 1976.

SILVA, N. D. V. Mercados de trabalho formal e informal: uma análise da discriminação e da segmentaçao. Piracicaba, 1997. 97p. Piracicaba, 1997. 137p. Dissertação (mestrado) - Escola Superior de Agricultura "Luiz de Queiroz", Universidade de São Paulo.

SOARES, R. R.; GONZAGA, G. Determinantes de salários no Brasil: dualidade ou não-linearidade no retorno à educação? In: ENCONTRO BRASILEIRO DE ECONOMETRIA, 20, Vitória, 1998. Anais. Brasília: SBE, 1998. v.1, p.119-137.

SOARES, S. S. D. O perfil da discriminação no mercado de trabalho: homens negros, mulheres brancas e mulheres negras. Rio de Janeiro: IPEA, 2000. 26p. (Texto para discussão, 769) 
SOUZA, A. M.; SILVA, N. V. Origem familiar, qualidade da educação, escolas públicas e particulares em São Paulo: relações e efeitos nas transições escolares, Pesquisa e Planejamento Econômico, v.24, n.1 p.97-114, abr. 1994.

TOSTA, W. IBGE mostra que Brasil mantém desigualdade. O Estado de São Paulo. São Paulo, 29 de abril, 2000, p.A10, A13.

UUSITALO, R. Return to education in Finland. Labour Economics, v.6, n.4, p.569580, nov.1999./Artigo em Elsivier Science Inc.: http://www.probe.br/sciencedirect.html (mar. 2000)

VELLA, F.; VERBEEK, M. Using rank order as na instrumental variable: a apllication to the return to schooling. Leuven: Center for Economic Studies, 1997. (Discussion Paper 9710): http://www.econ.kuleuven.ac.br/cw/academic/ (ago. 2000) 


\section{APÊNDICE}

O método de variável instrumental*

Considere o modelo

$$
Y_{i}^{*}=\alpha+\beta X_{i}^{*}+v_{i}^{*}
$$

onde os asteriscos indicam tratar-se de um modelo com erro nas variáveis e erros na formulação da equação adequada (erro de especificação). Neste modelo, as estimativas dos parâmetros através de mínimos quadrados serão inconsistentes, a menos que exista uma variável $\mathrm{Z}_{\mathrm{i}}$, chamada de variável instrumental, que satisfaça as condições seguintes:

$$
p \lim \left(\sum z_{i}^{\prime} u_{i}^{\prime}\right) / n=0
$$

e que

$$
p \lim \left(\sum z_{i}^{\prime} x_{i}^{\prime}\right) / n
$$

seja finito e diferente de zero, onde

$$
z_{i}^{\prime}=Z_{i}-\bar{Z}_{i} \text { e } x i_{i}^{\prime}=X^{*}{ }_{i}-\bar{X}^{*}{ }_{i}
$$

Podem ser determinadas estimativas consistentes para os parâmetros $\alpha$ e $\beta$ com emprego da variável instrumental.

O estimador de variáveis instrumentais fundamenta-se nas duas condições acima. A primeira estabelece que $Z_{i}$ não está correlacionado com $\mathrm{u}_{\mathrm{i}}{ }_{\mathrm{i}}$, consequentemente $\operatorname{cov}\left(Z_{i}, u_{i}\right)=0$. A segunda condição implica a correlação entre $Z_{i}$ e $\mathrm{X}_{\mathrm{i}}^{*}$, isto é, $\operatorname{cov}\left(\mathrm{Z}_{\mathrm{i}}, \mathrm{X}_{\mathrm{i}}^{*}\right) \neq 0$. Adicionalmente, deseja-se que $p \lim \left(\sum z_{i}^{\prime} x_{i}^{\prime}\right) / n$ seja o maior possível, ou seja, um elevado grau de correlação entre $\mathrm{Z}_{\mathrm{i}}$ e $\mathrm{X}_{\mathrm{i}}{ }_{\text {. }}$.

\footnotetext{
* Baseado em Hoffmann (1998a) e Kmenta (1988).
} 
Os estimadores de $\alpha$ e $\beta$ serão dados por

$$
\hat{\beta}^{V I}=\frac{\sum y_{i}^{*} z_{i}^{* \prime}}{\sum x_{i}^{* \prime} z_{i}^{* \prime}}=\beta+\frac{\sum x_{i}^{* \prime} u_{i}^{*}}{\sum x_{i}^{* \prime} z_{i}^{* \prime}}
$$

e

$$
\hat{\alpha}^{V I}=\bar{Y}^{*}-\hat{\beta}^{V I}\left(\bar{X}_{i}^{*}\right)
$$

Calculando o limite em probabilidade de cada estimador, temos

$$
p \lim \hat{\beta}^{V I}=\beta+\frac{p \lim \left(\sum x_{i}^{* \prime} u_{i}^{*}\right) / n}{p \lim \left(\sum x_{i}^{* \prime} z_{i}^{* \prime}\right)}=\beta+\frac{0}{\sigma Z X^{*}}=\beta
$$

De modo semelhante

$$
p \lim \hat{\alpha}^{V I}=p \lim \left(\bar{X}^{*}-\hat{\beta}^{V I} \bar{X}^{*}\right)=p \lim \left(\alpha+\beta \bar{X}^{*}+\bar{u}^{*}-\beta^{V I} \bar{X}^{*}\right)=\alpha
$$

Portanto, $\hat{\alpha}^{V I}$ e $\hat{\beta}^{V I}$ são estimadores consistentes. Convém observar que não se pode provar que o estimador $\hat{\beta}^{V I}$ é não tendencioso, pois no último termo de (8) não se pode separar $\mathrm{Z}_{\mathrm{i}}$ do resto.

A escolha do instrumento só é limitada pela exigência de que ele não deve ser correlacionado com $\mathrm{u}_{\mathrm{i}}{ }_{\mathrm{i}}$ e deve ser correlacionado com $\mathrm{X}_{\mathrm{i}}^{*}$. A escolha deverá recair sobre o instrumento que apresentar a mais alta correlação com $\mathrm{X}^{*}$, uma vez que isto resultará em estimadores com menores variâncias assintóticas, tornando os estimadores eficientes.

Em geral, salvo situações como aquela supra mencionada, os estimadores de variáveis instrumentais não são assintoticamente eficientes, pois na prática, o número de instrumentos disponíveis é maior do que o de variáveis explicativas, e nada garante que um particular instrumento $Z_{i}$, seja de fato o que conduzirá a um estimador de variância mínima, sinônimo de estimador eficiente. Dessa forma, a única propriedade que se espera dos estimadores de variáveis instrumentais é a consistência. 